\title{
Exercise-based rehabilitation for coronary heart disease (Review)
}

\author{
Jolliffe J, Rees K, Taylor RRS, Thompson DR, Oldridge N, Ebrahim S
}
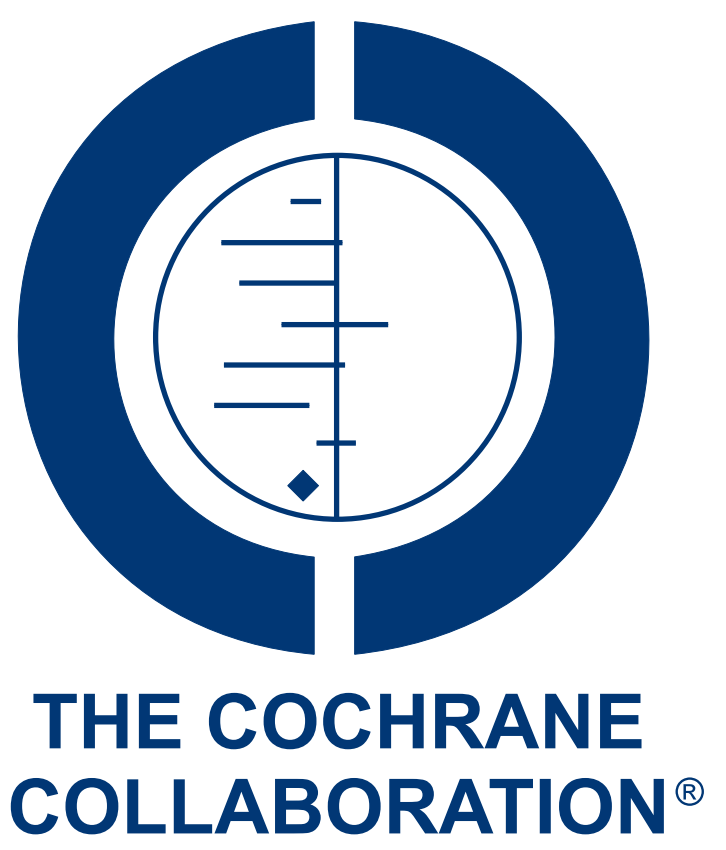

This is a reprint of a Cochrane review, prepared and maintained by The Cochrane Collaboration and published in The Cochrane Library 2001, Issue 1

http://www.thecochranelibrary.com

\section{WILEY}


TABLE OF CONTENTS

HEADER . . . . . . . . . . . . . . . . . . . . . . . . . . . . . . . . . . . . . . . . 1

ABSTRACT . . . . . . . . . . . . . . . . . . . . . . . . . . . . . . . . . . . . . . .

PLAIN LANGUAGE SUMMARY . . . . . . . . . . . . . . . . . . . . . . . . . . . . . . . . . . . . 2

BACKGROUND . . . . . . . . . . . . . . . . . . . . . . . . . . . . . . . . . . . . . 2

OBJECTIVES . . . . . . . . . . . . . . . . . . . . . . . . . . . . . . . . . . . . . . . . . . . . . . .

METHODS . . . . . . . . . . . . . . . . . . . . . . . . . . . . . . . . . . . . . . . .

RESULTS . . . . . . . . . . . . . . . . . . . . . . . . . . . . . . . . . . . . . . . 5

DISCUSSION . . . . . . . . . . . . . . . . . . . . . . . . . . . . . . . . . . . . . . 7

AUTHORS' CONCLUSIONS . . . . . . . . . . . . . . . . . . . . . . . . . . . . . . . . . . . 9

ACKNOWLEDGEMENTS . . . . . . . . . . . . . . . . . . . . . . . . . . . . . . . . .

REFERENCES . . . . . . . . . . . . . . . . . . . . . . . . . . . . . . . . . . . . . . . . . . . 9

CHARACTERISTICS OF STUDIES . . . . . . . . . . . . . . . . . . . . . . . . . . . . . . . . . . . . . . 14

DATA AND ANALYSES . . . . . . . . . . . . . . . . . . . . . . . . . . . . . . . . . . . . . . . . . . . . . . . . .

Analysis 1.1. Comparison 1 Exercise only versus usual care, Outcome 1 Total Mortality. . . . . . . . . . . . . . . 40

Analysis 1.2. Comparison 1 Exercise only versus usual care, Outcome 2 Total Cardiac Deaths. . . . . . . . . . 41

Analysis 1.3. Comparison 1 Exercise only versus usual care, Outcome 3 Non fatal MI. . . . . . . . . . . . . . 42

Analysis 1.4. Comparison 1 Exercise only versus usual care, Outcome 4 Pooled mortality, non-fatal MI, CABG, PTCA. 43

Analysis 1.5. Comparison 1 Exercise only versus usual care, Outcome 5 Total Cholesterol. . . . . . . . . . . . 44

Analysis 1.6. Comparison 1 Exercise only versus usual care, Outcome 6 LDL Cholesterol. . . . . . . . . . . . . . 44

Analysis 2.1. Comparison 2 Exercise plus other rehabilitation versus usual care, Outcome 1 Total Mortality. . . . . 45

Analysis 2.2. Comparison 2 Exercise plus other rehabilitation versus usual care, Outcome 2 Total Cardiac Deaths. $\quad .47$

Analysis 2.3. Comparison 2 Exercise plus other rehabilitation versus usual care, Outcome 3 Non fatal MI. . . . . . 48

Analysis 2.4. Comparison 2 Exercise plus other rehabilitation versus usual care, Outcome 4 Pooled mortality, non-fatal MI,

CABG, PTCA. . . . . . . . . . . . . . . . . . . . . . . . . . . . . . . . . . . . . . . . . . . 49

Analysis 2.5. Comparison 2 Exercise plus other rehabilitation versus usual care, Outcome 5 Total Cholesterol. . . . 51

Analysis 2.6. Comparison 2 Exercise plus other rehabilitation versus usual care, Outcome 6 LDL Cholesterol. . . . . 52

Analysis 3.1. Comparison 3 Any rehabilitation intervention including exercise versus usual care, Outcome 1 Pooled mortality, non-fatal MI, CABG, PTCA. . . . . . . . . . . . . . . . . . . . . . . . . . . . . . . . . . . . 53

Analysis 3.2. Comparison 3 Any rehabilitation intervention including exercise versus usual care, Outcome 2 Quality criteria - Random allocation: Outcome total mortality. . . . . . . . . . . . . . . . . . . . . . . 55

Analysis 3.3. Comparison 3 Any rehabilitation intervention including exercise versus usual care, Outcome 3 Quality criteria

- Loss to follow up: Outcome total mortality. . . . . . . . . . . . . . . . . . . . . . . . 57

Analysis 3.4. Comparison 3 Any rehabilitation intervention including exercise versus usual care, Outcome 4 Quality criteria

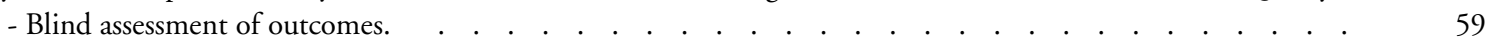

WHAT'S NEW . . . . . . . . . . . . . . . . . . . . . . . . . . . . . . . . . . . . . 61

HISTORY . . . . . . . . . . . . . . . . . . . . . . . . . . . . . . . . . . . . . . . . 61

CONTRIBUTIONS OF AUTHORS . . . . . . . . . . . . . . . . . . . . . . . . . . . . . . . . . . . . . . . . . . . .

DECLARATIONS OF INTEREST . . . . . . . . . . . . . . . . . . . . . . . . . . . . . . . . . . . . . . . . . . .

SOURCES OF SUPPORT . . . . . . . . . . . . . . . . . . . . . . . . . . . . . . . . . . 62

NOTES . . . . . . . . . . . . . . . . . . . . . . . . . . . . . . . . . . . . . . . . . . 62

INDEX TERMS . . . . . . . . . . . . . . . . . . . . . . . . . . . . . . . . . . . . . . . . . . . 62

Exercise-based rehabilitation for coronary heart disease (Review)

Copyright $\odot 2009$ The Cochrane Collaboration. Published by John Wiley \& Sons, Ltd. 


\title{
[Intervention Review]
}

\section{Exercise-based rehabilitation for coronary heart disease}

\author{
Judith Jolliffe ${ }^{1}$, Karen Rees ${ }^{2}$, Rod RS Taylor ${ }^{3}$, David R Thompson ${ }^{4}$, Neil Oldridge ${ }^{5}$, Shah Ebrahim ${ }^{6}$ \\ ${ }^{1}$ St Loyes School of health Studies, Exeter, UK. ${ }^{2}$ Department of Social Medicine, Universiry of Bristol, Bristol, UK. ${ }^{3}$ PenTAG, Peninsula \\ Medical School, Exeter, UK. ${ }^{4}$ Department of Health Studies, University of York, York, UK. ${ }^{5}$ Centre for Urban Population Health, \\ Milwaukee, USA. ${ }^{6}$ Department of Epidemiology \& Population Health, London School of Hygiene \& Tropical Medicine, London, \\ UK
}

Contact address: Judith Jolliffe, St Loyes School of health Studies, Millbrook House, Millbrook Lane, Exeter, EX2 6ES, UK. judyjolliffe@eclipse.co.uk.

\author{
Editorial group: Cochrane Heart Group. \\ Publication status and date: Edited (no change to conclusions), published in Issue 1, 2009. \\ Review content assessed as up-to-date: 31 October 2000.
}

Citation: Jolliffe J, Rees K, Taylor RRS, Thompson DR, Oldridge N, Ebrahim S. Exercise-based rehabilitation for coronary heart disease. Cochrane Database of Systematic Reviews 2001, Issue 1. Art. No.: CD001800. DOI: 10.1002/14651858.CD001800.

Copyright (C) 2009 The Cochrane Collaboration. Published by John Wiley \& Sons, Ltd.

\begin{abstract}
A B S T R A C T

\section{Background}

The burden of cardiovascular disease world-wide is one of great concern to patients and health care agencies alike. Cardiac rehabilitation aims to restore patients with heart disease to health through exercise only based rehabilitation or comprehensive cardiac rehabilitation.

\section{Objectives}

To determine the effectiveness of exercise only or exercise as part of a comprehensive cardiac rehabilitation programme on the mortality, morbidity, health-related quality of life (HRQoL) and modifiable cardiac risk factors of patients with coronary heart disease.
\end{abstract}

\section{Search strategy}

Electronic databases were searched for randomised controlled trials, using standardised trial filters, from the earliest date available to December 31st 1998.

\section{Selection criteria}

Men and women of all ages, in hospital or community settings, who have had myocardial infarction, coronary artery bypass graft or percutaneous transluminal coronary angioplasty, or who have angina pectoris or coronary artery disease defined by angiography.

\section{Data collection and analysis}

Studies were selected independently by two reviewers, and data extracted independently. Authors were contacted where possible to obtain missing information.

\section{Main results}

This systematic review has allowed analysis of an increased number of patients from approximately 4500 in earlier meta-analyses to 8440 (7683 contributing to the total mortality outcome).

The pooled effect estimate for total mortality for the exercise only intervention shows a $27 \%$ reduction in all cause mortality (random effects model OR $0.7395 \%$ confidence interval 0.54 to 0.98 ). Comprehensive cardiac rehabilitation reduced all cause mortality, but to a lesser degree (OR $0.8795 \%$ confidence interval 0.71 to 1.05 ). Total cardiac mortality was reduced by $31 \%$ (random effects model 
OR $0.6995 \%$ confidence interval 0.51 to 0.94 ) and $26 \%$ (random effects model OR $0.7495 \%$ confidence interval 0.57 to 0.96 ) in the exercise only and comprehensive cardiac rehabilitation groups respectively. We found no evidence of an effect of the interventions on the occurrence of non-fatal myocardial infarction. There was a significant net reduction in total cholesterol (pooled WMD random effects model $-0.57 \mathrm{mmol} / 195 \%$ confidence interval -0.83 to -0.31 ) and LDL (pooled WMD random effects model $-0.51 \mathrm{mmol} / \mathrm{l}$ $95 \%$ confidence interval- $0.82-0.19)$ in the comprehensive cardiac rehabilitation group.

\section{Authors' conclusions}

Exercise-based cardiac rehabilitation is effective in reducing cardiac deaths. It is not clear from this review whether exercise only or a comprehensive cardiac rehabilitation intervention is more beneficial. The population studied in this review is still predominantly male, middle aged and low risk. Identification of the ethnic origin of the participants was seldom reported. It is possible that patients who would have benefited most from the intervention were excluded from the trials on the grounds of age, sex or co-morbidity.

\section{PLAIN LANGUAGESUMMARY}

\section{Regular exercise or exercise with education and psychological support can reduce the likelihood of dying from heart disease}

Coronary heart disease (CHD) is one of the most common forms of heart disease. It affects the heart by restricting or blocking the flow of blood around it. This can lead to a feeling of tightness in the chest (angina) or a heart attack. Cardiac rehabilitation aims to restore people with CHD to health through regular exercise or a combination of exercise with education and psychological support. The findings of this review indicate that either form of cardiac rehabilitation can reduce the likelihood of dying from heart disease. More research is needed.

\section{B A C K G ROU N D}

The burden of cardiovascular disease (CVD) world-wide is one of great concern to patients and health care agencies alike. Circulatory diseases, including myocardial infarction (MI) and stroke, kill more people than any other disease. This accounts for 15 million deaths, 30\% of the annual total, every year. (WHO 1997). In the USA more than 13.5 million Americans have a history of MI, or experience angina pectoris (Wenger 1995). In Australia in 1994, cardiovascular disease (the largest component of which is coronary heart disease (CHD)), was certified as the primary cause in $43.33 \%$ of all deaths in Australia (Goble \& Worcester 99). Eastern Europe is now experiencing an increasing number of deaths from CVD, across all socio-economic groups, death rates exceeding those in Western Europe, the USA, Australia and New Zealand (WHO 1994). Asia too is suffering an increasing prevalence of CVD, particularly among the growing professional, managerial, business and factory supervising groups (Janus 1996).

CHD is the single leading cause of death for both men and women in the UK, accounting for 238 deaths per 100,000 population in 1997 (approximately 140,000 people) (OHE 1999). Scotland, Northern Ireland and England and Wales rank 3rd, 5th and 9th in the top ten of 30 selected Organisation for Economic Cooperation and Development (OECD) countries with CHD rates (in men and women aged 45-64) some four or five times those of the countries at the bottom of the list (OHE 1999). Diseases of the circulatory system accounted for 108.2 million days of certified incapacity in men and women in 1996/97, 12\% of the total (OHE 1999). In the older age group (over 65) one fifth of men and one eighth of women in England and Wales were treated for CHD in General Practice in 1996 (ONS 1999). These observations are likely to hold true for the population of other developed countries.

Cardiac rehabilitation services have been defined as:

“comprehensive, long-term programmes involving medical evaluation, prescribed exercise, cardiac risk factor modification, education and counselling for patients who have suffered a myocardial infarction (MI), undergone cardiac surgery or suffer from heart failure or angina pectoris" (Wenger 1995).

Goble \& Worcester (Goble \& Worcester 99) have taken previous definitions by the World Health Organisation (WHO), the United States Public Health Service and the Cardiac Rehabilitation Working Group of the European Society of Cardiology and give a broader definition of cardiac rehabilitation;

"Cardiac rehabilitation is the co-ordinated sum of interventions required to ensure the best physical, psychological and social conditions so that patients with chronic or post-acute cardiovascu- 
lar disease may, by their own efforts, preserve or resume optimal functioning in society and, through improved health behaviours, slow or reverse progression of disease."

Current provision of cardiac rehabilitation in the UK varies widely in practice and organisation (Davidson 1995). There is evidence that national guidelines for cardiac rehabilitation (Thompson 1996) and secondary prevention measures (ASPIRE 1996, Campbell 1998) are under applied (NHS 1998, Stokes 1998). The National Service Framework for CHD (Department of Health DOH 2000) has been published to address some of these issues.

Systematic reviews and meta-analyses of cardiac rehabilitation

Data from two published and widely cited meta-analyses ( Oldridge 1988, O'Connor 1989) of over 4,000 patients have demonstrated that patients randomised to exercise-based cardiac rehabilitation after MI have a statistically significant reduction in all-cause and cardiac mortality of about 20 to $25 \%$ compared to patients receiving conventional care. No significant effect on nonfatal re-infarctions was found. Reviews of cardiac rehabilitation (May 1982, Oldridge 1988, O’Connor 1989, Lau 1992, West 1995, Ebrahim 1996) have varied considerably in the trials they included and excluded, indicating the difficulty in defining precise criteria.

The USA (Wenger 1995), Australia (Goble \& Worcester 99) and the UK (NHS 1998) have published comprehensive analyses of the systematic reviews available to date to give the professions up to date information on which to base decisions. Two hundred and fifteen systematic reviews were identified by the NHS Centre for Reviews and Dissemination (NHS 1998) in the Health Care Bulletin on Cardiac Rehabilitation, of which seven were considered in detail (Oldridge 1988, Bobbio 1989, O’Connor 1989, Duryee 1992, Hill 1992, Bucher 1994, Wenger 1995). This bulletin concluded "exercise improves physical aspects of recovery at no additional risk, but as a sole intervention it is not sufficient to reduce risk factors, morbidity or mortality." This is at odds with the findings of the Oldridge (Oldridge 1988) and O'Connor (O'Connor 1989) reviews which suggested that there was no difference in the effects seen with exercise alone or in combination with other interventions.

However, commentators have raised a number of concerns regarding these reviews (Ebrahim 1996, West 1995, NHS 1998, Goble $\&$ Worcester 99). The trials included were small and often of poor methodological quality. Incomplete literature review methods may have resulted in publication bias thereby resulting in an over-estimate of the benefit of cardiac rehabilitation. The randomised controlled trials (RCTs) used in the reviews have focused almost exclusively on low-risk, middle-aged males post MI, thereby excluding women, elderly people, and other cardiac patient groups such as cardiac surgery patients or heart failure patients who may benefit more in absolute terms. These caveats apply to most of the trials on which all systematic reviews have been based.

Finally, the meta-analyses have reported evidence of statistical heterogeneity thereby putting in question the use of statistical pooling. Both Oldridge (Oldridge 1988) and O'Connor (O'Connor 1989) address the effect heterogeneity may have had on their results accepting that time to randomisation, type of intervention and length of follow-up may have had some effect on their metaanalyses. The NHS Centre for Reviews and Dissemination (NHS 1998) acknowledges that the evaluation of the cardiac rehabilitation literature is very difficult due to the variability of the interventions and patient populations studied.

Given the existence of new evidence, a current review of the effectiveness of cardiac rehabilitation is indicated. Given its breadth, it is proposed that cardiac rehabilitation be grouped into three separate interventions: (1) exercise-based interventions; (2) educational interventions; and (3) psycho-social interventions. This review will focus on exercise-based interventions for CHD and other Cochrane reviews will focus on the other areas.

\section{O B J E C T I VES}

To determine the effectiveness of exercise-based interventions compared with usual care on the mortality, morbidity, health-related quality of life (HRQoL) and modifiable cardiac risk factors of patients with coronary heart disease (CHD).

\section{METHODS}

\section{Criteria for considering studies for this review}

\section{Types of studies}

All English and non-English randomised controlled trials (RCTs) of exercise-based cardiac rehabilitation versus conventional care with a follow up period of greater than 6 months have been sought.

\section{Types of participants}

Men and women of all ages, in both hospital-based and community-based settings, who have had myocardial infarction (MI), coronary artery bypass graft (CABG) or percutaneous transluminal coronary angioplasty (PTCA), or who have angina pectoris or coronary artery disease defined by angiography have been included. These different patient types were grouped together. Studies involving participants following heart transplant, heart valve surgery or heart failure have been excluded. 


\section{Types of interventions}

Cardiac rehabilitation is defined for this review as inpatient, outpatient or community-based intervention that is applied to a cardiac patient population. The intervention must include some form of exercise training.

The following comparisons have been made:

1) Exercise training alone and usual care vs. usual care alone (exercise only vs. usual care).

2) Exercise training in addition to psychosocial and/or educational interventions vs. usual care alone (comprehensive cardiac rehabilitation vs. usual care).

\section{Types of outcome measures}

The principal outcome measures were:

1 All cause mortality

2 Cardiac mortality, further subdivided into deaths from MI, sudden cardiac deaths, deaths from cerebrovascular disease (CVD)

3 Non fatal MI

4 Revascularization, CABG, PTCA

5 Non fatal CVD events

6 Health related quality of life (HRQoL)

Secondary outcome measures:

Modifiable cardiac risk factors:

1 Smoking behaviour

2 Blood pressure

3 Blood lipid levels

\section{Search methods for identification of studies}

Electronic databases were searched from the earliest date available to December 31st 1998.

The search strategy below was used to identify RCTs of exercise based cardiac rehabilitation using the following electronic databases: Cardiovascular randomised controlled trials register at McMaster University, Central/CCTR, MEDLINE, EMBASE, CINAHL, AMED, BIDS ISI, and SPORTSDISCUS (using appropriate RCT filters for MEDLINE and EMBASE, Dickersin 1994, Lefebvre 1996). In addition, reference lists of retrieved articles have been examined for further trials, conference proceedings have been examined for unpublished and ongoing trials of cardiac rehabilitation, and expert advice has been sought.

Search Strategy

MYOCARDIAL-ISCHEMIA*:ME

CORONARY-ARTERY-BYPASS*:ME

(ISCHEMI* near HEART)

(ISCHAEMI* near HEART)

(CORONARY near DISEASE*)

(CORONARY near BYPASS)

(CORONARY near THROMBO*)

(CORONARY near ANGIOPLAST)

(CORONARY near ANGIOPLAST*)
(MYOCARD* near ISCHEMI*)

(MYOCARD* near ISCHAEMI*)

(MYOCARD* near INFARCT*)

(HEART near INFARCT*)

\section{ANGINA}

$((((((\# 1$ or \#2) or \#3) or \#4) or \#5) or \#6) or \#7) or \#8)

$((((\#)$ or $\# 10)$ or \#11) or \#12) or \#13) or \#14)

(\#15 or \#16)

REHABILITATION*:ME

EXERCISE*:ME

EXERCISE-THERAPY*:ME

SPORTS*:ME

PHYSICAL-EDUCATION-AND-TRAINING**:ME

EXERTION*:ME

REHABILITAT*

(PHYSICAL* near FIT)

(PHYSICAL* near FITNESS)

(PHYSICAL* near TRAIN*)

(PHYSICAL* near ACTIVIT*)

(TRAIN* near STRENGTH*)

(TRAIN* near AEROBIC*)

(AEROBIC* near EXERCISE*)

KINESIOTHERAP*

(EXERCISE* near TRAIN*)

(((((((\#18 or \#19) or \#20) or \#21) or \#22) or \#23) or \#24) or \#

25)

(((((((\#26 or \#27) or \#28) or \#29) or \#30) or \#31) or \#32) or \#

33)

(\#34 or \#35)

(\#17 and \#36)

\section{Data collection and analysis}

Over 4000 citations were retrieved from the search of databases. The titles and abstracts of these were examined by two reviewers, and 300 references were retrieved for possible inclusion. Two reviewers (JJ \& RT or KR) then independently selected trials to be included in this review, by the use of a 6-question inclusion/exclusion form. In all cases disagreements about any study inclusions have been resolved by consensus among the authors and a third reviewer (DT) was consulted if disagreement persisted.

Once studies had been formally included in the review, data was extracted independently by two reviewers (KR, JJ), and chief investigators were contacted where necessary to provide additional information. In addition to study outcome data, the quality of trials was assessed independently in terms of concealment of allocation, losses to follow up and blind assessment of outcomes. Data concerning patient characteristics; age, sex, type of CHD, chronic or acute condition, and details of the intervention, its duration and intensity, and length of follow up, were also collected as stated a priori to perform stratified analysis of the data using meta-regression.

Exercise-based rehabilitation for coronary heart disease (Review)

Copyright $\odot 2009$ The Cochrane Collaboration. Published by John Wiley \& Sons, Ltd. 
Dichotomous outcomes for each study have been expressed as odds ratios and $95 \%$ confidence intervals $(\mathrm{CI})$. Continuous variables have been expressed as the mean change from baseline to follow up, and the standard deviation difference from baseline to follow up for each comparison group. Where standard deviation differences have not been reported in the source papers, allowance has been made for within patient correlation from baseline to follow up measurements by using the correlation coefficient between the two (see Cochrane Heart Group website for details and, Follman 1992). A weighted mean difference (WMD) and 95\% CI have been calculated for each study. Data from each study were pooled as appropriate using a fixed effect model, except where substantial heterogeneity existed according to the $\mathrm{Z}$ statistic, and a random effects model was used (where a random effects model was used this is indicated in parentheses).

\section{RE S U L T S}

\section{Description of studies}

See: Characteristics of included studies; Characteristics of excluded studies.

Details of the studies included in the review are shown in the table of characteristics of included studies.

Several studies that had been included in previous meta-analyses (Oldridge 1988, O'Connor 1989) have not been included in this review (see table 1 for studies excluded from the current analyses and reasons).

\section{Risk of bias in included studies}

See tables 2 and 3, and also results section and discussion. The quality of reporting in general was poor with only a few authors describing the method of randomisation or confirming blind assessment of outcomes. Losses to follow up were relatively high across trials as has been reported elsewhere in the cardiac rehabilitation literature (O'Connor 1989), but reasons for dropout were often not reported. Several trials have excluded significant numbers of patients post randomisation, and thus in an intention to treat analysis, these then have been regarded as dropouts. Blinding of intervention allocation is not possible in rehabilitation interventions and this raises the possibility of bias. Lack of blinding of patients or investigators will however have little effect on mortality outcome data.

\section{Effects of interventions}

A total of 36 trials of exercise based cardiac rehabilitation were found. Four were excluded (see table of excluded studies). Of the 32 included trials, several were further subdivided into seperate studies on the basis of different intervention and comparison groups (WHO 83, Millar/Debusk 84, Sivarajan 82 and Carlsson 98). Thus the number of seperate studies totals 51 . Not all studies measured all outcomes of interest.

Clinical Events

The pooled effect estimate for total mortality for the exercise only intervention showed a $27 \%$ reduction in all cause mortality (random effects model OR $0.73(0.54,0.98))$. Similarly, comprehensive cardiac rehabilitation reduced all cause mortality compared to usual care, but to a lesser, and non-significant, degree (13\% OR $0.87(0.71,1.05))$.

Total cardiac mortality was reduced by $31 \%$ (random effects model OR $0.69(0.51,0.94))$ and $26 \%$ (random effects model OR 0.74 $(0.57,0.96))$ in the exercise only and comprehensive cardiac rehabilitation intervention groups respectively when compared to usual care. When subdividing cardiac deaths into those from coronary heart disease, the reduction in mortality is greater at $35 \%$ and $28 \%$ respectively for exercise only and comprehensive cardiac rehabilitation versus usual care. No significant effect was seen with either intervention on sudden cardiac deaths. However, only 4 exercise only intervention trials and 14 trials (of which 12 formed part of the WHO study) in the comprehensive cardiac rehabilitation group reported this as an outcome. CVD mortality was reported in only 1 trial in the exercise only group (NEHDP) where the intervention showed a reduction in CVD mortality (OR 0.45 $(0.18,1.08))$, and in the $12 \mathrm{WHO}$ trials of comprehensive cardiac rehabilitation the pooled effect estimate was $0.83(0.61,1.13)$.

Neither exercise only rehabilitation or comprehensive cardiac rehabilitation had any effect on recurrence of non-fatal MI, with pooled effect estimates of $0.96(0.69,1.35)$ and $0.88(0.7,1.12)$ respectively.

Only 5 trials reported CABG as an outcome measure in the exercise only group. The results from individual trials showed heterogeneity between studies, and no overall benefit on revascularization rates. In the comprehensive cardiac rehabilitation intervention group, the pooled effect estimate for 10 trials was 0.83 (0.6, 1.13). Similarly, there is little data for PTCA, with only 1 trial reporting this as an outcome in the exercise only group, and showing no effect of the intervention (Speccia 96). In the comprehensive cardiac rehabilitation group, there was considerable heterogeneity between studies.

Using a combined outcome of mortality, non-fatal MIs and revascularisations (CABG and PTCA), a pooled effect estimate of 0.81 $(0.65,1.01)$ for the exercise only rehabilitation group, and 0.81 (0.69, 0.96 random effects model) for comprehensive cardiac rehabilitation was found. Thus, cardiac rehabilitation, either exercise alone or comprehensive cardiac rehabilitation, results in a $20 \%$ reduction in pooled "adverse" clinical outcomes.

Modifiable risk factors

Lipids

Total blood cholesterol was measured in 3 trials in the exercise only 
group (approximately 120 patients in each comparison group) and in 9 trials in the comprehensive cardiac rehabilitation group (600 patients in each group). There was a significant net reduction in total cholesterol in the comprehensive cardiac rehabilitation group (pooled WMD random effects model $-0.57 \mathrm{mmol} / \mathrm{l}(-0.83$, $-0.31)$ ), but not the exercise only group (pooled WMD -0.03 $\mathrm{mmol} / \mathrm{l}(-0.27,0.22))$. Neither intervention had any significant effect on HDL cholesterol.

LDL cholesterol was measured in 2 small trials in the exercise only group (50 patients in each comparison group), and in 6 trials in the comprehensive cardiac rehabilitation group (360 patients in each group). LDL was significantly reduced in the comprehensive cardiac rehabilitation group (pooled WMD random effects model $-0.51 \mathrm{mmol} / \mathrm{l}(-0.82,-0.19))$, with no significant effect of intervention in the exercise only rehabilitation group.

Triglycerides were measured in 3 trials in the exercise only group, with approximately 120 patients in the comparison groups. There was significant heterogeneity between trials, with 1 trial showing favourable effects of exercise on triglyceride levels, and 2 trials (including one larger study) showing no effect. In the comprehensive cardiac rehabilitation group, triglycerides were measured in 5 trials with 400 patients in the comparison groups. There was a small but significant reduction in triglycerides in the comprehensive cardiac rehabilitation group (pooled WMD random effects model -0.29 $(-0.42,-0.15))$.

Only one trial reported concomitant use of cholesterol-lowering drugs which increased over the duration of the trial, suggesting that some or all the reduction in blood cholesterol could be attributed to pharmacological treatment (Carlsson $98 \mathrm{CABG}$ ). In other trials, this remains a possible explanation but no data were reported.

Blood pressure

Only one trial reports blood pressure as an outcome in the exercise only group where no effect was seen $(\mathrm{n}=70$ in each comparison group). Four trials reported blood pressure changes in the comprehensive cardiac rehabilitation group. There was significant heterogeneity in systolic blood pressure between trials. Two larger trials (WHO Helsinki, SCRIP) showed favourable effects of comprehensive cardiac rehabilitation, with reductions in SBP of $-9 \mathrm{mmHg}$ $(-13.6,-4.4)$, and $-6.4 \mathrm{mmHg}(-6.4,-0.99)$ respectively. DBP was significantly reduced in the comprehensive cardiac rehabilitation group (pooled WMD random effects model $-2.24 \mathrm{mmHg}(-3.63$, -0.85)). It should be noted that in two trials BP rose in both intervention and control groups, but as BP tended to rise more in the control groups, net changes were negative.

Smoking

There was no overall effect of rehabilitation on smoking status in the exercise only group in the 3 trials where smoking was reported as an outcome. In the 5 trials reporting smoking in the comprehensive cardiac rehabilitation group, the larger trials showed favourable but non-significant effects of the intervention (pooled effect estimate OR $0.78(0.55,1.11))$.

Health related quality of life
Health related quality of life (HRQoL) was reported in 11 trials overall. Description of these studies, HRQoL outcomes, results and comments are presented in tables 4 and 5. Eighteen different instruments were used to assess HRQoL, 4 studies used unvalidated self report measures, 2 used the Beck Depression Inventory, and 2 used the Quality of Life after Acute Myocardial Infarction Questionnaire (QoLAMI Guyatt 1986). For these reasons, and the relatively small number of trials reporting HRQoL as an outcome, it was not possible to combine data in a quantitative way, and so these data are presented qualitatively. In the exercise only group, in 4 trials, overall small changes or no change in various HRQoL measures were found. In the comprehensive cardiac rehabilitation group, 7 trials reported HRQoL outcomes. Most of these studies show small and variable effects in a number of HRQoL measures. One trial shows significant improvements with the intervention, showing reductions in anxiety and depression (Lewin 92). Oldridge (Oldridge 91) showed substantial and significant improvement in both rehabilitation and control groups over 12 months, although there was no significant difference between the two groups. Significant improvement in both intervention and control groups highlights the importance of recognising the natural course of recovery after MI.

Quality of trials

Individual studies from both groups of interventions were grouped into a number of categories based on quality criteria. Sixteen percent of all studies reported a clear description of an adequate method of randomisation, $2 \%$ reported a clear description of an inadequate method of randomisation, and in the remainder (82\%), reports were unclear. Blind assessment of outcomes was reported in only $8 \%$ studies. Using a $20 \%$ loss to follow up as a cut off, $71 \%$ of studies reported a less than $20 \%$ loss to follow up, and the remainder (29\%) a greater than $20 \%$ loss to follow up.

As the reporting of quality criteria in the published papers was so poor, we attempted to contact all authors for clarification of the method of concealment allocation, the number of patients lost to follow up, and whether outcome assessors were blind to group allocation. The method used by the authors to randomise patients in the primary studies was determined by giving a number of options to choose from thereby not suggesting one method was preferable to another. Seventy two percent of authors were located, of these $50 \%$ responded. The effect of the quality of studies on the pooled effect estimate has been examined using total mortality as the outcome measure for any exercise intervention. Following attempts to clarify the method of allocation concealment, 12/41 (29\%) studies reporting total mortality as an outcome used an adequate method of randomisation, $2 / 41(5 \%)$ studies used an inadequate method, and in the remainder (27 studies, 66\%) the method was unclear. The pooled effect estimate for those studies with an adequate method of randomisation was OR 0.78 (0.61, 0.99 random effects model), for those with an inadequate method of randomisation OR $0.53(0.2,1.4)$, and for those where the method remains unclear OR $0.88(0.7,1.1)$. Twenty seven studies

Exercise-based rehabilitation for coronary heart disease (Review) 
(66\%) reporting total mortality as an outcome measure and had less than $20 \%$ loss to follow up. For these studies the pooled effect estimate was $0.84(0.69,1.0)$. For the 14 remaining studies $(34 \%)$ with greater than $20 \%$ loss to follow up, the pooled effect estimate was $0.8(0.57,1.14$ random effects model). Following contact with the authors, 9/41 (22\%) studies reported blind assessment of outcomes, where the pooled effect estimate for total mortality was OR $0.78(0.54,1.12)$, and in 32 studies $(78 \%)$ this remains unclear (OR $0.84(0.7,0.97)$ random effects model).

The pooled effect estimate for total mortality, any exercise intervention was OR 0.83 (0.69, 0.96 random effects model). Excluding the 2 studies with inadequate randomisation had little effect on the summary estimate (OR 0.83 (0.7, 0.98 random effects model).

Evidence of publication bias using total mortality as an outcome for any intervention was examined both visually in the form of a funnel plot, and statistically (Egger 1997). There was no evidence of significant publication bias either visually or statistically (Egger test $\mathrm{p}=0.319)$.

\section{ISCUSSION}

In contrast to previous reviews, the current systematic review has allowed analysis of an increased number of patients from approximately 4500 in the earlier meta-analyses (Oldridge 1988, O'Connor 1989) to 8440 (2845 in exercise only and 5595 in the multiple rehabilitation group), with 7683 patients contributing to the total mortality outcome. Twenty-seven further RCTs have been included, most published since the original meta-analyses in the late 1980s. Both a more comprehensive search strategy and the passage of time have allowed the introduction of more trials and patients.

This review, in contrast to previous reviews and the NHS Centre for Reviews \& Dissemination bulletin, demonstrates a $27 \%$ reduction in total mortality in patients who have undergone exercise only based cardiac rehabilitation, and a $13 \%$ reduction in total mortality in those who have undergone comprehensive cardiac rehabilitation. Somewhat better outcomes were also achieved for cardiac deaths in those receiving exercise-only rehabilitation than comprehensive rehabilitation. However, there is insufficient data to determine whether exercise only rehabilitation is significantly better than comprehensive rehabilitation.

Trial quality

Unlike previous reviews, we have attempted to examine the quality of the trials included. It is clear that the majority of trials were under-powered. The reporting of quality issues in the primary studies was generally poor. For most of the trials the method of randomisation was not reported clearly, and only 4 trials reported blind assessment of outcomes. Approximately one third of trials reported a greater than $20 \%$ loss to follow up. Authors of the primary studies were contacted where possible to clarify methods of randomisation, losses to follow up and blinding. Stratified analysis using the additional information provided by authors had little effect on the pooled effect estimate for total mortality for all trials with any exercise intervention. For those trials where the method of randomisation was clear and adequate, the pooled effects estimate was OR 0.78 (0.61, 0.99 random effects model). We found no evidence of publication bias.

Role of drug treatments

The reasons for the differences between exercise only rehabilitation and comprehensive cardiac rehabilitation are unclear. Differences may be due to different medications taken during the trial period. These are generally not well reported, but are in part dependent on when the trials were carried out and hence what medication was prescribed. There are only five new trials in the exercise only analysis, the latest of these was published in 1999 (although the results pertain to patients from the late 1980s). None appeared to be receiving statins (although details were not always given), under $50 \%$ (approximately) were on beta-blockers (where stated) and there was no record of whether thrombolysis was given on admission. There are 15 new trials included in the comprehensive cardiac rehabilitation intervention analysis, eight published since 1995 and the latest being published in 1999. Again there are few details of medication or thrombolysis, although more patients seem to be prescribed statins or beta-blockers. There is only one study that details thrombolytic treatment (Carlsson 97). In another study (Carlsson $98 \mathrm{AMI}$ ) the proportion of participants receiving statins in the intervention group rose from $2.6 \%$ at the start of the trial to $75 \%$ at the one year follow up. Use of aspirin was detailed in Worsrnu, Bell and Schuler/Niebauer (Worsornu 96, Bell 99, Schuler/Niebauer) but was not mentioned in other trial reports. The incremental benefit of cardiac rehabilitation on mortality in a world where the majority of patients will receive thrombolysis, aspirin, statins and increasingly ACE inhibitors has not been studied adequately.

Non-fatal myocardial infarction

Both exercise only interventions and comprehensive cardiac rehabilitation have no effect on the recurrence of non-fatal MI. This confirms the findings of Oldridge and O'Connor. It is unclear why there is a decrease in the mortality rate after cardiac rehabilitation but not in the rate of non-fatal reinfarction. It has been suggested that either there is a true increase in the frequency of non-fatal MI after rehabilitation, or there may be increased survival after MI with rehabilitation. The mechanism for reduced mortality in patients who have received rehabilitation is not clear, but may be due to improved myocardial revascularisation, protection against fatal dysrhythmias, improved cardiovascular risk factor profile, improved cardiovascular fitness, or increased patient surveillance (Oldridge 1988). There is insufficient data in this re- 
view to make any conclusions about the effect of cardiac rehabilitation on revascularization rates.

\section{Reduction in blood cholesterol}

With comprehensive cardiac rehabilitation there were significant reductions in both total blood cholesterol and LDL cholesterol, however, the effects of cholesterol-lowering drugs cannot be excluded. No effect of exercise only based rehabilitation was seen for total or LDL cholesterol. There was no effect of rehabilitation of either type on levels of HDL cholesterol, although small but significant reductions in triglycerides occurred in the comprehensive cardiac rehabilitation group. Very little data were collected on blood pressure measurement. Similarly, the number of trials that reported smoking as an outcome were small.

Health related quality of life

One of the primary objectives of this review was to contribute to the evidence concerning HRQoL outcomes following MI. The diversity of instruments used in assessing psychological and HRQoL outcomes was surprising, as was the fact that four studies used unvalidated self-report instruments. The majority of measures that were used were long, psychological questionnaires not particularly suited for use in general practice, busy hospital departments or cardiac rehabilitation programmes. Only four studies used a disease specific questionnaire. With the advent of increasingly effective medication for post MI patients, mortality and reinfarction may not be the best method of measuring the effectiveness of cardiac rehabilitation. HRQoL and psychological measures assess the patient's performance in society and should be part of the standard outcome measures for all cardiac patients.

Characteristics of trial participants

All the participants in these studies had a specific exercise intervention with or without some formal education on lifestyle changes. The question as to whether the exercise only participants received ad hoc education while exercising or from other sources has not been addressed. All participants in the included studies had documented CHD, the majority of the participants having suffered an MI. Some participants had documented CHD having suffered angina or undergone coronary angiography (Fletcher 94, Krachler 97, Lifestyle Heart, Schuler/Niebauer, SCRIP), while others had undergone CABG (Carlsson 98 CABG, Engblom, Worsornu 96). We have combined these different patient groups as there is insufficient data at present to stratify trials by type of CHD. The number of women participants (4.4\% in exercise only and $11 \%$ in comprehensive cardiac rehabilitation) was low and few studies mentioned the ethnic origin of their participants. The mean age of the participants was 53.1 (exercise only) and 56.3 (comprehensive cardiac rehabilitation). Although most studies had an upper age limit of at least 65 years of age, this is not reflected in the mean age of the participants. The majority of the studies had exclusion criteria that would have excluded those participants who had co-morbidity, or heart failure. In some studies this may have accounted for up to $60 \%$ of the patients considered for the trial, and certainly the older patients would be more likely to be affected. There would seem to be no biological reason why patients who are older, female or from differing ethnic background should not benefit from cardiac rehabilitation. Observational and non randomised controlled trials have found benefits to older (Willmer 1999, Stahle 1999) and female (Cannistra 1992) patients.

\section{Variation in rehabilitation interventions}

The separate classification of trials into exercise only and comprehensive cardiac rehabilitation in the current systematic review was implemented to try to reduce heterogeneity between the trials. In any analysis of a complex, multidisciplinary intervention, heterogeneity between trials will inevitably pose a problem to interpreting any overall effects. However within each of these groups there are some variations in the time post event to randomisation, type of participant or intervention and length of follow up. Within the exercise only group of studies the point of randomisation varied between the time of acute MI (Kentala 72, Sivarajan 82) to 6 weeks or 1 year after acute MI (Stern 83). In the comprehensive cardiac rehabilitation group time of randomisation varied between the time of acute MI (Bengtsson 83, Fridlund 91, Sivarajan 82) to 4 to 6 weeks post event (Oldridge 91, Vermuelen 83, PRECOR). Duration of follow up again varied within each of the groups. In the exercise only group follow up varied between 6 months (Ballantyne 82, Sivarajan 82, Worsornu 96) to 5 years (Bethell 90, Erdman 86, Wilhelmson 75). In the comprehensive cardiac rehabilitation group the follow up varied between 6 months (Fletcher 94, Miller/DeBusk 1A, Miller/DeBusk 1B, Miller/DeBusk 2A, Miller/DeBusk 2B, Sivarajan 82) to 6 years (Schuler/Niebauer). The benefits of cardiac rehabilitation reported in this systematic review have accrued over an average of 2.4 years, and we cannot extrapolate the benefits beyond the period of the trials. The effect of trial length on the benefit of cardiac rehabilitation in terms of duration over which benefits are seen and maintained will be addressed in an update of this review. The type of intervention varied between gym based aerobic exercise twice a week for 4 weeks (Bertie 92) to a four stage intervention lasting 30 months with inpatient stays (Engblom). Other interventions included being sent home with a tape and manual, supported by a facilitator (Lewin 92), intensive dietary changes, stress management techniques, and daily exercise and support groups (Lifestyle Heart), or mail out packages on diet and exercise (Heller 93). Five trials gave all participants some instruction and education prior to the intervention (Carlsson 97, NEHDP, Schuler/Niebauer, Speccia 96, Wilhelmson 75). This varied between information on increasing exercise levels and diet (Wilhelmson 75) to all participants taking part in a low level exercise course for 6 weeks (NEHDP). Given the differences in the trials, in the age, sex, and diagnosis of the participants, type and length of intervention, the differing length of follow up, and the quality of trials, it is our intention 
to perform stratified analyses using meta-regression techniques in a subsequent update of this review to further explore differences between the studies.

Long-term follow up

Three of the trials included in this meta-analysis have published long term results of 15,19 and 11 years respectively: WHO Helsinki (Hamalainen 1995), NEHDP (Dorn 1999) and Bethell 1990 (Bethell 1999). The two trials of exercise only rehabilitation (NEHDP, Bethell 90) found no effect for the intervention on total mortality at 10 and 11 years respectively, or at 19 years (NEHDP). Both studies noted that there were drop outs from the original intervention group and "drop ins" from the control groups (31\% drop ins NEHDP, 25\% drop ins Bethell). This and the advent of improved drug intervention may have compromised the treatment effect over time. The comprehensive cardiac rehabilitation trial (Hamalainen 1995) found a significantly lower incidence of sudden death ( $16.5 \%$ vs. $28.9 \%, \mathrm{p}=0.006)$ and coronary mortality ( $47.9 \%$ vs. $58.5 \%, \mathrm{p}=0.04)$ in the intervention group compared with controls. It has been suggested that the addition of educational and counselling programmes may have contributed to the study group differences in survival in the Hamalainen study (Dorn 1999).

\section{AUTHORS' CONCLUSIONS}

\section{Implications for practice}

Exercise-based cardiac rehabilitation is effective in reducing cardiac deaths. It is reasonable to promote exercise-based cardiac rehabilitation to patients similar to those included in the randomised controlled trials - predominantly younger men who had suffered myocardial infarction. There appears to be little to chose between exercise only or more comprehensive rehabilitation, so it would be rational to use cost considerations to determine practise. It is a question of judgement whether such evidence is sufficient to base extension of current practise to under-represented groups, such as elderly people, women and those with angina, heart failure or following revascularisation.

\section{Implications for research}

Larger scale well-designed and executed RCTs are needed to determine whether the effects of comprehensive rehabilitation found in a heterogeneous set of small trials can be confirmed and extended to other patient groups. A British NHS R\&D funded trial has recently been completed and its results are awaited with interest. The population studied in this review is still predominately male, middle aged and low risk. There has been little identification of the ethnic origin of the participants. It is possible that patients who would have benefited most from the intervention were excluded from the trials on the grounds of age, sex or co-morbidity. These groups should be included in future trials. The method of service delivery, either through supervised settings, home-based services or in combination, needs to be studied. Outcome measures that accurately reflect the effect of rehabilitation on the patient and their family need to be generated and used in everyday practice.

\section{ACKNOW LEDGEMENTS}

Steering Group: Mr David Batty, Professor Peter Fentem, Dr Ann Taylor, Dr Robert West.

Translators: Ellen Ingham, Cornelia Junghans, Fenicia Vescio

We would also like to thank all the authors who provided additional information about their trials.

\section{RE F E R E N C E S}

\section{References to studies included in this review}

Anderson 81 \{published data only\} Andersen GS, Christansen P, Madsen S, Scmidt G. The value of regular, supervised training after acute myocardial infarction [Vaerdien af regelmaessig og overvaget fysisk traening efter akut myokardieinfarkt.]. Ugeskrift for laeger 1981;143(45):2952-2955.

Ballantyne 82 \{published data only\} Ballantyne FC, Clarke RS, Simpson HS, Ballantyne D. The effect of moderate physical exercise on the plasma lipoprotein subfractions of male survivors of myocardial infarction. Circulation 1982;65(5):913-918.

Bell 99 \{unpublished data only\} Bell J. A comparison of a Multi-Disciplinary Home Based
Cardiac Rehabilitation Programme with Comprehensive Conventional Rehabilitation in Post-Myocardial Infarction Patients. PhD Thesis, University of London 1998.

Bengtsson 83 \{published data only\} Bengtsson K. Rehabilitation after myocardial infarction. Scand J Rehab Med 1983;15:1-9.

Bertie 92 \{published data only\} Bertie J, King A, Reed N, Marshall AJ, Ricketts C. Benefits and weaknesses of a cardiac rehabilitation programme. Journal of the Royal College of Physicians of London 1992;26: 147-51.

Bethell 90 \{published and unpublished data\} Bethell HJN, Mullee MA. A controlled trial of community based coronary rehabilitation.. Br Heart J 1990;64:370-5. 
Carlsson 98 CABG \{published data only\}

Carlsson R. Serum Cholesterol, lifestyle, working capacity and quality of life in patients with coronary artery disease. Experiences from a hospital-based secondary prevention programme. Scandinavian Cardiovascular Journal 1998;S 50:1-20.

Carlsson 97 \{published data only\}

Carlsson R, Lindberg G, Westin L, Bo Israelsson. Influence of coronary nursing management follow up on lifestyle after acute myocardial infarction. Heart 1997;77:256-259.

Carlsson 98 AMI \{published data only\}

Carlsson R. Serum Cholesterol, lifestyle, working capacity and quality of life in patients with coronary artery disease. Experiences from a hospital-based secondary prevention programme. Scandinavian Cardiovascular Journal 1998; S50:1-20.

Carson 82 \{published data only\} Carson P, Phillips R, Lloyd M, Tucker H, Neophytou M, Buch NJ, Gelson A, Lawton A, Simpson T. Exercise after myocardial infarction: a controlled trial. J Royal Coll Physicians of London 1982;16(3):147-151.

Engblom \{published data only\}

Engblom E, Hamalainen H, lind J, Mattlar CE, Ollila S, Kallio V, Inberg M, Knuts L-R. Quality of life during rehabilitation after coronary bypass surgery. Quality of Life Research 1992;1:167-75. [MEDLINE: 93244729]

Engblom E, hietanen EK, Hamalainen H, Kallio V, Inberg M, Knuts L-R. Exercise habits and physical performance during comprehensive rehabilitation after coroanry arery bypass surgery. European Heart Journal 1992;13:1053-9. [MEDLINE: 92209581]

Engblom E, Korpilahti K, Hamalainen H, Puukka P, Ronnemaa T. Effects of five years of cardiac rehabilitation after coronary artery bypass grafting on coronary risk factors. American Journal of Cardiology 1996;78:1428-31. [MEDLINE: 97125341]

Engblom E, Korpilahti K, Hamalainen H, Ronnemaa T, Puukka P. Quality of life and return to work 5 years after coronary artery bypass surgery. J Cardiopulmonary Rehabil 1997;17:29-36. [MEDLINE: 97193477]

Engblom E, Ronnemaa T, Hamalainen H, Kallio V, Vanttinene, Knuts LR. Coronary heart disease risk factors before and after bypass surgery: results of a controlled trial on multifactorial rehabilitation. European Heart Journal 1992;13:232-237. [MEDLINE: 92209581]

Erdman 86 \{published data only\}

Erdman RAM, Duivenvoorden HJ, Verhage F, Kazmier M, Hugenholtz PG. Predictability of beneficial effects in cardiac rehabilitation: A randomized clinical trial of psychosocial variables. J Cardiopulmaonary Rehabil 1986;6(6):206-213.

Fletcher 94 \{published data only\}

Fletcher BJ, Dunbar SB, Feiner JM, Jensen BE, Almon L, Cotsonis G, Fletcher G. Exercise testing and training in physically disabled men with clinical evidence of coronary artery disease. American journal of Cardiology 1994;73: $170-174$.
Fridlund 91 \{published data only\}

* Fridlund B, Hogstedt B, Lidell, Larsson P. Recovery after myocardial infarction. Scand J Caring Soc 1991;5(1):23-32. Fridlund B, Pihilgren C, Wannestig L-B. A supportive educative caring rehabilitation programme: improvements of physical health after myocardial infarction. Journal of Clinical Nursing 1992;1:141-146.

Lidell E, Fridlund B. Long - term effects of a comprehensive rehabilitation programme after myocardial infarction. Scand J Caring Soc 1996;10:67-74.

Heller 93 \{published data only\}

* Heller RF, Knapp JC, Valenti LA, Dobson AJ. Secondary prevention after acute myocardial infarction. Am J Cardiol 1993;72:759-762.

Holmback 94 \{published data only\}

Holmback AM, Sawe U, Fagher B. Training after myocardial infarction: lack of long term effects on physical capacity and psychological variables. Arch Phys Med Rehabil 1994; 75:551-554.

Kentala 72 \{published data only\}

Kentala E. Physical fitness and feasibility of physical rehabilitation after myocardial infacrction in men of working age. Ann Clin Res 1972;suppl 9:1-84.

Krachler 97 \{published data only\}

Krachler M, Lindschinger M, Eber B, Watzinger N, Wallner S. Trace elements in coronary heart disease. Biological Trace Element Research 1997;60:175-185.

Lewin 92 \{published data only\}

Lewin B, Robertson IH, Cay EL, Irving JB, Campbell M. Effects of self-help post-myocardial infarction rehabilitation on psychological adjustment and use of health services. Lancet 1992;339:1036-40.

Lifestyle Heart \{published data only\}

* Ornish D, Brown SE, Scherwitz LW, Billings JH, Armstrong WT, Porst TA, McLanaghan SM, Kirkeeide RL, Brand RJ, Gould KL. Can lifestyle changes reverse coronary heart disease?. Lancet 1990;336:129-33.

Ornish D, Scherwitz LW, Billings JH, Gould L, Merritt TA, Sparler S, Armstrong WT, Ports TA, Kirkeeide RL, Hogeboom C, Brand RJ. Intensive Lifestyle Changes for Reversal of Coronary Heart Disease. JAMA 1998;280(23): 2001-2007.

\section{Miller/DeBusk 1A \{published data only\}} DeBusk RF, Haskell WL, Miller NH, Berra K, Taylor $\mathrm{CB}$, Berger WE, Lew H. Medically directed at-home rehabilitation soon after clinically uncomplicated acute myocardial infarction: a new model for patient care. $A m J$ Cardiol 1985;55:251-257.

* Miller NH, Haskell WL, Berra K, DeBusk RF. Home versus group exercise training for increasing functional capacity after myocardial infarction. Circulation 1984;4: 645-649.

Taylor CB, Houston Miller N, Haskell WL, DeBusk RF. Smoking cessation after acute myocardial infarction: the 
effects of exercise training. Addictive Behaviours 1988;13: $331-5$.

Taylor C Barr, Miller NH, Ahn DK, Haskell WL, DeBusk RF. The effect of exercise training programs on psychological improvement in uncomplicated postmyocardial infarction patients. Journal of Psychosomatic Research 1986;30(5): 581-587.

Miller/DeBusk 1B \{published data only\} Miller NH, Haskell WL, Berra K, DeBusk RF. Home versus group exercise training for increasing functional capacity after myocardial infarction (patient group 1B). Circulation 1984;4:645-649.

Miller/DeBusk 2A \{published data only\} Taylor C Barr, Miller NH, Ahn DK, Haskell WL, DeBusk RF. Home versus group exercise training for increasing functional capacity after myocardial infarction (patient group 2A). Circulation 1984;4:645-649.

Miller/DeBusk 2B \{published data only\} Taylor C Barr, Miller NH, Ahn DK, Haskell WL, DeBusk RF. Home versus group exercise training for increasing functional capacity after myocardial infarction (patient group 2B). Circulation 1984;4:645-9.

\section{NEHDP \{published data only\}}

Naughton J. The National Exercise and Heart Disease Project. Cardiology 1978;63:352-367.

* Shaw LW. Effects of a prescribed supervised exercise program on mortality and cardiovascular morbidity in ptients after a myocardial infarction. American Journal of Cardiology 1981;48:39-46.

Stern MJ, Cleary P. The National Exercise and Heart Disease Project: Long term psychosocial outcome. Arch Intern Med 1982;142:1093-1097.

\section{Oldridge 91 \{published and unpublished data\}}

Oldridge N, Streiner D, Hoffman R, Guyatt G. Profile of mood states and cardiac rehabilitation after acute myocardial infarction. Med Sci Sports Exerc 1995;27(6):900-905.

* Oldridge NO, Guyatt GG, Jones N, Crowe J, Singer J, Feeny D, McKelvie R, Runions J, Streiner D, Torrance G. Effects on quality of life with comprehensive rehabilitation after acute myocardial infarction. Am J Cardiol 1991;67: 1084-1089.

\section{PRECOR \{published data only\}}

The P.R.E. COR group. Comparison of a rehabilitation programme, a counselling programme and usual care after an acute myocardial infarction: results of a longterm randomized trial. European Heart Journal 1991;12: 612-616.

Schuler/Niebauer \{published data only\}

Hambrecht R, Neibauer J, Marburger C, Grunze M, Kalberer B, Huer K, Schlierf G, Kubler W, Schuler G. Various intensities of leisure time physical activity in patients with coronary artery disease: Effects on cardiorespiratory fitness and progression of coronary atherosclerotic lesions. $J$ Am Coll Cardiol 1993;22(2):468-477.

Niebauer J, Hambrecht R, Marburger C, Hauer K, Velich T, von Hodenberg E, Schlierf G, Kubler W, Schuler G.
Impact of intensive physical exercise and low fat diet on collateral vessel formation in stable angina pectorisa $\mathrm{dn}$ angiographically comfirmed cornary artery diesease. $\mathrm{Am} \mathrm{J}$ Cardiol 1995;76:771-775.

Niebauer J, Hambrecht R, Velich T, Hauer K, Marburger C, Kalberer B, Wiess C, von Hodenberg E, Schlierf G, Schuler G, Zimmerman R, Kubler W. Attenuated progression of coronary artery diesase after 6 years of multifactorial intervention. Circulation 1997;96:2534-2541.

Niebauer J, Hambrecht R, Velich T, Marburger C, Hauer K, Kreuzer J, Zimmerman R, von Hodenberg E, Schlierf G, Schuler G, Kubler W. Predictive value of lipid profile for salutary coronary angiographic changes in patients on a low-fat diet and physical exerciese program. Am J Cardiol 1996;78:163-167.

* Schuler G, Hambrecht R, Schlierf G, Niebauer J, Hauer K, Neumann J, Hoberg E, Drinkmann A, Bacher F, Grunze M, Kubler W. Regular physical exercise and low fat diet: effects on progression of coronary artery disease. Circulation 1992;86:1-11.

\section{SCRIP \{published data only\}}

Haskell WL, Alderamn EL, Fair JM, Maron DJ, Mackey SF, Superko R, Williams PT, Johnstone IM, Champagene A, Krauss RM, Farquhar JW. Effects of intensive multpiple risk factor reduction on cornary atherosclerosis and clinical cardiac evnets in men and women with coronary artery disease: The Stanford Coronary Risk Intervention Project (SCRIP). Circulation 1994;89:975-990.

\section{Sivarajan 82 \{published data only\}}

Ott CR, Sivarajan S, Newton KM, Almes MJ, Bruce RA, Bergner M, Gilson BS. A controlled randomized study of early cardiac rehabilitation: the sickness impact profile as an assessment tool. Heart \& Lung 1983;12(2):162-170. Sivarajan ES, Bruce RA, Almes MJ, Green B, Belanger L, Lindskog BD, Newton KM, Mansfield LW. In hospital exercise after myocardial infarction does not improve treadmil performance. New England Journal of Medicine 1981;305:357-62.

* Sivarajan ES, Bruce RA, Lindskog BD, Almes MJ, Belanger L, Green B. Treadmill test responses to an early exercise program after myocardial infarction: a randomized study. Circulation 1982;65(7):1420-1428.

Sivarajan ES, Newton KM, Almes MJ, Kempf TM, Mansfield LW, Bruce RA. Limited effects of outpatient teaching and counselling after myocardial infarction: A controlled study. Heart \& Lung 1983;12(1):65-73.

\section{Sivarajan 82 ex plus \{published data only\}}

References as for Sivarajan 82, second intervention group with comprehensive cardiac rehabilitation.

Speccia 96 \{published data only\} Spechia G, DeServi S, Scrire A, Assandri J, Berzuini C, Angoli L, La Rovere MT, Cobelli F. Interaction between exercise training and ejection fraction in predicting prognosis after first myocardial infarction. Circulation 1996;94:978-982. 
Stern 83 \{published data only\}

Stern MJ, Gorman PA, Kaslow L. The group counselling $\mathrm{v}$ exercise therapy study: A controlled intervention with subjects following myocardial infarction. Arch Intern Med 1983;143:1719-1725.

Taylor 97 \{published data only\}

Taylor C Barr, Houston Miller N, Smith PM, DeBusk RF. The effect of a home-based, case-managed, multifactorial risk-reduction program on reducing psychological distress in patients with cardiovascular disease. J Cardiopulmonary Rehab 1997;17:157-162.

Vecchio 81 \{published data only\}

Vecchio C, Cobelli F, Opasich C, Assandri J, Poggi G, Griffo R. Early functional evaluation and physical rehabilitation in patients with myocardial infarction [Valutazione funzionale precoce e riabilitazione fisica nei pazienti con infartio miocardico esteso]. G Ital Cardiol 1981;11:419-429.

Vermuelen 83 \{published data only\}

Vermuelen A, Lie KI, Durrerr D. Effects of cardiac rehabilitation after myocardial infarction: changes in coronary risk factors and long-term prognosis. Am Heart $J$ 1983;105:798-801.

WHO Balatonfured \{published data only\}

World Health Organisation. Rehabilitation and comprehensive secondary prevention after acute myocardial infaction. EURO Reports and Studies 841983.

WHO Brussels \{published data only\} World Health Organisation. Rehabilitation and comprehensive secondary prevention after acute myocardial infaction. EURO Reports and Studies 841983.

WHO Bucharest \{published data only\}

World Health Organisation. Rehabilitation and comprehensive secondary prevention after acute myocardial infaction. EURO Reports and Studies 841983.

WHO Budapest \{published data only\}

World Health Organisation. Rehabilitation and comprehensive secondary prevention after acute myocardial infaction. EURO Reports and Studies 841983.

WHO Dessau \{published data only\}

World Health Organisation. Rehabilitation and comprehensive secondary prevention after acute myocardial infaction. EURO Reports and Studies 841983.

WHO Erfut \{published data only\}

World Health Organisation. Rehabilitation and comprehensive secondary prevention after acute myocardial infaction. EURO Reports and Studies 841983.

WHO Ghent \{published data only\}

World Health Organisation. Rehabilitation and comprehensive secondary prevention after acute myocardial infaction. EURO Reports and Studies 841983.

WHO Helsinki \{published data only\}

Kallio V, Hamalainen H, Hakkila J, Luurila OJ. Reduction in sudden deaths by a multifactorial intervention programme after acute myocardial infarction. Lancet 1979; November 24th:1091-1094.
WHO Kaunas \{published data only\}

World Health Organisation. Rehabilitation and comprehensive secondary prevention after acute myocardial infaction. EURO Reports and Studies 841983.

WHO Prague \{published data only\}

World Health Organisation. Rehabilitation and

comprehensive secondary prevention after acute myocardial infaction. EURO Reports and Studies 841983.

WHO Rome \{published data only\}

World Health Organisation. Rehabilitation and comprehensive secondary prevention after acute myocardial infaction. EURO Reports and Studies 841983.

WHO Tel Aviv \{published data only\}

World Health Organisation. Rehabilitation and comprehensive secondary prevention after acute myocardial infaction. EURO Reports and Studies 841983.

\section{WHO Warsaw \{published data only\}}

World Health Organisation. Rehabilitation and comprehensive secondary prevention after acute myocardial infaction. EURO Reports and Studies 841983.

Wilhelmson 75 \{published data only\} Sanne H. Exercise tolerance and physical training of nonselected patients after myocardial infarction. Acta Med Scand 1973;suppl 551:1-124.

* Wilhelmson L, Sanne H, Elmfeldt D, Grimby G, Tibblin G, Wedel H. A controlled trial of physical trainingafter myocardial infarction.. Preventive Medicine 1975;4: 491-508.

Worsornu 96 \{published data only\}

Wosornu D, Bedford D, Ballantyne D. A comparison of the effects of strength and aerobic exercise training on exercise capacity and lipids after coronary artery bypass surgery. European Heart Journal 1996;17:854-863.

\section{References to studies excluded from this review}

Bar 92 \{published data only\} Bar FW, Hoppener P, Diederiks J, Vonken H, Bekkers J, V.H.Hoofd W, Appels A, Wellens HJJ. Cardiaac rehabilitation contributes to the restoration of leisure and social activities. J Cardiopulmonary Rehabil 1992;12: $117-125$.

\section{Bjorntorp 72 \{published data only\}}

Bjorntorp, Berchtold P, Grimby G, Lindholm B, Sanne H, Tibblin G, Wilhelmson L. Effects of physical training on glucose tolerance, plasma insulin and lipids and on body composition in men after myocardial infarction. Acta Med Scand 1972;192:439-443.

Blumenthal 97 \{published data only\} Blumenthal JA, Wei Jang, Babyak MA, Krantz DS, Frid DJ, Coleman RE, Waugh R, Hanson M, Appelbaum M, O'Connor C, Morris JJ. Stress management and exercise training in cardiac patients with myocardial ischemia: Effects on prognosis and evaluation of mechanisms. Arch Intern Med 1997;157:2213-2223. 
Nikolaus 91 \{published data only\}

Nikolaus T, Schlierf G, Vogel G, Schuler G, Wagner I. Treatment of coronary heart disease with diet and exercise: problems of compliance. Ann Nutr Metab 1991;35:1-7.

\section{References to studies awaiting assessment}

\author{
Adachi 96 \{published data only\} \\ Ades 95 \{published data only\} \\ Agren 89 \{published data only\} \\ Ali 98 \{published data only\} \\ Aronov 80 \{published data only\} \\ Bigi 85 \{published data only\} \\ Bjernulf 74 \{published data only\} \\ Campbell 98 \{published data only\} \\ DeBG 74 \{published data only\} \\ Foster 84 \{published data only\} \\ Franklin 98 \{published data only\} \\ Geissler 79 \{published data only\} \\ Gutscher 77 \{published data only\} \\ Halfen 76 \{published data only\} \\ Hands 87 \{published data only\} \\ Jitraphi 98 \{published data only\} \\ Kallio 81 \{published data only\} \\ Prosser 85 \{published data only\} \\ Rakov 97 \{published data only\} \\ Roseler 97 \{published data only\} \\ Rovario 84 \{published data only\} \\ Rudnicki 77 \{published data only\} \\ Rudnicki 90 \{published data only\} \\ Saunamaki 77 \{published data only\} \\ Wallner \{published data only\} \\ Winter 84 \{published data only\}
}

\section{Additional references}

\section{ASPIRE 1996}

ASPIRE Steering Group. A British Cardiac Society survey of the potential for the secondary prevention of coronary heart disease: ASPIRE (Action on Secondary Prevention through Intervention to Reduce events) principal results. Heart 1996;75:334-42.

Bethell 1999

Bethell HJN, Turner SC, Mullee MA. Cardiac rehabilitation in the community: 11 year follow-up after a randomized controlled trial. Coronary Health Care 1999;3(4):183-88.

Bobbio 1989

Bobbio M. Does myocardial infarction rehabilitation prolong survival? A meta-analytic survey. G Ital Cardiol 1989;19:1059-67. [MEDLINE: 90152276]
Bucher 1994

Bucher HC. Social support and prognosis following first myocardial infarction. Gen Intern Med 1994;9:409-17. [MEDLINE: 95017185]

\section{Campbell 1998}

Campbell NC, Thain J, Deans HG, Ritchie LD, Rawles JM. Secondary prevention in coronary heart disease: baseline survey of provision in general practice. British Medical Journal 1998;316:1430-4.

Cannistra 1992

Cannistra LB, Balady GJ, O’Malley CJ, Weiner DA, Ryan TJ. Comparison of the clinical profile and outcome of women and men in cardiac rehabilitation. Am J Cardiology 1992;69:1274-79.

\section{Davidson 1995}

Davidson C, Reval DA, Chamberlain DA, Pentecost B, Parker J. A report of a working group of the British Cardiac Society: cardiac rehabilitation services in the United Kingdom. Br Heart J 1995;73:201-2. [MEDLINE: 95210019]

Dickersin 1994

Dickersin K, Scherer R, Lefebvre C. Identifying relevant studies for systematic reviews. British Medical Journal 1994; 309:1286-91.

\section{DOH 2000}

Department of Health. National Service Framework for Coronary Heart Disease. London: DOH, 2000.

Dorn 1999

Dorn J, Naughton J, Imamura D, Trevisan M for the NEHDP staff. Results of a multicenter randomized clinical trial of exercise and long term survival in myocardial infarction patients. Circulation 1999;100:1764-9.

Duryee 1992

Duryee R. The efficacy of inpatient education after myocardial infarction. Heart Lung 1992;21:217-25. [MEDLINE: 92275989]

\section{Ebrahim 1996}

Ebrahim S, Davey Smith G. Health promotion in older people for cardiovascular disease prevention - a systematic review and meta-analysis. London: Health Education Authority, 1996.

Egger 1997

Egger M, Davey Smith G, Schneider M, Minder C. Bias in meta-analysis detected by a simple graphical test. British Medical Journal 1997;315:629-34.

\section{Follman 1992}

Follmann D, Elliot P, Suh I, Cutler J. Variance imputation for overviews of clinical trials with continuous response. $J$ Clin Epidemiol 1992;45(7):769-73.

Goble \& Worcester 99

Goble AJ, Worcester MUC. Best Practice Guidelines for Cardiac Rehabilitation and Secondary Prevention. Victoria, Australia: Department of Human Services, 1999. 


\section{Guyatt 1986}

Guyatt G, Bombardier C, Tugwell PX. Measuring diseasespecific quality of life in clinical trials. Can Med Assoc J 1986;134:889-95.

Hamalainen 1995

Hamalainen H, Luurila OJ, Kallio V, Knuts L-R. Reduction in sudden death and coronary mortality in myocardial infarction patients after rehabilitation. European Heart Journal 1995;16:1839-44.

Hill 1992

Hill DR, Kelleher K, Schumaker SA. Psychosocial interventions in adult patients with coronary heart disease and cancer. A literature review. Gen Hosp Psychiatry 1992; 14:28S-42S. [MEDLINE: 94063498]

\section{Janus 1996}

Janus ED, Postiglione E, Singh RB, Lewis B. The modernisation of Asia: implications for coronary heart disease. Council of Arteriosclerosis of the International Society and Federation of Cardiology. [cited in Goble \& Worcester]. Circulation 1996;94:2671-3.

Lau 1992

Lau J, Antman E, Jimenez-Silva J, Kupelnick B, Mosteller F, Chalmers TC. Cumulative meta-analysis of therapeutic trials for myocardial infarction. NEJM 1992;327:248-54. [MEDLINE: 92310490]

\section{Lefebvre 1996}

Lefebvre C, McDonald S. Development of a sensitive search strategy for reports of randomised controlled trials in EMBASE. Paper presented at the Fourth International Cochrane Colloquium, 20 -24 Oct ; Adelaide, Australia. 1996.

May 1982

May GS, Eberlein KA, Furberg CD, Passamani ER, DeMets DL. Secondary Prevention After Myocardial Infarction: A Review of Long-Term Trials. Progress in Cardiovascular Diseases 1982;24:331-52. [MEDLINE: 82106696]

\section{NHS 1998}

NHS Centre for Reviews and Dissemination. Cardiac Rehabilitation. Effective Health Care Bulletin. Vol. 4, York: University of York, 1998.

\section{O'Connor 1989}

O'Connor GT, Buring JE, Yusuf S, Goldhaber SZ, Olmstead EM, Paffenbarger RS, Hennekens CH. An overview of randomised trials of rehabilitation with exercise after myocardial infarction. Circulation 1989;80:234-44. [MEDLINE: 89324326]

\section{OHE 1999}

Office of Health Economics. OHE Compendium of Health Statistics 1999. London: OHE, 1999.

\section{Oldridge 1988}

Oldridge NB, Guyatt GH, Fischer ME, Rimm AA. Cardiac rehabilitation after myocardial infarction. Combined experience of randomised clinical trials. JAMA 1988;260: 945-50. [MEDLINE: 88286972]

\section{ONS 1999}

Carter M, Moser K, Kelly S. Health of older people: disease prevalence, prescription and referral rates, England and Wales 1996. Health Statistics Quarterly. Vol. Winter, London: HMSO, 1999:9-15.

\section{Stahle 1999}

Stahle A, Mattsson E, Ryden L, Unden AL, Nordlander R. Improved physical fitness and quality of life following training of elderly patients after acute coronary events - A 1 year follow-up randomized controlled study. EUROPEAN HEART JOURNAL 1999;20(20):1475-84.

\section{Stokes 1998}

Stokes HC, Thompson DR, Seers K. The implementation of multiprofessional guidelines for cardiac rehabilitation: a pilot study. Coronary Health Care 1998;2:60-71.

\section{Thompson 1996}

Thompson D, Bowman GS, Kitson AL, de Bono DP, Hopkins A. Cardiac rehabilitation in the United Kingdom: Guidelines and Audit Standards. Heart 1996;75:89-93.

\section{Wenger 1995}

Wenger NK, Froelicher ES, Smith LK, et al.Cardiac rehabilitation as secondary prevention. Clinical Practice Guideline. Vol. 17, Rockville, Maryland: Agency for Health Care Policy and Research and National Heart, Lung and Blood Institute, 1995. [MEDLINE: 96172040]

\section{West 1995}

West, R. Ch 9. Evaluation of cardiac rehabilitation programmes. In: Jones D, West R editor(s). Cardiac Rehabilitation. BMJ Publishing, 1995.

\section{WHO 1994}

World Health Organisation. World Health Statistics Annual [cited in Goble \& Worcester 1999]. Geneva: WHO, 1994.

\section{WHO 1997}

World Health Organisation. The World Health Report: conquering suffering, enriching humanity. Report of the Director-General [cited in Goble \& Worcester 1999]. Geneva: WHO, 1997.

Willmer 1999

Willmer KA, Simpson T, Hackett K, Creamer J. Effects of exercise rehabilitation in the elderly. Coronary Health Care 1999;3(3):117-20.

* Indicates the major publication for the study 


\section{CHARACTERISTICS OF STUDIES}

\section{Characteristics of included studies [ordered by study ID]}

\section{Anderson 81}

\begin{tabular}{|c|c|}
\hline Methods & $\begin{array}{l}\text { Post MI randomised } 4 \text { weeks after discharge. } 88 \text { participants were randomised, but } 13 \text { failed to follow up. Therefore } \\
75 \text { took part in the study }\end{array}$ \\
\hline Participants & $\begin{array}{l}75 \text { men }<66 \text { yrs with } 1 \text { st MI. } \\
\text { Mean age } \\
\mathrm{I}=52.2(+/-7.5) \\
\mathrm{C}=55.6(+/-6.3)\end{array}$ \\
\hline Interventions & $\begin{array}{l}\text { Aerobic activity e.g. running, cycling, skipping + weights for } 1 \text { hour } \times 2 \text { weekly for } 2 \text { months, then } x 1 \text { week for } 10 \\
\text { months. Then continue at home. } \\
\text { F/U @ } 1,13,25, \& 37 \text { months post discharge. }\end{array}$ \\
\hline Outcomes & Total \& CHD mortality and non fatal MI. \\
\hline Notes & $\begin{array}{l}\text { Several participants in } \mathrm{C} \text { trained on own initiative, but were analysed as intention to treat. } \\
\text { Authors concluded that PT after MI appears to reduce consequences and to improve PWC, but PWC declines once } \\
\text { participant on their own. } \\
\text { PT had no effect on period of convalescence or return to work, but age and previous occupation were of significance. } \\
\text { A }\end{array}$ \\
\hline
\end{tabular}

\section{Ballantyne 82}

\begin{tabular}{|c|c|}
\hline Methods & Randomised 3 months post MI. \\
\hline Participants & $\begin{array}{l}42 \text { men }<65 \text { yrs post MI. } \\
\text { Mean age } \\
\mathrm{I}=51(+/-5.2) \\
\mathrm{C}=54.3(+/-6.2)\end{array}$ \\
\hline Interventions & $\begin{array}{l}\text { Canadian Air Force 5BX Plan run by physiotherapists in a group. } \\
\text { F/U - } 6 \text { months }\end{array}$ \\
\hline Outcomes & Total, HDL, LDL cholesterol \& triglycerides. \\
\hline Notes & $\begin{array}{l}\text { After the study both groups increased their time to maximum exercise, more significantly in the trained group, } \\
\text { possibly due to familiarisation and greater physical confidence }\end{array}$ \\
\hline
\end{tabular}


Bell 99

\begin{tabular}{ll} 
Methods & $\begin{array}{l}\text { Post MI } \\
\text { Randomised 4-6 days post event. }\end{array}$ \\
\hline Participants & $\begin{array}{l}311 \text { men / } 89 \text { women }<65 \text { yrs. } \\
\text { Mean ages for women } \\
60.7(+/-7.2) \text { to } 64.3(+/-7.3), \\
\text { for men } \\
57.8(+/-8.9) \text { to } 59.4(+/-9.4) . \\
2 \text { comparisons conventional CR v: the HM and HM v: control. }\end{array}$ \\
\hline Interventions & $\begin{array}{l}\text { Conventional CR - } 1 \text { to } 2 \text { group classes per week, walking etc other days for } 8-12 \text { weeks with multidisciplinary team. } \\
\text { HM - individual - walking programme up to } 6 \text { weeks post MI, facilitator and written text. } \\
\text { F/U - } 1 \text { year. }\end{array}$ \\
\hline Outcomes & $\begin{array}{l}\text { Total mortality, } \\
\text { SBP, DBP, smoking, total treadmill time, HRQLL. }\end{array}$ \\
\hline Notes & $\begin{array}{l}\text { Hospital readmissions significantly reduced in HM group compared with conventional CR and control in initial } 6 \\
\text { month period }\end{array}$
\end{tabular}

\section{Bengtsson 83}

\begin{tabular}{ll} 
Methods & $\begin{array}{l}\text { Random allocation at time of event. } 171 \text { patients were randomised and at discharge the cardiologist decided whether } \\
\text { the patient was fit to take part in the rehab programme }-45 \text { patients were excluded at this point. } 7 \text { of intervention } \\
\text { group declined to take part, but } 6 \text { of these were seen at follow up and included in the analysis because "control group } \\
\text { probably had a comparable number who would have declined further treatment." }\end{array}$ \\
\hline Participants & $\begin{array}{l}72 \text { men / } 13 \text { women }<65 \text { yrs following acute MI. } \\
\text { Mean age } \\
\text { I }=55.3+/-6.6, \\
\text { C }=57.1+/-6.6 .\end{array}$
\end{tabular}

Interventions Exercise intervention: physical training, interval training of large muscle groups, jogging, calisthenics. Co-interventions:

counselling, social measures, group and individual.

F/U 14 months

Outcomes Total mortality, CHD mortality, non-fatal MI,

SBP, DBP, exercise tolerance

HRQoL; psychological tests.

Notes

Most emphasis on social/ psychological aspects. 
Bertie 92

\begin{tabular}{|c|c|}
\hline Methods & Randomised on day of discharge after MI \\
\hline Participants & $\begin{array}{l}110 \text { participants men } \& \text { women }<65 \text { yrs post } M I \text {. } \\
\text { Mean age } \\
I=52.1+/-1.3 \text {, } \\
C=52.7+/-1.3 \text {, range } 32-64\end{array}$ \\
\hline Interventions & $\begin{array}{l}2 \mathrm{x} \text { week for } 4 \text { weeks. } \\
12 \text { station circuit started } 3 \text { weeks post discharge. } \\
\text { F/U } 12-24 \text { months. }\end{array}$ \\
\hline Outcomes & Total mortality, non fatal MI, revascularisation \\
\hline Notes & $\begin{array}{l}\text { At } 4 \text { months I walked farther } \& \text { faster than } C \text {, with less breathlessness and angina in } 12 \text { min walking test and } \\
\text { pedometry. I also more likeky to be doing housework and resumed normal sexual activity at } 4 \text { months }\end{array}$ \\
\hline \multicolumn{2}{|l|}{ Bethell 90} \\
\hline Methods & $\begin{array}{l}\text { Randomised } 5 \text { days post MI. } 229 \text { patients were randomised; } 14 \text { in the intervention group and } 15 \text { in control dropped } \\
\text { out before the first exercise test due to death, refusal or other problems. Therefore } 200 \text { took part in the study }\end{array}$ \\
\hline Participants & $\begin{array}{l}200 \text { men }<65 \text { yrs post MI. } \\
\text { Mean age } \\
\mathrm{I}=54.2(+/-7.2), \mathrm{C}=53.2(+/-7.7)\end{array}$ \\
\hline Interventions & $\begin{array}{l}3 \mathrm{x} \text { week for } 3 \text { months. } 8 \text { stage circuit aerobic } \& \text { weight training. } 70-85 \% \text { predicted Hrmax. } \\
11 \text { year follow up published in } 1999 . \\
5 \text { year follow up data from unpublished material used for meta analysis }\end{array}$ \\
\hline Outcomes & $\begin{array}{l}\text { Total mortality, CHD mortality, non fatal MI, } \\
\text { smoking }\end{array}$ \\
\hline Notes & $\begin{array}{l}\text { Cardiac mortality of } 3 \% \text { pa, once patients survived to be in the trial. Suggests more severely affected patients were } \\
\text { not included. } \\
\text { Significant predictors of cardiac death were pulmonary oedema on admission, complications during admission, one } \\
\text { or more previous infarcts, increasing age and low initial fitness }\end{array}$ \\
\hline
\end{tabular}

\section{Carlsson 98 CABG}

Methods Groups of 20 patients randomly allocated to intervention and control groups (usual care). Randomised 4 weeks post discharge

In first 3 weeks post discharge all participants ( I \& C) had 2 visits by nurse \& 1 by cardiologist + all participants invited to join regular exercise group x 1 per week for 30 mins information $\& 30$ mins easy interval training

Participants Men \& women aged 50 - 70 yrs with CABG $(n=67)$.

Mean age

$\mathrm{I}=62.7+/-4.8$

$\mathrm{C}=59.8+/-4.8$. 


\section{Carlsson 98 CABG (Continued)}

\begin{tabular}{ll} 
Interventions & $\begin{array}{l}\text { Nurse counselling: } 9 \text { hours of counselling in individual \& group sessions over } 1 \text { year; smoking cessation } 1.5 \text {, dietary } \\
\text { management 5.5 \& physical activity } 2 \text { hours. } \\
\text { After randomisation exercise programme 2-3 x weekly for 2-3 months. } 40 \text { mins of aerobic activity. } \\
\text { F/U 1 year }\end{array}$ \\
\hline Outcomes & Total cholesterol \& LDL. \\
\hline Notes & Only $5 \%$ over all on lipid lowerers at randomisation. At one year $82 \%$ of I on lipid lowering agents, and $28 \%$ of C \\
\hline
\end{tabular}

\section{Carlsson 97}

\begin{tabular}{|c|c|}
\hline Methods & $\begin{array}{l}\text { Groups of } 20 \text { patients randomly allocated to intervention and control groups (usual care). Randomised } 4 \text { weeks post } \\
\text { discharge } \\
\text { In first } 3 \text { weeks post discharge all participants ( I \& C) had } 2 \text { visits by nurse \& } 1 \text { by cardiologist + all participants } \\
\text { invited to join regular exercise group x } 1 \text { per week for } 30 \text { mins information \& } 30 \text { mins easy interval training }\end{array}$ \\
\hline Participants & $\begin{array}{l}126 \text { men and } 42 \text { women aged } 50 \text { years and older post MI. } \\
\text { Mean age } \\
I=62.2 \\
\mathrm{C}=61.9\end{array}$ \\
\hline Interventions & $\begin{array}{l}\text { Exercise intervention: } \\
\text { exercise training, interval training with jogging and cycling. } \\
\text { Cointerventions: } \\
\text { counselling, smoking cessation and dietry advice, Control group: usual care. Follow up } 1 \text { year }\end{array}$ \\
\hline Outcomes & Physiological: Smoking and physical fitness (level of activity by questionnaire) \\
\hline Notes & $\begin{array}{l}\text { Self report data. Rehabilitaion programme successful in improving food habits, but no advantage in supporting } \\
\text { physical activity compared to usual care }\end{array}$ \\
\hline
\end{tabular}

\section{Carlsson 98 AMI}

Methods Groups of 20 patients randomly allocated to intervention and control groups (usual care). Randomised 4 weeks post discharge

In first 3 weeks post discharge all participants ( I \& C) had 2 visits by nurse \& 1 by cardiologist + all participants invited to join regular exercise group x 1 per week for 30 mins information $\& 30$ mins easy interval training

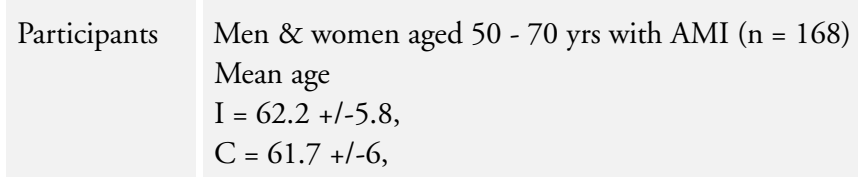

Interventions Nurse counselling: 9 hours of counselling in individual \& group sessions over 1 year; smoking cessation 1.5, dietary management $5.5 \&$ physical activity 2 hours.

After randomisation exercise programme 2-3 x weekly for 2-3 months. 40 mins of aerobic activity.

F/U 1 year 


\section{Carlsson 98 AMI (Continued)}

\begin{tabular}{ll}
\hline Outcomes & Total cholesterol \& LDL. \\
\hline Notes & $\begin{array}{l}\text { Only } 5 \% \text { over all on lipid lowerers at randomisation. At one year 75\% pts in I on lipid lowering agents and 23\% of } \\
\text { C }\end{array}$ \\
\hline Carson 82 & Randomised 6 weeks post admission \\
\hline Methods & $\begin{array}{l}303 \text { men }<70 \text { yrs with MI. } \\
\text { Mean age }\end{array}$ \\
\hline Participants & I $=50.3$ (SE 0.65) C=52.8 (SE 0.67) \\
\hline Interventions & $\begin{array}{l}\text { Circuit } 2 \text { x weekly for } 12 \text { weeks. } \\
\text { F/U } 2 \text { years }\end{array}$ \\
\hline Outcomes & Total mortality, non fatal MI \\
\hline Notes & There appears to be a reduction in mortality in exercise participants with inferior MI \\
\hline
\end{tabular}

\section{Engblom}

\begin{tabular}{ll}
\hline Methods & Randomised pre CABG \\
\hline Participants & $\begin{array}{l}\text { 201 men \& } 27 \text { women }<65 \text { yrs with CABG. } \\
\text { Mean age }=54+1-6, \text { range } 40-64 .\end{array}$ \\
\hline Interventions & $\begin{array}{l}4 \text { stage rehab over } 30 \text { months starting pre CABG with meeting of physician, psychologist and } \\
\text { OT/PT. } \\
\text { 6-8 weeks post CABG }-3 \text { weeks IP with group sessions with psychologist, aerobic physical activity, relaxation \& } \\
\text { group discussion. } \\
8 \text { months post CABG - } 2 \text { days meeting with OT, nutritionist, physician, physio. } \\
\text { 30 months post CABG - one day with nutritionist, physician \& exercise. } \\
\text { F/U I year \& } 6 \text { years }\end{array}$ \\
\hline Outcomes & $\begin{array}{l}\text { Lipids. } \\
\text { HRQoL; } \\
\text { Beck depression inventory. }\end{array}$ \\
\hline Notes & $\begin{array}{l}\text { 5 years after CABG only 20\% of participants were working, despite 90\% of patients being in functional classes 1-2. } \\
\text { Almost half of patients had retired pre CABG. Many other factors affect RTW post CABG - age, education, physical } \\
\text { requirements of the job, type of occupation, self employed status, non work income, personality type, self perception } \\
\text { of working capacity and mostly length of absence from work pre CABG }\end{array}$ \\
\hline
\end{tabular}


Erdman 86

\begin{tabular}{ll}
\hline Methods & Randomised within 6 months of first MI. \\
\hline Participants & $\begin{array}{l}80 \text { men aged }<65 \text { yrs (mean 51, range 35-60) within } 6 \text { months post MI. Also with CABG/angina. } \\
\text { Three psychologic inclusion criteria - one or more symptoms of the anxiety reaction, diminished self-esteem, positive } \\
\text { motivation to take part in the programme }\end{array}$ \\
\hline Interventions & $\begin{array}{l}\text { Exercise intervention: fitness training, Cointerventions: } \\
\text { relaxation exercises. } \\
\text { Controls: } \\
\text { Usual care plus educational brochure with guidelines about physical fitness training. }\end{array}$ \\
\hline Follow up 5 years. \\
\hline Outcomes & $\begin{array}{l}\text { Smoking. } \\
\text { HRQoL }\end{array}$ \\
\hline Notes & $\begin{array}{l}\text { Complex presentation of results. } \\
\text { Authors conclude that patients who will benefit from rehab can be detected on psychological grounds. Those who } \\
\text { have engaged in habitual exercise, but feel seriously disabled, yet do not feel inhibited in a group will benefit from } \\
\text { rehab }\end{array}$ \\
\hline
\end{tabular}

Fletcher 94

\begin{tabular}{ll}
\hline Methods & Randomised at time of study. \\
\hline Participants & $\begin{array}{l}88 \text { men }<73 \text { yrs. } \\
\text { Mean age } \\
\text { I }=62+/-8, \\
\mathrm{C}=63+/-7 \text { (range } 42-72) . \\
\text { Participants had CAD and physical disability; CVA, amputee/musculoskeletal }\end{array}$ \\
\hline Interventions & $\begin{array}{l}\text { Home exercise training programme using stationary wheelchair ergometer } 20 \text { mins/day, } 5 \text { days/week for } 6 \text { months } \\
\text { with telephone telemetry. }\end{array}$ \\
\hline F/U 6 months. \\
\hline Outcomes & $\begin{array}{l}\text { Total mortality, non fatal MI, non fatal stroke, } \\
\text { SBP, DBP. }\end{array}$ \\
\hline Notes & \begin{tabular}{l} 
The treatment programme decreased myocardial oxygen demand. \\
\hline
\end{tabular}
\end{tabular}

\section{Fridlund 91}

Methods 178 patients randomised at time of MI. After randomisation \& before start of study, 77 patients were excluded, refused or died

Participants 101 men \& 15 women $<65$ yrs with MI.

Mean age 56.3 . 


\section{Fridlund 91 (Continued)}

Interventions 2 hours x 1 weekly for 6 months. 1 hours exercise +1 hours group discussion led by nurse.

F/U 1 \& 5 years.

Outcomes Total mortality, non fatal MI, revascularisations

HRQoL:

WHO (Stocksmeier 79)

Notes Positive long term effects on physical condition, life habits, cardiac health knowledge. No effects found for cardiac events or psychological condition

\section{Heller 93}

\begin{tabular}{ll}
\hline Methods & Cluster by GP, randomisation on discharge. \\
\hline Participants & $\begin{array}{l}323 \text { men } \& 127 \text { women }<70 \text { yrs with MI. } \\
\text { Mean age } \\
\text { I }=59+/-8, \\
\text { C }=58+/-8 .\end{array}$ \\
\hline Interventions & $\begin{array}{l}3 \text { letters to participant - information on fats, smoking and a walking programme. } \\
\text { F/U } 6 \text { months. }\end{array}$ \\
\hline Outcomes & $\begin{array}{l}\text { Total mortality, } \\
\text { Total, HDL cholesterol, } \\
\text { smoking. }\end{array}$ \\
& $\begin{array}{l}\text { HRQL: } \\
\text { Quality of Life after MI. }\end{array}$ \\
\hline Notes & $\begin{array}{l}\text { Low use of preventative services (dietary, anti smoking) by both groups. } \\
\text { 10\% of patients received rehab - mostly having had CABG. }\end{array}$ \\
\hline
\end{tabular}

Holmback 94

\begin{tabular}{l|l}
\hline Methods & Randomised 6 weeks post MI. \\
\hline Participants & $\begin{array}{l}67 \text { men } \& 2 \text { women }<65 \text { yrs } \\
\text { (mean age 55, range } 38-63), \text { post MI. }\end{array}$ \\
\hline Interventions & $\begin{array}{l}12 \text { weeks interval training (cycle, callisthenics, jogging \& relaxation) for } 45 \text { mins x } 2 \text { weekly, starting } 8 \text { weeks post } \\
\text { MI. }\end{array}$ \\
\hline F/U 1 year. \\
\hline $\begin{array}{l}\text { Total mortality, non-fatal MI \& revascularisation. } \\
\text { HRQ } \\
\text { Self report questionnaire. }\end{array}$
\end{tabular}




\section{Holmback 94 (Continued)}

Notes Authors found no benefit from exercise training. Outcomes were related to self-rated levels of physical and psychological well being

\section{Kentala 72}

Methods 298 patients were randomised by year of birth on admission with MI. Of these, 158 were accepted for follow up and 10 dropped out between being accepted for follow up and the start of the programme

$\begin{array}{ll}\text { Participants } & 148 \text { men < 65 yrs with MI. } \\ & \text { Mean age } \\ & I=53, C=52.8 \text { (range } 29-64) .\end{array}$

Interventions 40 minutes exercise (10-relaxation, 10-warm up, 2 -cycling, stairs $\&$ rowing + cool down )., 2 x then 3 x weekly. Encouraged to continue with $2 \times 0.5 \mathrm{~km}$ walk daily.

$\mathrm{F} / \mathrm{U} 1$ year and 2 years for recurrent MI.

Outcomes Total \& CHD mortality, non fatal MI. SBP, DBP,

smoking

\section{Notes No influence of ET on RTW.}

No significant differences between groups - possibly because control group were fitter before MI or exercised anyway

\section{Krachler 97}

\begin{tabular}{l|l}
\hline Methods & $\begin{array}{l}\text { No details of randomisation. } \\
\text { Participants all undergoing PTCA. }\end{array}$ \\
\hline Participants & $\begin{array}{l}47 \text { men \& } 13 \text { women with CHD, undergoing PTCA. } \\
\text { Mean age } 59 \text { yrs. }\end{array}$ \\
\hline Interventions & $\begin{array}{l}\text { Moderate exercise + diet. } \\
\text { F/U } 1 \text { year. }\end{array}$ \\
\hline Outcomes & $\begin{array}{l}\text { Further need for PTCA. } \\
\text { Only baseline figures for SBP, total, HDL \& LDL cholesterol, triglycerides }\end{array}$ \\
\hline Notes & $\begin{array}{l}\text { I lost weight compared with C }(\mathrm{p}<0.01) . \\
\text { I had lower BP than C ( }<<0.01), \text { and needed less revascularization over the year }(10 \% \text { of } \mathrm{I}, 42 \% \text { of C) }\end{array}$ \\
\hline
\end{tabular}


Lewin 92

\begin{tabular}{ll}
\hline Methods & MI patients randomised 3 days post event, by stratified protocol \\
\hline Participants & 126 men \& 50 women, mean age 55.8 yrs, post MI. \\
\hline Interventions & $\begin{array}{l}\text { Heart manual: home based facilitated programme with manual and tapes, } 3 \text { stage exercise plan - home, walking and } \\
\text { life long, graded according to patient's ability. } \\
\text { Control had placebo facilitator's time. } \\
\text { F/U } 1 \text { year }\end{array}$ \\
\hline Outcomes & $\begin{array}{l}\text { HRQoL; } \\
\text { HAD } \\
\text { GHQ }\end{array}$ \\
\hline Notes & $\begin{array}{l}\text { Study terminated (due to expiry of funding) before all pts reached } 6 \text { or } 12 \text {-month stage. } \\
\text { Anxiety scores showed significant treatment effect @ } 6 \text { weeks and } 1 \text { year, depression @ } 6 \text { weeks. } \\
\text { Pre hospital discharge } 52 \% \text { of all pts had HAD scores indicating clinically significant anxiety or depression (8+). C } \\
\text { were significantly more anxious and depressed at all follow ups }\end{array}$ \\
\hline
\end{tabular}

\section{Lifestyle Heart}

\begin{tabular}{|c|c|}
\hline Methods & 93 patients randomised and then invited to take part in the study, 48 accepted, 5 year results presented on 35 \\
\hline Participants & $\begin{array}{l}48 \text { men } \& \text { women aged } 35-75 \text { yrs. } \\
\text { Mean age } \\
\mathrm{I}=56.1+/-7,5 \\
\mathrm{C}=59.8+/-9.1 \\
\text { All had moderate to severe CAD (MI, PTCA, CABG, angina) }\end{array}$ \\
\hline Interventions & $\begin{array}{l}\text { Exercise intervention: aerobic exercise, walking and jogging. Co-interventions: stress management, low fat vegetarian } \\
\text { diet, group psychosocial support. } \\
\text { Control group: usual care. Follow up } 5 \text { years. }\end{array}$ \\
\hline Outcomes & $\begin{array}{l}\text { CHD mortality, non-fatal MI, revascularisation, } \\
\text { Physiological: } \\
\text { cholesterol, HDL, LDL, triglycerides, SBP, DBP. }\end{array}$ \\
\hline Notes & $\begin{array}{l}\text { I had } 91 \% \text { reduction in reported frequency of angina after } 1 \text { year and } 72 \% \text { after } 5, \mathrm{C} \text { had } 186 \% \text { increase in reported } \\
\text { frequency of angina after } 1 \text { year and } 36 \% \text { decrease after } 5 \text {. } \\
\text { I had } 7.9 \% \text { relative improvement in coronary artery diameter at } 5 \text { years, } \mathrm{C} \text { had } 27.7 \% \text { relative worsening @ } 5 \text { years }\end{array}$ \\
\hline
\end{tabular}

\section{Miller/DeBusk 1A}

\begin{tabular}{l|l}
\hline Methods & Randomised 3 weeks post MI \\
\hline Participants & $\begin{array}{l}198 \text { men }<70 \text { yrs with MI. } \\
\text { Mean age } 52+/-9 .\end{array}$
\end{tabular}


Miller/DeBusk 1A (Continued)

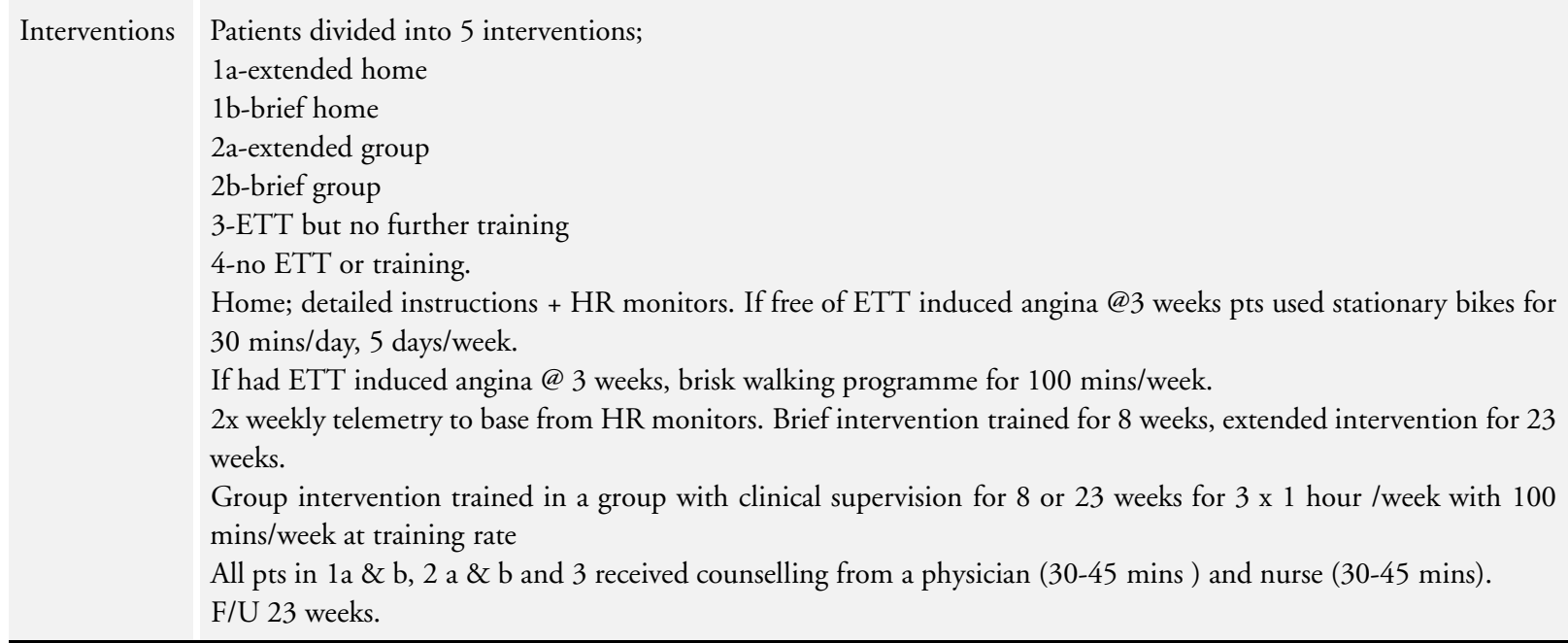

Outcomes CHD mortality, non fatal MI and revascularisation

Notes Low rate of cardiac events reflects identification of low risk population.

Group 3 were unexpectedly active, th authors concluding that ETT + good explanation may enhance physical activity in the early stages

\section{Miller/DeBusk 1B}

\begin{tabular}{ll} 
Methods & Randomised 3 weeks post MI \\
\hline Participants & $\begin{array}{l}198 \text { men }<70 \text { yrs with MI. } \\
\text { Mean age } 52+/-9 .\end{array}$
\end{tabular}

Interventions Patients divided into 5 interventions;

la-extended home

1b-brief home

2a-extended group

2b-brief group

3-ETT but no further training

4-no ETT or training.

Home; detailed instructions + HR monitors. If free of ETT induced angina @3 weeks pts used stationary bikes for $30 \mathrm{mins} /$ day, 5 days/week.

If had ETT induced angina @ 3 weeks, brisk walking programme for 100 mins/week.

2x weekly telemetry to base from HR monitors. Brief intervention trained for 8 weeks, extended intervention for 23 weeks.

Group intervention trained in a group with clinical supervision for 8 or 23 weeks for 3 x 1 hour /week with 100 mins/week at training rate

All pts in 1a \& b, 2 a \& b and 3 received counselling from a physician (30-45 mins ) and nurse (30-45 mins). F/U 23 weeks.

Outcomes CHD mortality, non fatal MI and revascularisation 
Miller/DeBusk 1B (Continued)

Notes Low rate of cardiac events reflects identification of low risk population.

Group 3 were unexpectedly active, th authors concluding that ETT + good explanation may enhance physical activity in the early stages

Miller/DeBusk 2A

\begin{tabular}{|c|c|}
\hline Methods & Randomised 3 weeks post MI \\
\hline Participants & $\begin{array}{l}198 \text { men }<70 \text { yrs with MI. } \\
\text { Mean age } 52+/-9\end{array}$ \\
\hline Interventions & $\begin{array}{l}\text { Patients divided into } 5 \text { interventions; } \\
\text { 1a-extended home } \\
\text { 1b-brief home } \\
\text { 2a-extended group } \\
\text { 2b-brief group } \\
\text { 3-ETT but no further training } \\
\text { 4-no ETT or training. } \\
\text { Home; detailed instructions + HR monitors. If free of ETT induced angina @3 weeks pts used stationary bikes for } \\
30 \text { mins/day, } 5 \text { days/week. } \\
\text { If had ETT induced angina @ } 3 \text { weeks, brisk walking programme for } 100 \text { mins/week. } \\
2 x \text { weekly telemetry to base from HR monitors. Brief intervention trained for } 8 \text { weeks, extended intervention for } 23 \\
\text { weeks. } \\
\text { Group intervention trained in a group with clinical supervision for } 8 \text { or } 23 \text { weeks for } 3 \text { x } 1 \text { hour } / \text { week with } 100 \\
\text { mins/week at training rate } \\
\text { All pts in } 1 \mathrm{a} \& \mathrm{~b}, 2 \text { a } \& \text { b and } 3 \text { received counselling from a physician }(30-45 \text { mins ) and nurse (30-45 mins). } \\
\text { F/U } 23 \text { weeks. }\end{array}$ \\
\hline Outcomes & CHD mortality, non fatal MI and revascularisation \\
\hline Notes & $\begin{array}{l}\text { Low rate of cardiac events reflects identification of low risk population. } \\
\text { Group } 3 \text { were unexpectedly active, th authors concluding that ETT + good explanation may enhance physical activity } \\
\text { in the early stages }\end{array}$ \\
\hline
\end{tabular}

Miller/DeBusk 2B

\begin{tabular}{ll}
\hline Methods & Randomised 3 weeks post MI \\
\hline Participants & $\begin{array}{l}198 \text { men }<70 \text { yrs with MI. } \\
\text { Mean age } 52+/-9 .\end{array}$ \\
\hline Interventions & $\begin{array}{l}\text { Patients divided into } 5 \text { interventions; } \\
\text { 1a-extended home } \\
\text { 1b-brief home } \\
\text { 2a-extended group } \\
\text { 2b-brief group } \\
\text { 3-ETT but no further training }\end{array}$ \\
\hline
\end{tabular}


Miller/DeBusk 2B (Continued)

\begin{tabular}{|c|c|}
\hline & $\begin{array}{l}\text { 4-no ETT or training. } \\
\text { Home; detailed instructions + HR monitors. If free of ETT induced angina @ } 3 \text { weeks pts used stationary bikes for } \\
30 \text { mins/day, } 5 \text { days/week. } \\
\text { If had ETT induced angina @ } 3 \text { weeks, brisk walking programme for } 100 \text { mins/week. } \\
2 \mathrm{x} \text { weekly telemetry to base from HR monitors. Brief intervention trained for } 8 \text { weeks, extended intervention for } 23 \\
\text { weeks. } \\
\text { Group intervention trained in a group with clinical supervision for } 8 \text { or } 23 \text { weeks for } 3 \text { x } 1 \text { hour /week with } 100 \\
\text { mins/week at training rate } \\
\text { All pts in 1a \& b, } 2 \text { a \& b and } 3 \text { received counselling from a physician }(30-45 \text { mins }) \text { and nurse ( } 30-45 \text { mins). } \\
\text { F/U } 23 \text { weeks. }\end{array}$ \\
\hline Outcomes & CHD mortality, non fatal MI and revascularisation \\
\hline Notes & $\begin{array}{l}\text { Low rate of cardiac events reflects identification of low risk population. } \\
\text { Group } 3 \text { were unexpectedly active, th authors concluding that ETT + good explanation may enhance physical activity } \\
\text { in the early stages }\end{array}$ \\
\hline \multicolumn{2}{|l|}{ NEHDP } \\
\hline Methods & $\begin{array}{l}\text { Participants treated at one of } 5 \text { participating centres. Participants randomised after participating in low level exercise } \\
\text { course for } 6 \text { weeks }\end{array}$ \\
\hline Participants & $\begin{array}{l}651 \text { men aged } 30-64 \text { yrs with MI between } 8 \text { weeks and } 3 \text { years prior to start of study (mean } 14 \text { months). } \\
\text { Mean age } \\
I=51.5+/-7.4 \\
C=52.1+/-7.2\end{array}$ \\
\hline Interventions & $\begin{array}{l}\text { ET- } 1 \text { hour/day, } 3 \text { days/week for } 8 \text { weeks. } 6 \text { station circuit + gym exercises or swimming and games. } \\
\text { F/U } 3 \text { years. } \\
\text { Long term follow up to } 19 \text { years published in } 1999 \text {, but not used for meta analysis }\end{array}$ \\
\hline Outcomes & $\begin{array}{l}\text { Total \& CHD mortality, non fatal MI } \\
\text { Various psychological measures. }\end{array}$ \\
\hline Notes & $\begin{array}{l}90 \% \text { of ET attended } 90 \% \text { of } 24 \text { scheduled sessions post randomisation, only } 48 \% \text { attending }>50 \% \text { of sessions at } 18 \\
\text { months. } \\
30 \% \text { of control alleged exercising regularly, on own initiative. } \\
\text { At } 19 \text { years any protective } \\
\text { effect form the programme had decreased over time, but an increase with PWC from the beginning to the end of the } \\
\text { trial was associates with a consistent reduction in mortality throughout the } 19 \text { years of follow up }\end{array}$ \\
\hline
\end{tabular}

Exercise-based rehabilitation for coronary heart disease (Review) 
Oldridge 91

\begin{tabular}{ll}
\hline Methods & $\begin{array}{l}\text { Stratified by status (work type and employed or not) and randomised at time of MI. All participants were depressed } \\
\text { and/or anxious (Beck Depression Inventory }<5,<43 \text { on Spielberger State Anxiety Inventory, or }<42 \text { on Spielberger } \\
\text { Trait Anxiety Inventory.) }\end{array}$ \\
\hline Participants & $\begin{array}{l}177 \text { men } \& 24 \text { women with MI. Mean age } \\
\text { I }=52.9+/-9.5 \text { yrs, } \\
\text { C }=52.7+/-9.5 \text { yrs. }\end{array}$ \\
\hline Interventions & $\begin{array}{l}\text { ET for participant \& spouse. } \\
50 \text { minutes } 2 \times \text { weekly for } 8 \text { weeks at } 65 \% \text { of HRmax during ETT. } \\
\text { Plus cognitive behavioural group intervention of } 8 \text { sessions of } 1.5 \text { hours }+ \text { relaxation. } \\
\text { CPR training offered to spouse. }\end{array}$ \\
\hline F/U 1 year. \\
\hline Outcomes & $\begin{array}{l}\text { Mortality } \\
\text { HRQoL: } \\
\text { QoLAMI } \\
\text { Quality of well being. } \\
\text { Time trade-off. }\end{array}$ \\
\hline Notes & Both groups improved over 12 months, with the biggest changes occurring in the first 8 weeks \\
\hline
\end{tabular}

\section{PRECOR}

Methods Randomised 30 -60 days post MI into usual care, exercise based rehab programme or counselling programme

\begin{tabular}{ll}
\hline Participants & 182 men $<65$ with MI. \\
& Mean age \\
& $\mathrm{I}=51, \mathrm{C}=49 \mathrm{yrs}$. \\
\hline
\end{tabular}

Interventions $\mathrm{RP}-3$ sessions per week for 6 weeks + relaxation, education on risk factors and recommendation for continuing exercise.

F/U 2 years

Outcomes Non fatal MI, angina, surgery,

smoking

Notes Only $14 \%$ of all MI patients admitted to the participating hospitals were randomised to the trial. Exclusion of women and patients $>65$ accounted for $60 \%$ of exclusions

\section{Schuler/Niebauer}

Methods Participants randomised after routine angiography for angina. 66\% study population had previous MI. All participants spent one week as inpatient on a metabolic ward receiving instruction on exercise and diet

Participants 113 men with CAD, aged $35-68$ yrs (mean 53.5) 


\section{Schuler/Niebauer (Continued)}

\begin{tabular}{ll} 
Interventions & $\begin{array}{l}2 \text { further weeks as IP, then daily exercise at home on cycle (30 mins at } 75 \% \text { HR max })+2 \text { group training sessions of } \\
60 \text { mins/week. Informative session held } 5 \text { times/year for participants and spouses. } \\
\text { F/U yearly for } 6 \text { years. }\end{array}$ \\
\hline Outcomes & $\begin{array}{l}\text { Total and CHD mortality, non fatal MI, revascularisation, } \\
\text { total, HDL \& LDL cholesterol, triglycerides, } \\
\text { coronary artery diameter }\end{array}$ \\
\hline Notes & $\begin{array}{l}\text { Exercise adherence in the first year was } 68 \%(39-92 \% \text {, over the next } 5 \text { years } 33 \%(3-89 \%) . \\
\text { Pts with regression of coronary atheroma attended exercise sessions significantly more often }(54+/-24 \%) \text { than patients } \\
\text { with no change }(20+/-24 \%) \text { or progression } 31+/-20 \%)\end{array}$
\end{tabular}

\section{SCRIP}

\begin{tabular}{ll}
\hline Methods & Participants randomised after angiography at one of four hospitals \\
\hline Participants & $\begin{array}{l}259 \text { men } \& 41 \text { women with CAD }<75 \text { yrs. } \\
\text { Mean age } \\
\text { I }=58.3=/-9.2, \\
\text { C }=56.2+/-8.2 .\end{array}$ \\
\hline
\end{tabular}

Interventions Nurse managed, home based programme based on Miller, with specific goals to be attained. F/U 4 years.

Outcomes Total \& CHD mortality, non fatal MI \& stroke, revascularisation, SDP, DBP, smoking, total, HDL, LDL cholesterol, coronary artery diameter.

Notes The rate of change in the minimal coronary artery diameter was $47 \%$ less in I than C. This was still significant when adjusted for age and baseline segment diameter $(\mathrm{p}=0.03)$

\section{Sivarajan 82}

Methods Multicentre study. Random allocation of individuals to two intervention groups (exercise only or exercise plus teaching and counselling) and a control group (usual care)

Participants 258 patients ( $>80 \%$ men) aged $<71$ yrs.

Mean age

$\mathrm{I}=55.6+/-9.3,56.3+/-8.3$,

$\mathrm{C}=57.1+/-7.3$. Following acute MI.

Interventions All patients exercise whilst in hospital.

Ex only:

Weekly clinic appointments 3 months post discharge for progressive calisthenics and walking. Exercise $2 \mathrm{x}$ daily until RTW and then $x 1$ daily.

Ex + T\&C:

Same exercise programme $+8 \times 1$ hour teaching/ counselling sessions with family $\&$ friends 


\section{Sivarajan 82 (Continued)}

F/U 6 months.

\begin{tabular}{ll}
\hline Outcomes & $\begin{array}{l}\text { Total mortality, } \\
\text { smoking, physical fitness (distance HRQoL; } \\
\text { Sickness Impact Profile. }\end{array}$ \\
\hline Notes & $\begin{array}{l}\text { Several reports of the same trial all with various bits of information. Authors conclude that multiple intervention } \\
\text { trial of this short duration did not change patient's behaviour. MI itself acts as a strong stimulus to alter behaviour } \\
\text { with respect to risk factors }\end{array}$ \\
\hline
\end{tabular}

\section{Sivarajan 82 ex plus}

\begin{tabular}{|c|c|}
\hline Methods & $\begin{array}{l}\text { Multicentre study. Random allocation of individuals to two intervention groups (exercise only or exercise plus teaching } \\
\text { and counselling) and a control group (usual care) }\end{array}$ \\
\hline Participants & $\begin{array}{l}258 \text { patients }(>80 \% \text { men }) \text { aged }<71 \text { yrs. } \\
\text { Mean age } \\
I=55.6+/-9.3,56.3+/-8.3 \\
C=57.1+/-7.3 . \text { Following acute MI. }\end{array}$ \\
\hline Interventions & $\begin{array}{l}\text { All patients exercise whilst in hospital. } \\
\text { Ex only: } \\
\text { Weekly clinic appointments } 3 \text { months post discharge for progressive calisthenics and walking. Exercise } 2 \text { x daily until } \\
\text { RTW and then } x 1 \text { daily. } \\
\text { Ex }+ \text { T\&C: } \\
\text { Same exercise programme }+8 \times 1 \text { hour teaching/ counselling sessions with family } \& \text { friends } \\
\text { F/U } 6 \text { months. }\end{array}$ \\
\hline Outcomes & $\begin{array}{l}\text { Total mortality, } \\
\text { smoking, physical fitness (distance HRQoL; } \\
\text { Sickness Impact Profile. }\end{array}$ \\
\hline Notes & $\begin{array}{l}\text { Several reports of the same trial all with various bits of information. Authors conclude that multiple intervention } \\
\text { trial of this short duration did not change patient's behaviour. MI itself acts as a strong stimulus to alter behaviour } \\
\text { with respect to risk factors }\end{array}$ \\
\hline
\end{tabular}

\section{Speccia 96}

Methods Randomised at hospital discharge.

All participants went to a rehab centre for 3 weeks for ETT, 24 hour tape. All participants had sessions with cardiologist $\&$ psychologist for secondary prevention advice

Participants 182 men \& 18 women $<65$ yrs with MI.

Mean age

$\mathrm{I}=51.5+/-7$

$\mathrm{C}=54.3+/-8$. 


\section{Speccia 96 (Continued)}

\begin{tabular}{ll} 
Interventions & $\begin{array}{l}4 \text { weeks supervised cycling for } 30 \text { mins } 5 \text { days/week + calisthenics @ } 75 \% \text { max work capacity. After discharge to walk } \\
\text { for } 30 \text { minutes every } 2 \text { days. } \\
\text { F/U } 34 \text { months. }\end{array}$ \\
\hline Outcomes & CHD mortality, revascularisations \\
\hline Notes & $\begin{array}{l}\text { Ejection fraction was the only prognostic factor. } \\
\text { Among } 51 \text { patients with EF }<41 \% \text {, relative risk for the } 27 \text { untrained participants was } 8.63 \text { times higher than for } 24 \\
\text { trained ones. ( } \mathrm{p}=0.04) \\
\text { If } \mathrm{EF}>40 \%, \text { estimated risk for untrained participant was } 1.07 \text { times higher than for trained }\end{array}$ \\
\hline
\end{tabular}

\section{Stern 83}

Methods Randomized by blocks of 6 into one of three groups: exercise, group counselling \& control.

Eligibility - work capacity <7 METs (men), <6 METs (women), Taylor Manifest Anxiety Scale raw score of 19+ and/ or Zung self rating Depression Scale raw score of $40+$

Participants 91 men \& 15 women aged 30-60 yrs with MI between 6 weeks and 1 year prior to entry to study

Interventions $3 \times 1$ hour sessions/week over 12 week period for 36 sessions.

All exercises dynamic against resistance, exercising upper limb and lower limb alternately for 4 minutes with 2 mins rest in between. Target HR $85 \%$ of HRmax at ETT.

F/U 1 year.

Outcomes Psychological scales, work capacity.

Notes Minimal differences between groups at one year.

Taylor 97

\begin{tabular}{ll}
\hline Methods & Randomised 3rd day post MI. \\
\hline Participants & 294 men \& 8 women $\mathrm{F}<70$ yrs (mean age $57+/-8)$, post MI, in 5 centres \\
\hline Interventions & $\begin{array}{l}\text { Nurse managed, home based, multifactorial risk factor intervention programme with exercise training based on De } \\
\text { Busk/Miller. F/U } 12 \text { months }\end{array}$ \\
\hline Outcomes & $\begin{array}{l}\text { Total mortality } \\
\text { HRQoL: } \\
\text { Single item rating scales. }\end{array}$ \\
\hline Notes & Levels of psychological distress dropped significantly for both groups by 12 months \\
\hline
\end{tabular}




\section{Vecchio 81}

Methods Randomised after ETT, 30 days after MI.

Participants 50 patients aged 40 to 60 yrs with MI (mean 50.1).

Interventions 6 weeks physical training programme.

F/U 1 year.

Outcomes Physical work capacity, clinical events.

Notes Trained patients showed a better mid term prognosis than controls, but this could not be explained by the physical training procedure

\section{Vermuelen 83}

\begin{tabular}{ll}
\hline Methods & Randomised 4-6 weeks post MI after ETT. \\
\hline Participants & $\begin{array}{l}98 \text { men aged } 40-55 \text { yrs with MI. Mean age } \\
\mathrm{I}=49.4+/-3.7, \\
\mathrm{C}=49.1+/-4.5 .\end{array}$ \\
\hline Interventions & $\begin{array}{l}\text { Rehabilitation programme. } \\
\text { F/U } 5 \text { years }\end{array}$ \\
\hline Outcomes & $\begin{array}{l}\text { Morbidity \& mortality, } \\
\text { Smoking, } \\
\text { cholesterol }\end{array}$ \\
\hline Notes & $\begin{array}{l}\text { Authors conclude that cardiac rehab benefits patients after MI due to direct effect on myocardial perfusion and to } \\
\text { lowering of cholesterol levels }\end{array}$ \\
\hline
\end{tabular}

\section{WHO Balatonfured}

Methods 24 centre, pan European study conducted between 1973 and 1978. Randomised on discharge from hospital. 12 centres accepted for meta analysis

Participants 160 Men $<65$ yrs with first or consecutive MI.

Mean age for all participants

$\mathrm{I}=52.3, \mathrm{C}=53.5$.

Interventions Comprehensive programme dependent on local provision. Physical training was not compulsory but was strongly recommended.

F/U 3 years

Local training for 6 weeks

Outcomes Clinical:

Total, CVD, CHD \& sudden death.

Fatal \& non fatal re-infarction.

RTW, RPP,anxiety \& depression, incidence of angina or heart failure at follow up not included in meta-analysis 
WHO Balatonfured (Continued) Notes $\begin{aligned} & \text { Methodological problems with the execution of the study allowed only death and reinfarction to be successfully used } \\ & \text { as endpoints }\end{aligned}$

\section{WHO Brussels}

Methods 24 centre, pan European study conducted between 1973 and 1978. Randomised on discharge from hospital. 12 centres accepted for meta analysis

Participants 166 Men < 65 yrs with first or consecutive MI.

Mean age for all participants

$\mathrm{I}=52.3, \mathrm{C}=53.5$.

Interventions Comprehensive programme dependent on local provision. Physical training was not compulsory but was strongly recommended.

F/U 3 years

Local training for 8 weeks

Outcomes Clinical:

Total, CVD, CHD \& sudden death.

Fatal \& non fatal re-infarction.

RTW, RPP,anxiety \& depression, incidence of angina or heart failure at follow up not included in meta-analysis

Notes

Methodological problems with the execution of the study allowed only death and reinfarction to be successfully used as endpoints

\section{WHO Bucharest}

Methods 24 centre, pan European study conducted between 1973 and 1978. Randomised on discharge from hospital. 12 centres accepted for meta analysis

Participants 129 Men < 65 yrs with first or consecutive MI.

Mean age for all participants

$\mathrm{I}=52.3, \mathrm{C}=53.5$.

Interventions Comprehensive programme dependent on local provision. Physical training was not compulsory but was strongly recommended.

F/U 3 years

Local training for 12 weeks

Outcomes Clinical:

Total, CVD, CHD \& sudden death.

Fatal \& non fatal re-infarction.

RTW, RPP,anxiety \& depression, incidence of angina or heart failure at follow up not included in meta-analysis

Notes Methodological problems with the execution of the study allowed only death and reinfarction to be successfully used as endpoints 


\section{WHO Budapest}

\begin{tabular}{l|l} 
Methods & $\begin{array}{l}24 \text { centre, pan European study conducted between } 1973 \text { and } 1978 . \text { Randomised on discharge from hospital. } 12 \\
\text { centres accepted for meta analysis }\end{array}$ \\
\hline Participants & $\begin{array}{l}200 \text { Men }<65 \text { yrs with first or consecutive MI. } \\
\text { Mean age for all participants } \\
\text { I }=52.3, \mathrm{C}=53.5 .\end{array}$
\end{tabular}

\begin{tabular}{ll} 
Interventions & $\begin{array}{l}\text { Comprehensive programme dependent on local provision. Physical training was not compulsory but was strongly } \\
\text { recommended. } \\
\text { F/U 3 years } \\
\text { Local training for } 8 \text { weeks }\end{array}$ \\
\hline Outcomes & $\begin{array}{l}\text { Clinical: } \\
\text { Total, CVD, CHD \& sudden death. } \\
\text { Fatal \& non fatal re-infarction. } \\
\text { RTW, RPP,anxiety \& depression, incidence of angina or heart failure at follow up not included in meta-analysis }\end{array}$ \\
\hline Notes & $\begin{array}{l}\text { Methodological problems with the execution of the study allowed only death and reinfarction to be successfully used } \\
\text { as endpoints }\end{array}$
\end{tabular}

\section{WHO Dessau}

Methods 24 centre, pan European study conducted between 1973 and 1978. Randomised on discharge from hospital. 12 centres accepted for meta analysis

Participants 54 Men $<65$ yrs with first or consecutive MI.

Mean age for all participants

$\mathrm{I}=52.3, \mathrm{C}=53.5$.

Interventions Comprehensive programme dependent on local provision. Physical training was not compulsory but was strongly recommended.

F/U 3 years

Local training for 6 weeks

Outcomes Clinical:

Total, CVD, CHD \& sudden death.

Fatal \& non fatal re-infarction.

RTW, RPP,anxiety \& depression, incidence of angina or heart failure at follow up not included in meta-analysis

Notes Methodological problems with the execution of the study allowed only death and reinfarction to be successfully used as endpoints 


\section{WHO Erfut}

Methods 24 centre, pan European study conducted between 1973 and 1978. Randomised on discharge from hospital. 12 centres accepted for meta analysis

Participants 119 Men $<65$ yrs with first or consecutive MI.

Mean age for all participants

$\mathrm{I}=52.3, \mathrm{C}=53.5$.

Interventions Comprehensive programme dependent on local provision. Physical training was not compulsory but was strongly recommended.

F/U 3 years

Local training for 5 weeks

Outcomes Clinical:

Total, CVD, CHD \& sudden death.

Fatal \& non fatal re-infarction.

RTW, RPP,anxiety \& depression, incidence of angina or heart failure at follow up not included in meta-analysis

Notes Methodological problems with the execution of the study allowed only death and reinfarction to be successfully used as endpoints

\section{WHO Ghent}

Methods 24 centre, pan European study conducted between 1973 and 1978. Randomised on discharge from hospital. 12 centres accepted for meta analysis

Participants 168 Men $<65$ yrs with first or consecutive MI.

Mean age for all participants

$\mathrm{I}=52.3, \mathrm{C}=53.5$.

Interventions Comprehensive programme dependent on local provision. Physical training was not compulsory but was strongly recommended.

F/U 3 years

Local training for 6 weeks

Outcomes Clinical:

Total, CVD, CHD \& sudden death.

Fatal \& non fatal re-infarction.

RTW, RPP,anxiety \& depression, incidence of angina or heart failure at follow up not included in meta-analysis

Notes Methodological problems with the execution of the study allowed only death and reinfarction to be successfully used as endpoints 
WHO Helsinki

Methods Part of WHO trial published separately. Randomised 2 weeks post MI

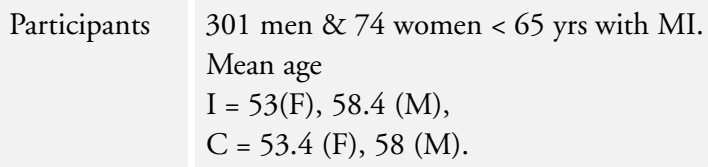

Interventions Medical exam, health education, discussion of psychosocial problems + tailored exercise programme, mostly under supervision. Most intense for first 3 months - no details. F/U 3, $10 \& 15$ years. Only 3 year follow up used for meta analysis

Outcomes Total \& CHD mortality, non fatal MI, SBP, lipids, smoking.

Notes

I increased therapeutic intervention over 3 years, particularly beta blockers

\section{WHO Kaunas}

Methods 24 centre, pan European study conducted between 1973 and 1978. Randomised on discharge from hospital. 12 centres accepted for meta analysis

Participants 115 Men $<65$ yrs with first or consecutive MI.

Mean age for all participants

$\mathrm{I}=52.3, \mathrm{C}=53.5$.

Interventions Comprehensive programme dependent on local provision. Physical training was not compulsory but was strongly recommended.

F/U 3 years

Local training for $8-16$ weeks

Outcomes Clinical:

Total, CVD, CHD \& sudden death.

Fatal \& non fatal re-infarction.

RTW, RPP,anxiety \& depression, incidence of angina or heart failure at follow up not included in meta-analysis

Notes

Methodological problems with the execution of the study allowed only death and reinfarction to be successfully used as endpoints

\section{WHO Prague}

Methods 24 centre, pan European study conducted between 1973 and 1978. Randomised on discharge from hospital. 12 centres accepted for meta analysis

Participants 112 Men $<65$ yrs with first or consecutive MI.

Mean age for all participants

$\mathrm{I}=52.3, \mathrm{C}=53.5$. 


\section{WHO Prague (Continued)}

\begin{tabular}{ll} 
Interventions & $\begin{array}{l}\text { Comprehensive programme dependent on local provision. Physical training was not compulsory but was strongly } \\
\text { recommended. } \\
\text { F/U 3 years } \\
\text { Local training continuously for the period of the study. }\end{array}$ \\
\hline Outcomes & $\begin{array}{l}\text { Clinical: } \\
\text { Total, CVD, CHD \& sudden death. } \\
\text { Fatal \& non fatal re-infarction. } \\
\text { RTW, RPP,anxiety \& depression, incidence of angina or heart failure at follow up not included in meta-analysis }\end{array}$ \\
\hline Notes & $\begin{array}{l}\text { Methodological problems with the execution of the study allowed only death and reinfarction to be successfully used } \\
\text { as endpoints }\end{array}$
\end{tabular}

\section{WHO Rome}

Methods 24 centre, pan European study conducted between 1973 and 1978. Randomised on discharge from hospital. 12 centres accepted for meta analysis

\section{Participants 63 Men $<65$ yrs with first or consecutive MI.}

Mean age for all participants

$\mathrm{I}=52.3, \mathrm{C}=53.5$.

Interventions Comprehensive programme dependent on local provision. Physical training was not compulsory but was strongly recommended.

F/U 3 years

Local training for 8 weeks

\begin{tabular}{ll} 
Outcomes & Clinical: \\
& $\begin{array}{l}\text { Total, CVD, CHD \& sudden death. } \\
\text { Fatal \& non fatal re-infarction. } \\
\text { RTW, RPP,anxiety \& depression, incidence of angina or heart failure at follow up not included in meta-analysis }\end{array}$ \\
\hline Notes & $\begin{array}{l}\text { Methodological problems with the execution of the study allowed only death and reinfarction to be successfully used } \\
\text { as endpoints }\end{array}$
\end{tabular}

\section{WHO Tel Aviv}

Methods 24 centre, pan European study conducted between 1973 and 1978. Randomised on discharge from hospital. 12 centres accepted for meta analysis

Participants 114 Men $<65$ yrs with first or consecutive MI.

Mean age for all participants

$\mathrm{I}=52.3, \mathrm{C}=53.5$.

Interventions Comprehensive programme dependent on local provision. Physical training was not compulsory but was strongly recommended.

F/U 3 years 


\section{WHO Tel Aviv (Continued)}

Local training for 20 weeks

\begin{tabular}{ll}
\hline Outcomes & $\begin{array}{l}\text { Clinical: } \\
\text { Total, CVD, CHD \& sudden death. } \\
\\
\text { Fatal \& non fatal re-infarction. } \\
\text { RTW, RPP,anxiety \& depression, incidence of angina or heart failure at follow up not included in meta-analysis }\end{array}$ \\
\hline Notes & $\begin{array}{l}\text { Methodological problems with the execution of the study allowed only death and reinfarction to be successfully used } \\
\text { as endpoints }\end{array}$ \\
\hline
\end{tabular}

\section{WHO Warsaw}

Methods 24 centre, pan European study conducted between 1973 and 1978. Randomised on discharge from hospital. 12 centres accepted for meta analysis

Participants 79 Men $<65$ yrs with first or consecutive MI.

Mean age for all participants

$\mathrm{I}=52.3, \mathrm{C}=53.5$.

Interventions Comprehensive programme dependent on local provision. Physical training was not compulsory but was strongly recommended.

F/U 3 years

Local training full time.

Outcomes Clinical:

Total, CVD, CHD \& sudden death.

Fatal \& non fatal re-infarction.

RTW, RPP,anxiety \& depression, incidence of angina or heart failure at follow up not included in meta-analysis

Notes Methodological problems with the execution of the study allowed only death and reinfarction to be successfully used as endpoints

\section{Wilhelmson 75}

\begin{tabular}{ll}
\hline Methods & Randomised on discharge. All patients received information on increasing physical activity during convalescence \\
\hline Participants & $\begin{array}{l}280 \text { men } \& 35 \text { women }<55 \text { yrs with MI. } \\
\text { Mean age } 50.6 .\end{array}$ \\
\hline Interventions & $\begin{array}{l}\text { Training programme } 3 \text { months after MI, } 3 \text { x half hour sessions per week based in hospital, at home or in workplace. } \\
\text { F/U } 5 \text { years }\end{array}$ \\
\hline Outcomes & Mortality, re-infarction. \\
\hline Notes & $\begin{array}{l}1 \text { year post MI, 39\% of those who started training were training at the hospital. A further 21\% trained at home or } \\
\text { at work }\end{array}$ \\
\hline
\end{tabular}


Worsornu 96

\begin{tabular}{ll}
\hline Methods & Random allocation of individuals to intervention and control groups (usual care) \\
\hline Participants & 81 men aged $57.4(+/-7.6)$ yrs, post CABG \\
\hline Interventions & $\begin{array}{l}\text { Exercise intervention: } \\
\text { Two interventions, aerobic and strength exercise training } \\
\text { Control group: usual care. Follow up period } 6 \text { months }\end{array}$ \\
\hline Outcomes & Cholesterol, HDL, LDL, triglycerides, exercise capacity \\
\hline Notes & $\begin{array}{l}\text { Primary focus of paper - comparing strength and aerobic exercise training on exercise capacity (outcome 1) and lipid } \\
\text { levels (outcome 2) post CABG }\end{array}$ \\
\hline
\end{tabular}

MI: Myocardial infarction

CHD: Coronary heart disease

SBP: Systolic blood pressure

DBP: Diastolic blood pressure

HDL: High density lipoprotein

LDL: Low density lipoprotein

QoL: Quality of life

V02max: Maximum oxygen uptake

CV: Cardiovascular

PWC: physical work capacity.

ET: exercise training

RTW: return to work

Characteristics of excluded studies [ordered by study ID]

\begin{tabular}{ll}
\hline Study & Reason for exclusion \\
\hline Bar 92 & $\begin{array}{l}\text { Method of randomisation was inadequate in that of a study population of } 265 \text { across } 5 \text { centres only one centre } \\
\text { randomised their patients, leaving a control group of } 50 \text { and an intervention group of } 215\end{array}$ \\
\hline Bjorntorp 72 & Participants randomised alternately after admission. \\
\hline Blumenthal 97 & Control group was not randomised, but selected on geographical basis \\
\hline Nikolaus 91 & Participants were a subgroup of Schuler study and have already been included \\
\hline
\end{tabular}


DATA ANDANALYSES

Comparison 1. Exercise only versus usual care

\begin{tabular}{lcccc} 
Outcome or subgroup title & $\begin{array}{c}\text { No. of } \\
\text { studies }\end{array}$ & $\begin{array}{c}\text { No. of } \\
\text { participants }\end{array}$ & Statistical method & Effect size \\
\hline 1 Total Mortality & 12 & 2582 & Peto Odds Ratio (Peto, Fixed, 95\% CI) & $0.74[0.56,0.98]$ \\
2 Total Cardiac Deaths & 8 & 2312 & Peto Odds Ratio (Peto, Fixed, 95\% CI) & $0.70[0.51,0.94]$ \\
3 Non fatal MI & 9 & 2104 & Peto Odds Ratio (Peto, Fixed, 95\% CI) & $0.96[0.69,1.35]$ \\
4 Pooled mortality, non-fatal MI, & 12 & 2582 & Peto Odds Ratio (Peto, Fixed, 95\% CI) & $0.81[0.65,1.01]$ \\
$\quad$ & & & & \\
CABG, PTCA & 3 & 237 & Mean Difference (IV, Fixed, 95\% CI) & $-0.03[-0.27,0.22]$ \\
6 Total Cholesterol & 2 & 95 & Mean Difference (IV, Fixed, 95\% CI) & $-0.02[-0.33,0.30]$ \\
\hline
\end{tabular}

Comparison 2. Exercise plus other rehabilitation versus usual care

\begin{tabular}{lcclc} 
Outcome or subgroup title & $\begin{array}{c}\text { No. of } \\
\text { studies }\end{array}$ & $\begin{array}{c}\text { No. of } \\
\text { participants }\end{array}$ & Statistical method & Effect size \\
\hline 1 Total Mortality & 29 & 5101 & Peto Odds Ratio (Peto, Fixed, 95\% CI) & $0.87[0.71,1.05]$ \\
2 Total Cardiac Deaths & 22 & 2903 & Peto Odds Ratio (Peto, Fixed, 95\% CI) & $0.75[0.59,0.97]$ \\
3 Non fatal MI & 26 & 3541 & Peto Odds Ratio (Peto, Fixed, 95\% CI) & $0.88[0.70,1.12]$ \\
4 Pooled mortality, non-fatal MI, & 29 & 5101 & Peto Odds Ratio (Peto, Fixed, 95\% CI) & $0.81[0.70,0.93]$ \\
$\quad$ & & & & \\
CABG, PTCA & 9 & 1198 & Mean Difference (IV, Fixed, 95\% CI) & $-0.65[-0.75,-0.55]$ \\
6 LDL Cholesterol & 6 & 728 & Mean Difference (IV, Fixed, 95\% CI) & $-0.61[-0.73,-0.50]$ \\
\hline
\end{tabular}

\section{Comparison 3. Any rehabilitation intervention including exercise versus usual care}

\begin{tabular}{lcccc} 
Outcome or subgroup title & $\begin{array}{c}\text { No. of } \\
\text { studies }\end{array}$ & $\begin{array}{c}\text { No. of } \\
\text { participants }\end{array}$ & Statistical method & Effect size \\
\hline $\begin{array}{l}1 \text { Pooled mortality, non-fatal MI, } \\
\text { CABG, PTCA }\end{array}$ & 41 & 7683 & Peto Odds Ratio (Peto, Fixed, 95\% CI) & $0.81[0.72,0.91]$ \\
$\begin{array}{l}2 \text { Quality criteria - Random } \\
\text { allocation: Outcome total } \\
\text { mortality }\end{array}$ & 41 & 7683 & Peto Odds Ratio (Peto, Fixed, 95\% CI) & $0.82[0.70,0.97]$ \\
$\quad \begin{array}{l}2.1 \text { Clear description - } \\
\text { adequate randomisation } \\
\quad 2.2 \text { Unclear description of }\end{array}$ & 12 & 3201 & Peto Odds Ratio (Peto, Fixed, 95\% CI) & $0.79[0.62,1.00]$ \\
$\begin{array}{l}\text { method of randomisation } \\
2.3 \text { Clear description - }\end{array}$ & 27 & 4006 & Peto Odds Ratio (Peto, Fixed, 95\% CI) & $0.88[0.70,1.10]$ \\
$\quad$ inadequate randomisation & 2 & 476 & Peto Odds Ratio (Peto, Fixed, 95\% CI) & $0.53[0.20,1.40]$ \\
\hline
\end{tabular}

Exercise-based rehabilitation for coronary heart disease (Review)

Copyright $\odot 2009$ The Cochrane Collaboration. Published by John Wiley \& Sons, Ltd. 
3 Quality criteria - Loss to follow up: Outcome total mortality

3.1 Less than $20 \%$ loss to

follow up

3.2 Greater than $20 \%$ loss to follow up

4 Quality criteria - Blind

\section{Analysis I.I. Comparison I Exercise only versus usual care, Outcome I Total Mortality.}

\begin{tabular}{|c|c|c|}
\hline \multicolumn{3}{|c|}{ bilitation for } \\
\hline \multicolumn{3}{|c|}{ Comparison: I Exercise only versus usual care } \\
\hline Outcome: I Total $N$ & & \\
\hline \multirow[t]{2}{*}{ Study or subgroup } & Treatment & Control \\
\hline & $n / N$ & $\mathrm{n} / \mathrm{N}$ \\
\hline Anderson 81 & $4 / 46$ & $3 / 42$ \\
\hline Bethell 90 & $16 / 113$ & $12 / 116$ \\
\hline Carson 82 & $|2 / 15|$ & $21 / 152$ \\
\hline Erdman 86 & $4 / 40$ & $0 / 40$ \\
\hline Holmback 94 & $1 / 34$ & $1 / 35$ \\
\hline Kentala 72 & $5 / 152$ & $8 / 146$ \\
\hline NEHDP & $15 / 323$ & $24 / 328$ \\
\hline Sivarajan 82 & $3 / 88$ & $2 / 84$ \\
\hline Speccia 96 & $5 / 125$ & $|3 / 13|$ \\
\hline Stern 83 & $0 / 42$ & $1 / 29$ \\
\hline Vecchio 81 & $0 / 25$ & $2 / 25$ \\
\hline Wilhelmson 75 & $28 / 158$ & $35 / 157$ \\
\hline Total (95\% CI) & 1297 & 1285 \\
\hline \multicolumn{3}{|c|}{ Total events: 93 (Treatment), I 22 (Control) } \\
\hline \multicolumn{3}{|c|}{ Heterogeneity: $\mathrm{Chi}^{2}=14.33, \mathrm{df}=1 \mathrm{I}(\mathrm{P}=0.22) ; \mathrm{I}^{2}=23 \%$} \\
\hline \multicolumn{3}{|c|}{ Test for overall effect: $Z=2.09(P=0.037)$} \\
\hline \multicolumn{3}{|c|}{ Test for subgroup differences: Not applicable } \\
\hline
\end{tabular}


Analysis I.2. Comparison I Exercise only versus usual care, Outcome 2 Total Cardiac Deaths.

Review: Exercise-based rehabilitation for coronary heart disease

Comparison: I Exercise only versus usual care

Outcome: 2 Total Cardiac Deaths

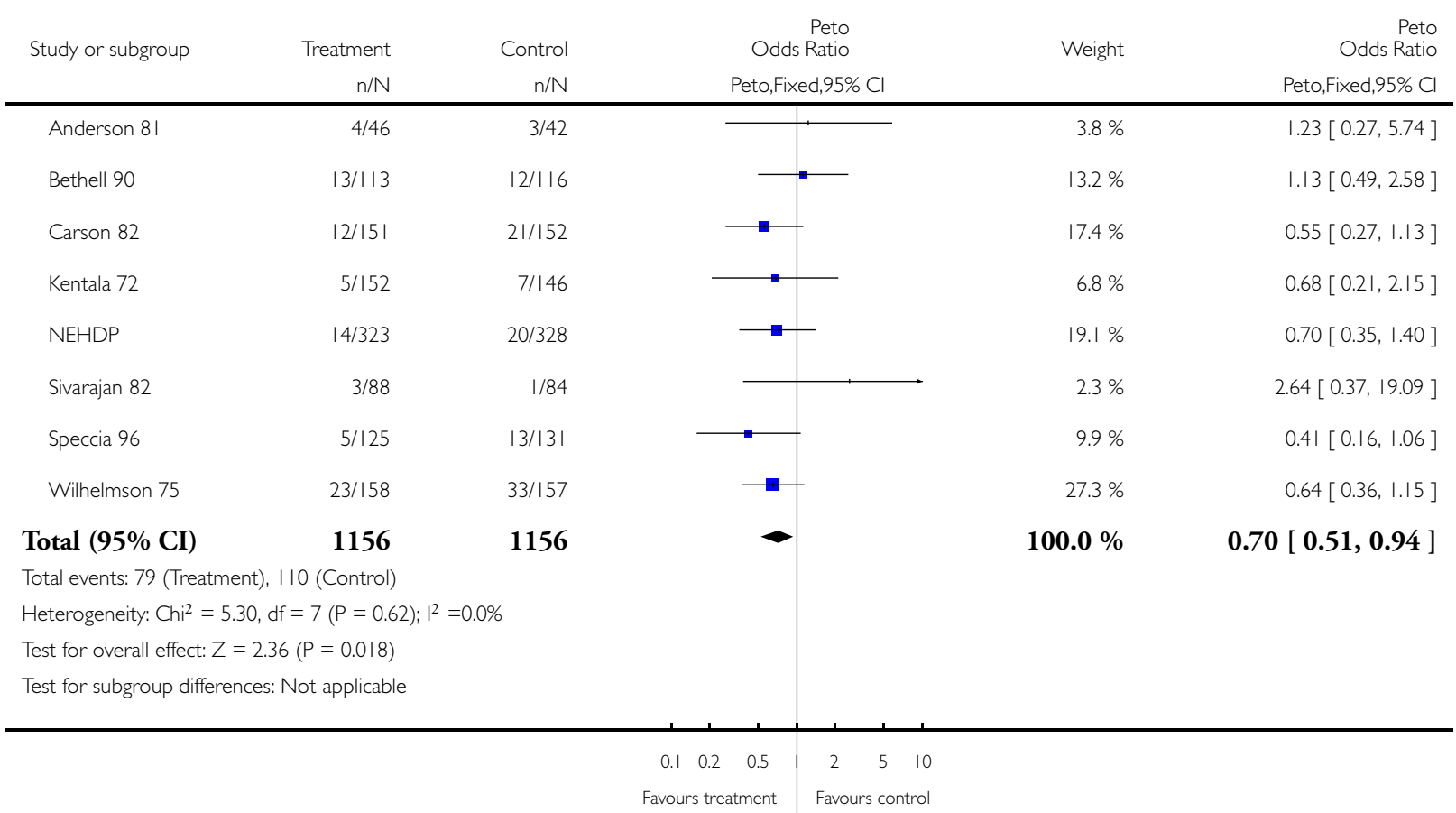




\section{Analysis I.3. Comparison I Exercise only versus usual care, Outcome 3 Non fatal MI.}

Review: Exercise-based rehabilitation for coronary heart disease

Comparison: I Exercise only versus usual care

Outcome: 3 Non fatal MI

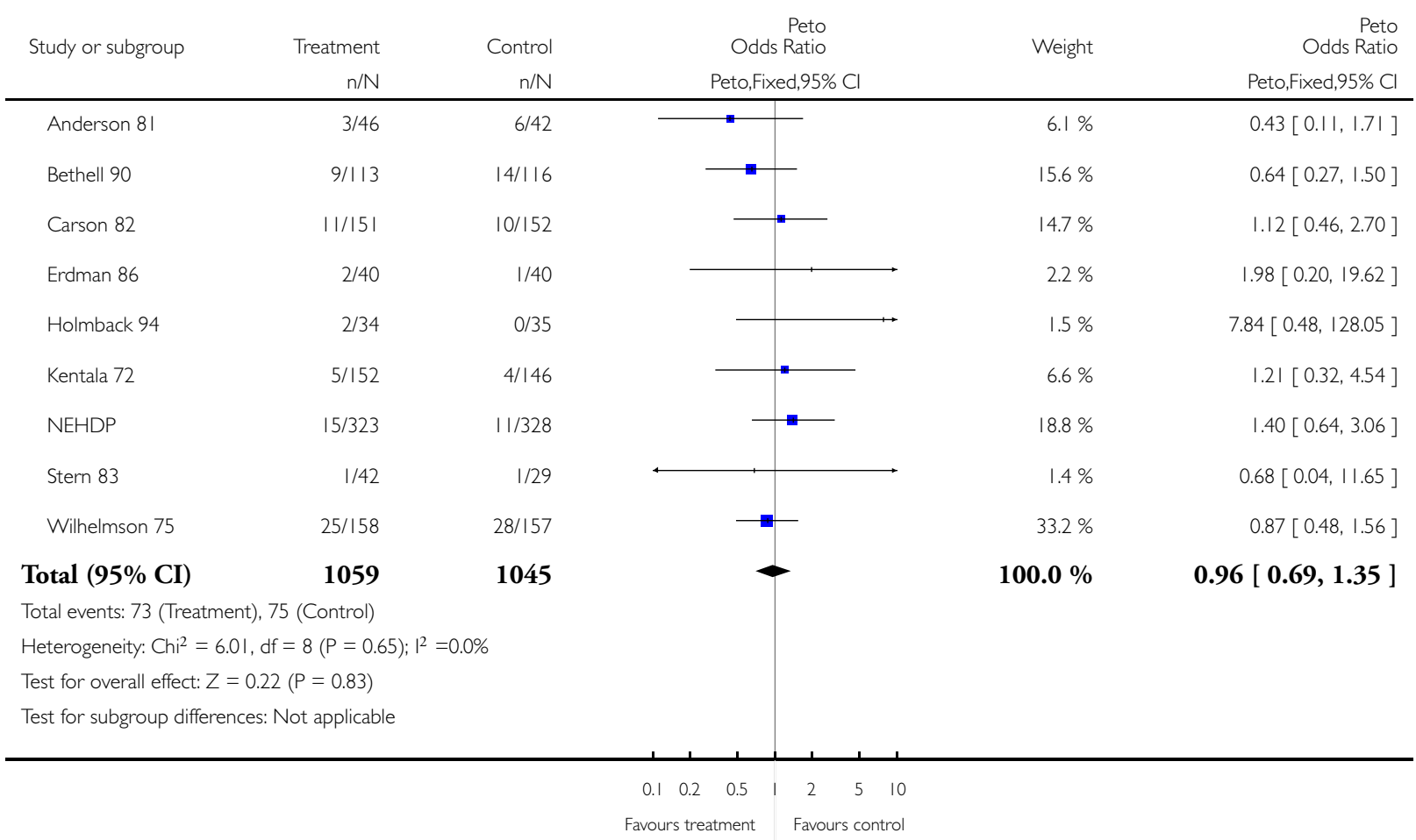


Analysis I.4. Comparison I Exercise only versus usual care, Outcome 4 Pooled mortality, non-fatal MI, CABG, PTCA.

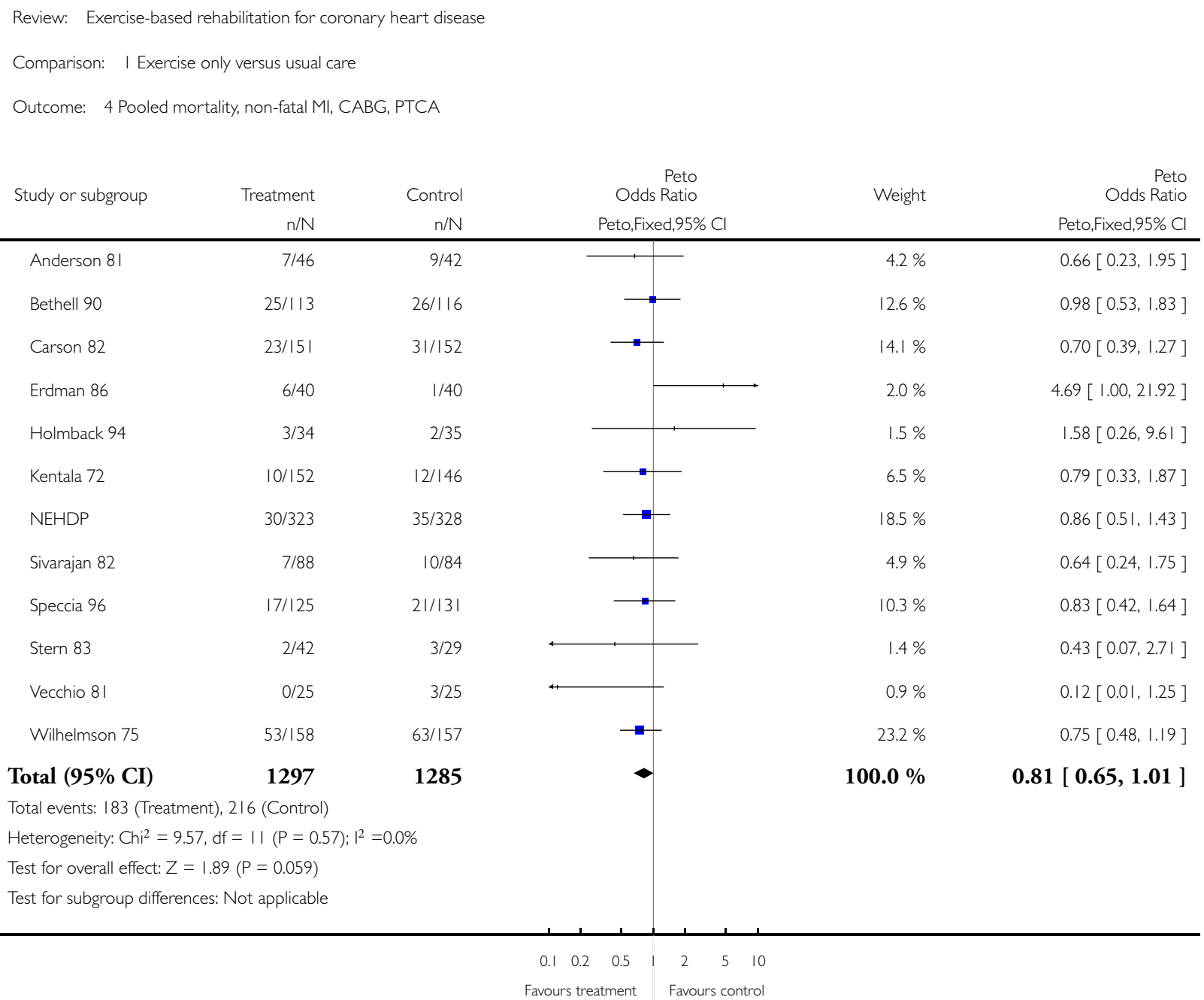




\section{Analysis I.5. Comparison I Exercise only versus usual care, Outcome 5 Total Cholesterol.}

Review: Exercise-based rehabilitation for coronary heart disease

Comparison: I Exercise only versus usual care

Outcome: 5 Total Cholesterol

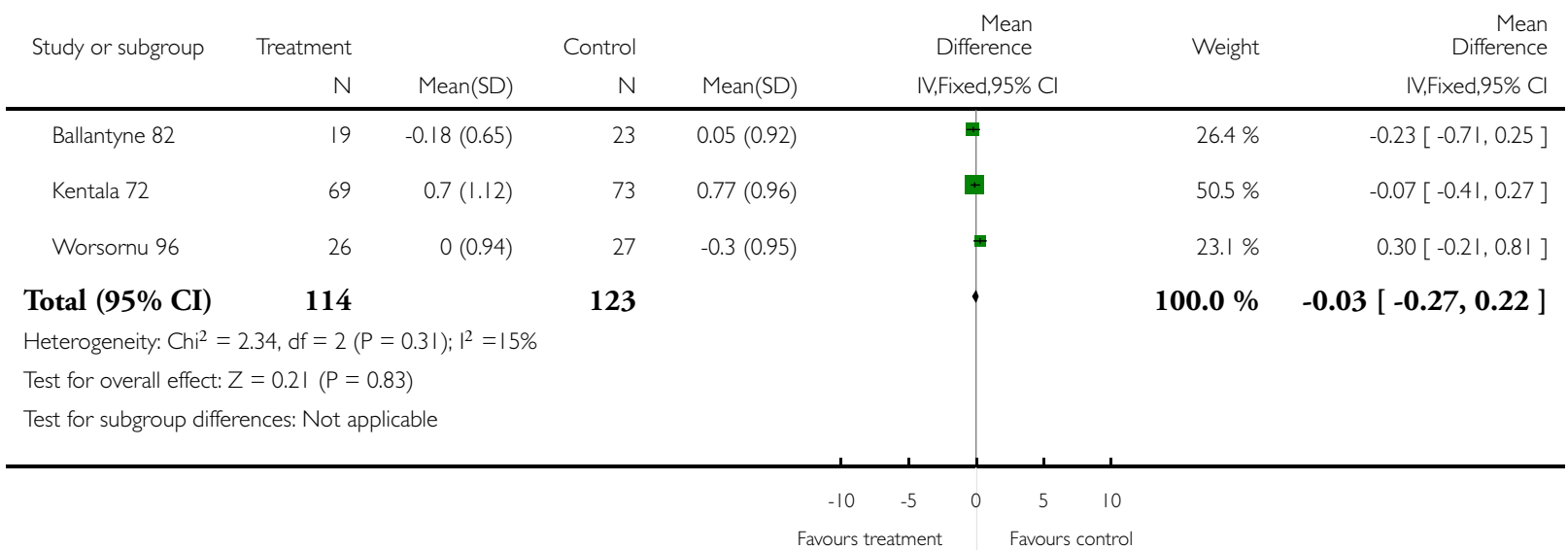

Analysis I.6. Comparison I Exercise only versus usual care, Outcome 6 LDL Cholesterol.

Review: Exercise-based rehabilitation for coronary heart disease

Comparison: I Exercise only versus usual care

Outcome: 6 LDL Cholesterol

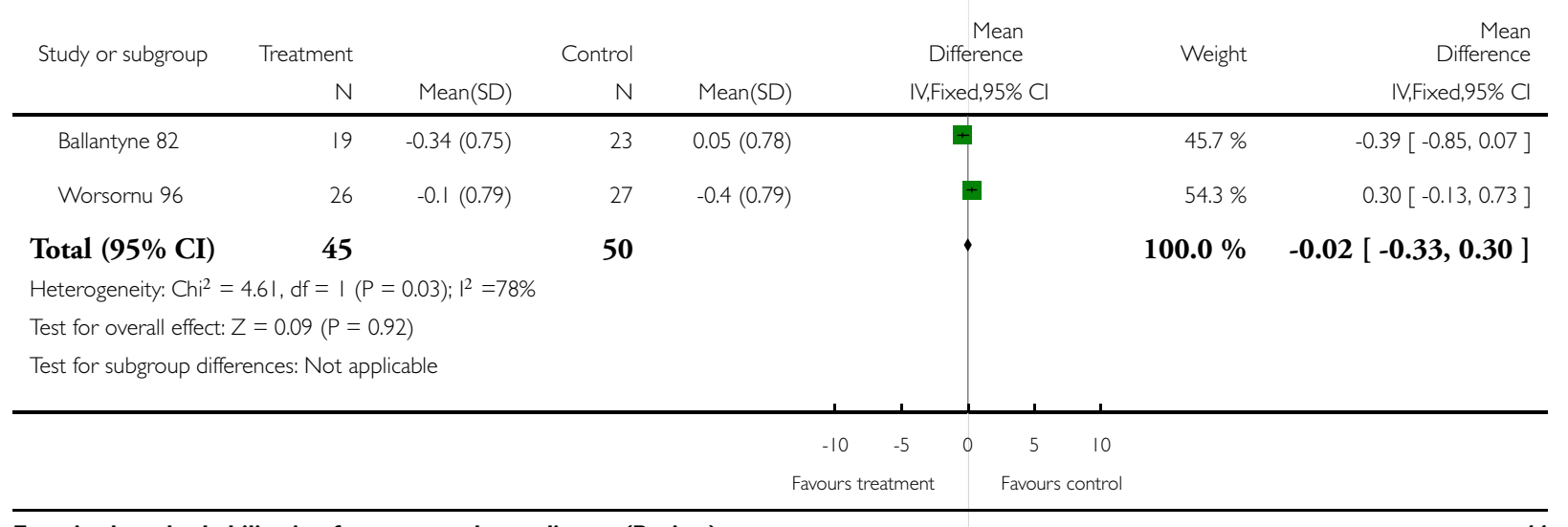

Exercise-based rehabilitation for coronary heart disease (Review)

Copyright @ 2009 The Cochrane Collaboration. Published by John Wiley \& Sons, Ltd. 
Analysis 2.I. Comparison 2 Exercise plus other rehabilitation versus usual care, Outcome I Total Mortality.

Review: Exercise-based rehabilitation for coronary heart disease

Comparison: 2 Exercise plus other rehabilitation versus usual care

Outcome: I Total Mortality

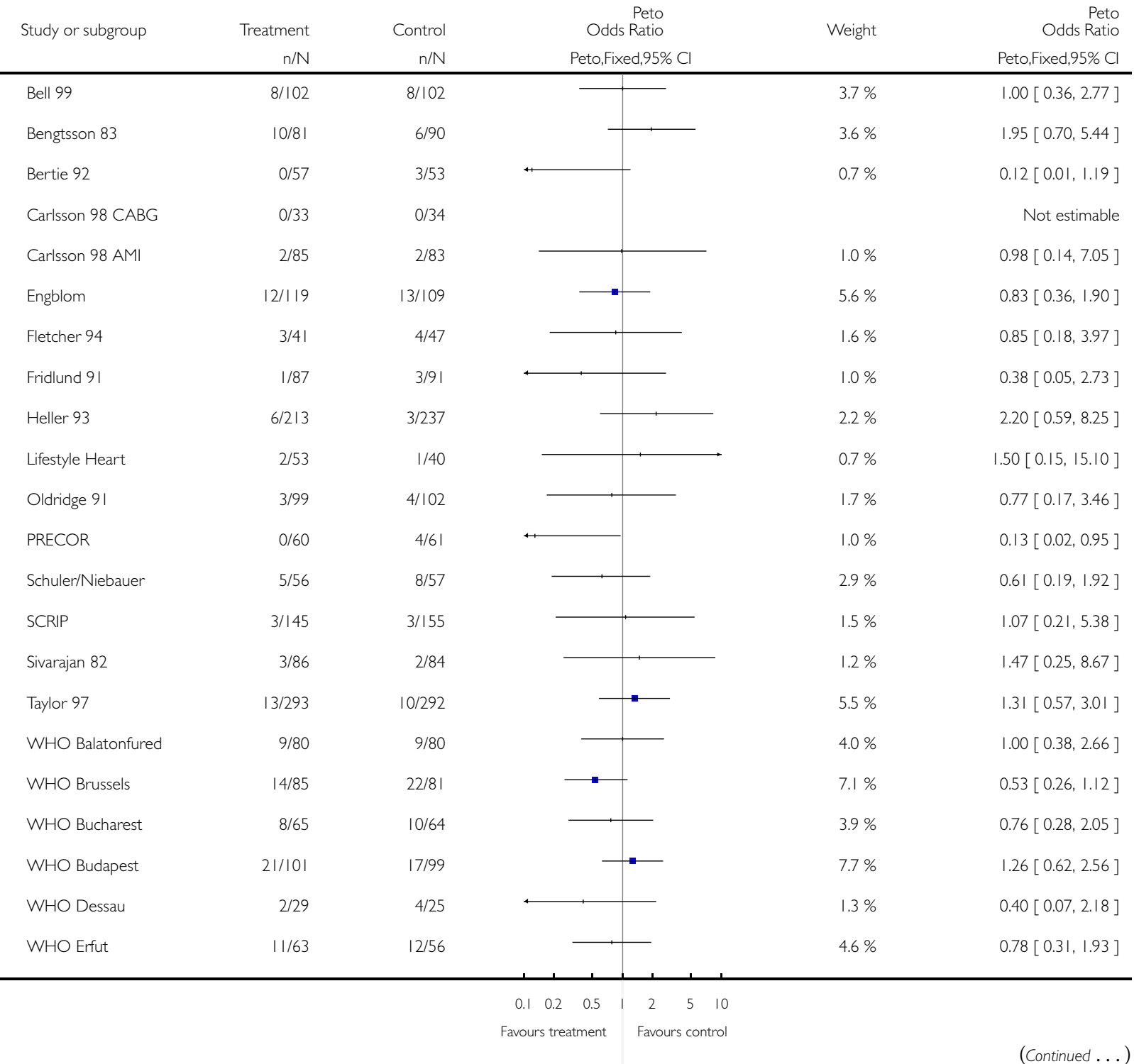

Exercise-based rehabilitation for coronary heart disease (Review) 


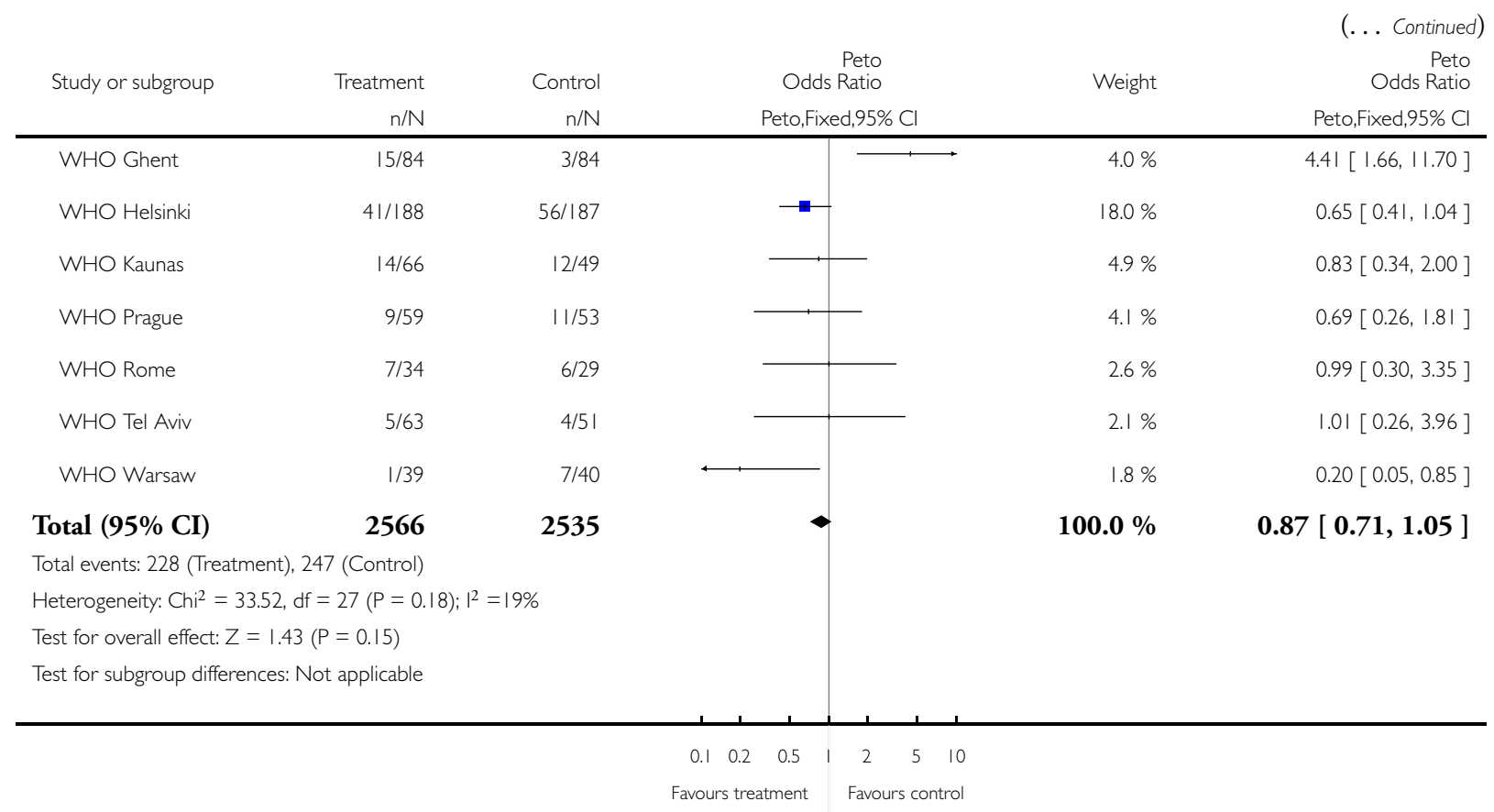


Analysis 2.2. Comparison 2 Exercise plus other rehabilitation versus usual care, Outcome 2 Total Cardiac Deaths.

Review: Exercise-based rehabilitation for coronary heart disease

Comparison: 2 Exercise plus other rehabilitation versus usual care

Outcome: 2 Total Cardiac Deaths

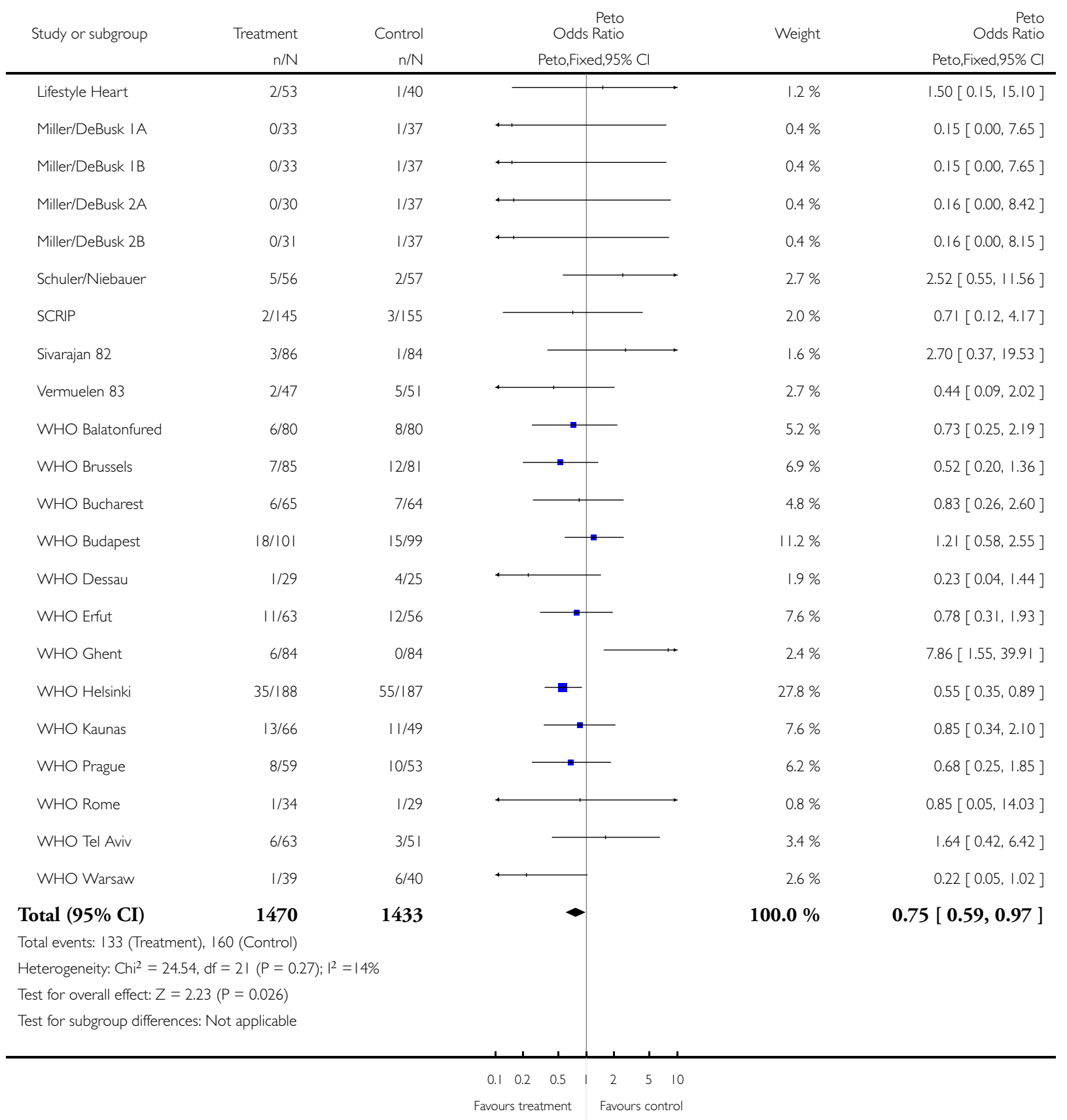

Exercise-based rehabilitation for coronary heart disease (Review) 


\section{Analysis 2.3. Comparison 2 Exercise plus other rehabilitation versus usual care, Outcome 3 Non fatal MI.}

Review: Exercise-based rehabilitation for coronary heart disease

Comparison: 2 Exercise plus other rehabilitation versus usual care

Outcome: 3 Non fatal MI

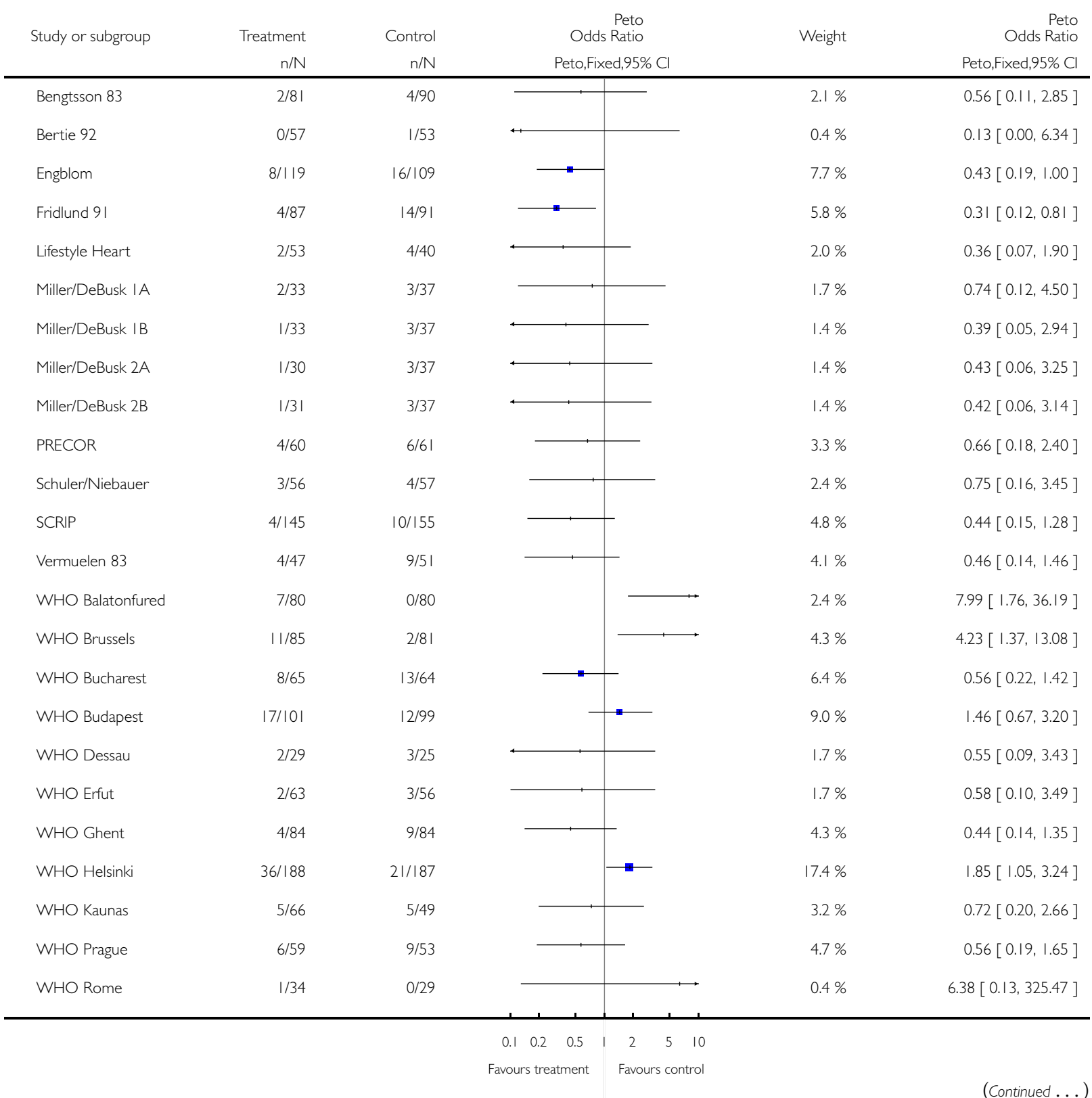

Exercise-based rehabilitation for coronary heart disease (Review) 


\begin{tabular}{|c|c|c|c|c|c|}
\hline \multirow[t]{2}{*}{ Study or subgroup } & Treatment & Control & $\begin{array}{r}\text { Peto } \\
\text { Odds Ratio }\end{array}$ & Weight & $\begin{array}{c}\text { (... Continued) } \\
\text { Peto } \\
\text { Odds Ratio }\end{array}$ \\
\hline & $\mathrm{n} / \mathrm{N}$ & $n / N$ & Peto,Fixed,95\% Cl & & Peto,Fixed,95\% Cl \\
\hline WHO Tel Aviv & 9/63 & $4 / 51$ & $\longrightarrow$ & $4.1 \%$ & $1.88[0.59,5.98]$ \\
\hline WHO Warsaw & $5 / 39$ & $1 / 40$ & & $2.0 \%$ & $4.27[0.82,22.34]$ \\
\hline Total $(95 \% \mathrm{CI})$ & 1788 & 1753 & 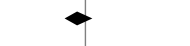 & $100.0 \%$ & $0.88[0.70,1.12]$ \\
\hline \multicolumn{6}{|c|}{ Total events: I49 (Treatment), 162 (Control) } \\
\hline \multicolumn{6}{|c|}{ Heterogeneity: $\mathrm{Ch}^{2}{ }^{2}=47.95, \mathrm{df}=25(P=0.004) ; 1^{2}=48 \%$} \\
\hline \multicolumn{6}{|c|}{ Test for overall effect: $Z=1.02(P=0.31)$} \\
\hline \multicolumn{6}{|c|}{ Test for subgroup differences: Not applicable } \\
\hline
\end{tabular}

\section{Analysis 2.4. Comparison 2 Exercise plus other rehabilitation versus usual care, Outcome 4 Pooled} mortality, non-fatal MI, CABG, PTCA.

Review: Exercise-based rehabilitation for coronary heart disease

Comparison: 2 Exercise plus other rehabilitation versus usual care

Outcome: 4 Pooled mortality, non-fatal MI, CABG, PTCA

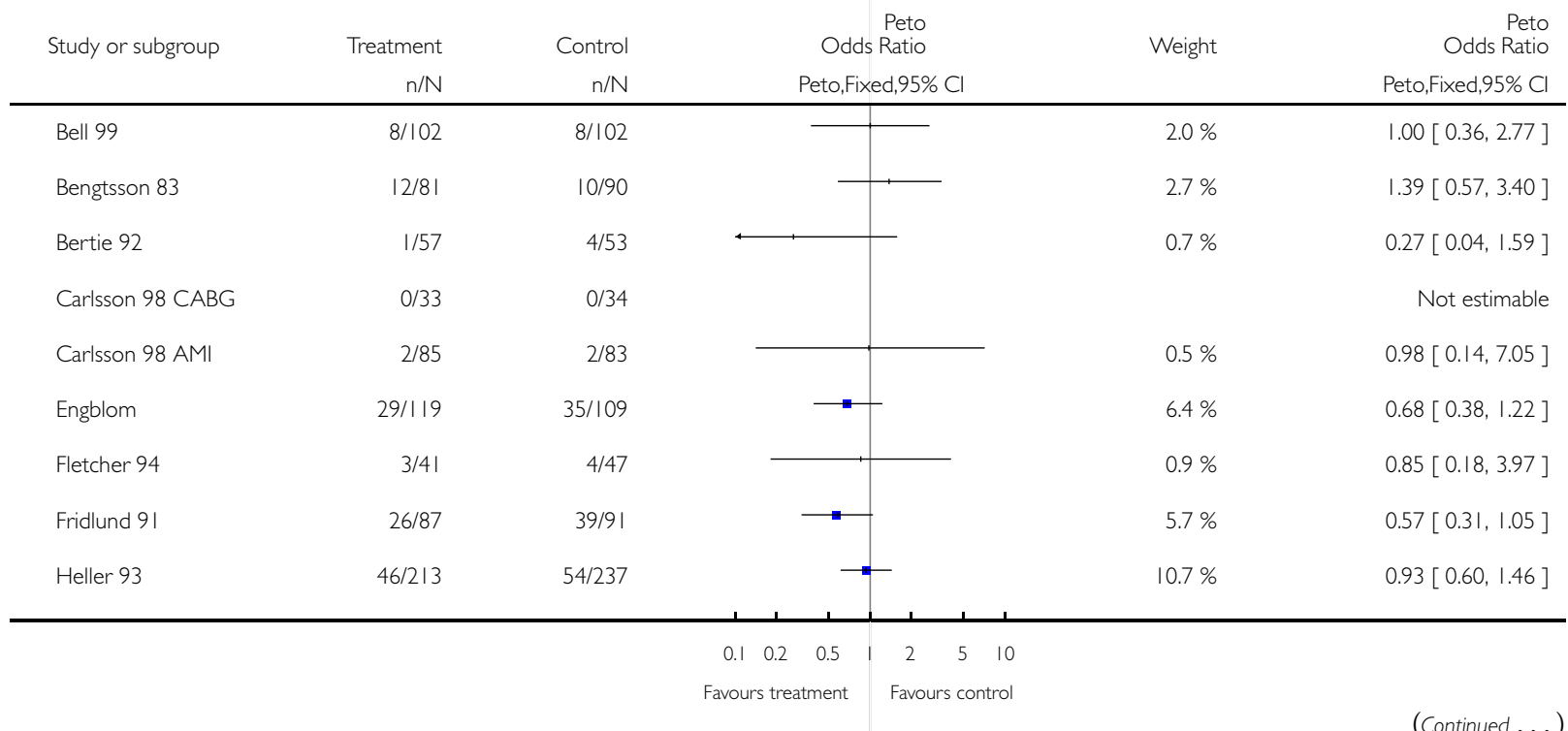




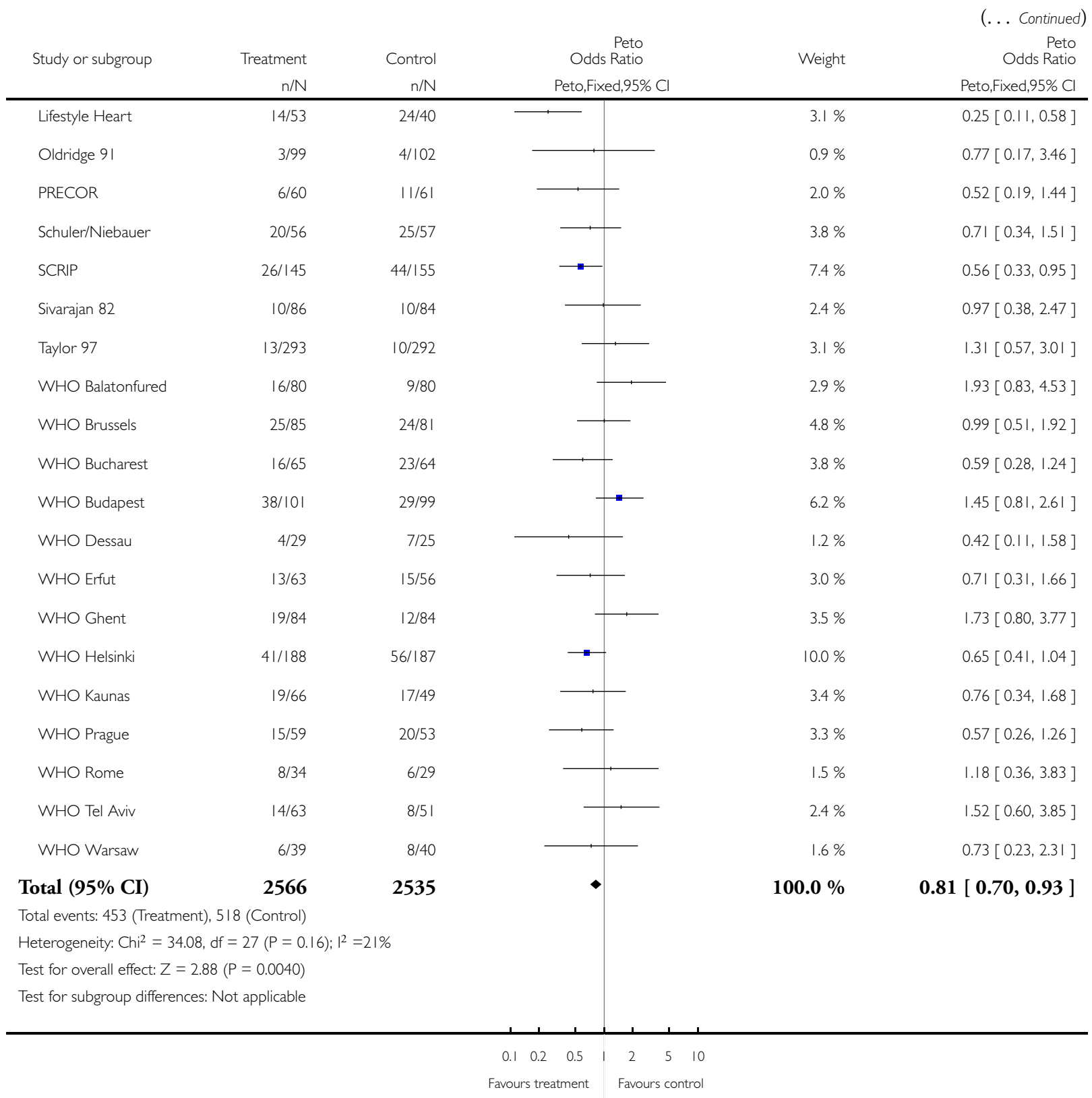


Analysis 2.5. Comparison 2 Exercise plus other rehabilitation versus usual care, Outcome 5 Total Cholesterol.

Review: Exercise-based rehabilitation for coronary heart disease

Comparison: 2 Exercise plus other rehabilitation versus usual care

Outcome: 5 Total Cholesterol

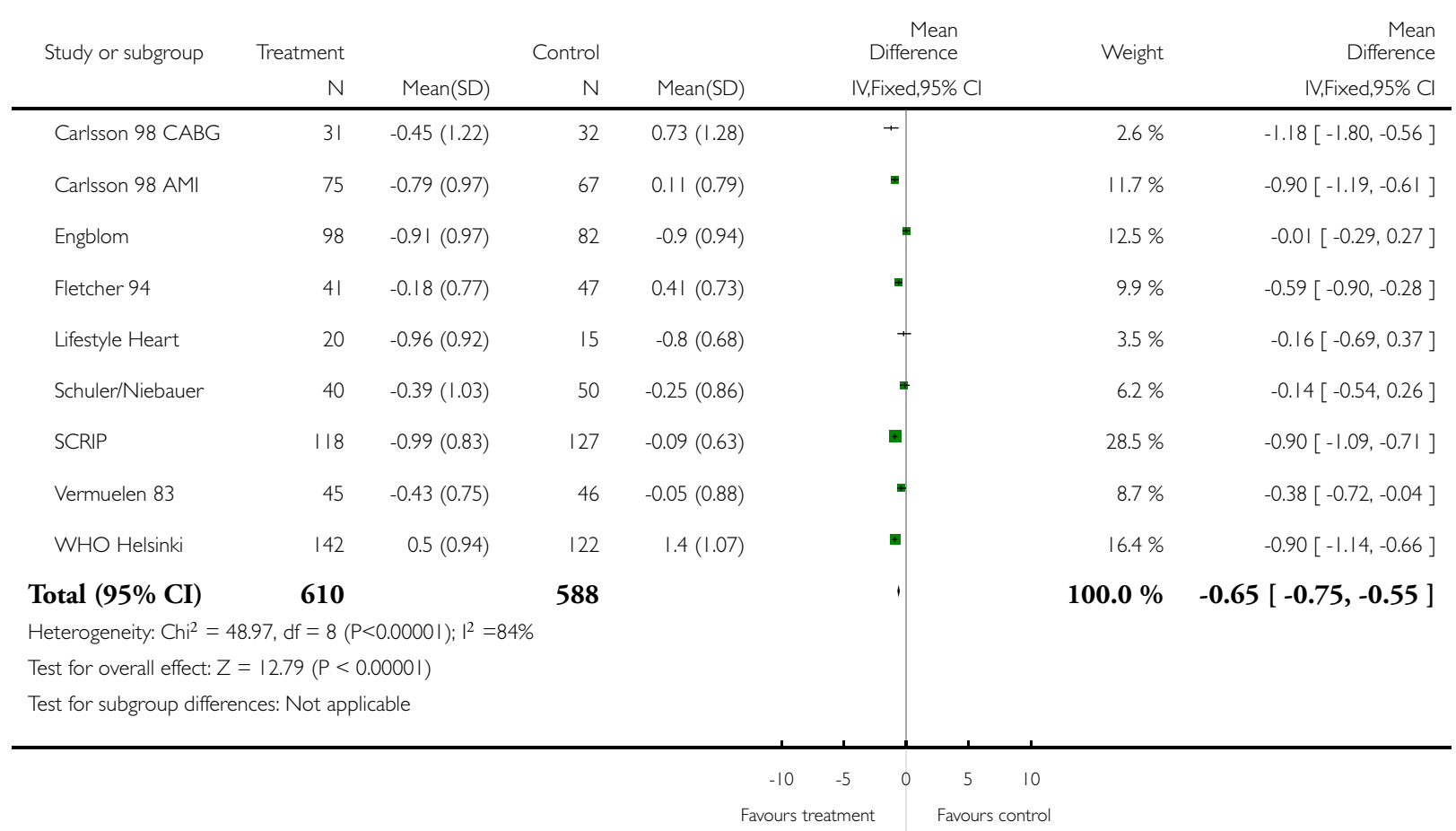

Exercise-based rehabilitation for coronary heart disease (Review) 
Analysis 2.6. Comparison 2 Exercise plus other rehabilitation versus usual care, Outcome 6 LDL Cholesterol.

Review: Exercise-based rehabilitation for coronary heart disease

Comparison: 2 Exercise plus other rehabilitation versus usual care

Outcome: 6 LDL Cholesterol

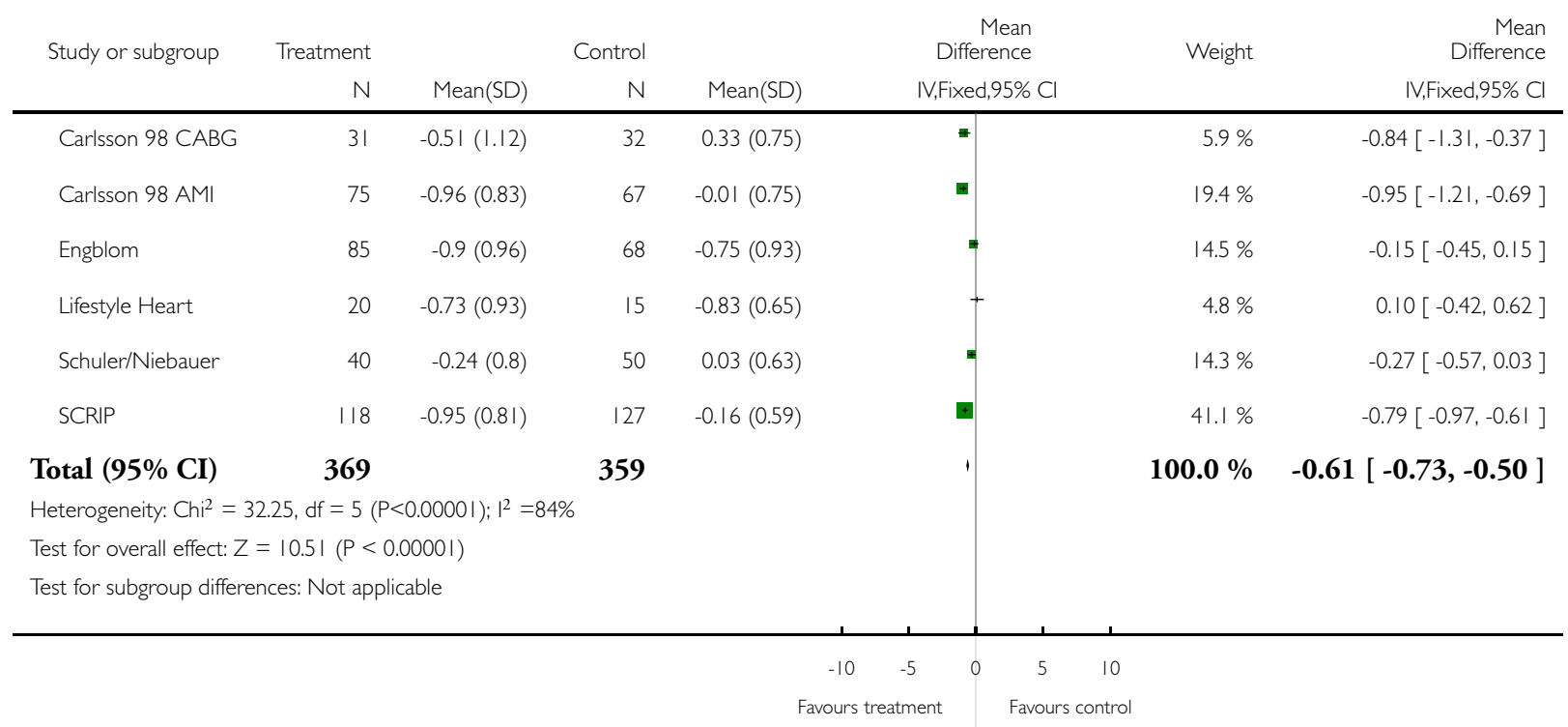


Analysis 3.I. Comparison 3 Any rehabilitation intervention including exercise versus usual care, Outcome I Pooled mortality, non-fatal MI, CABG, PTCA.

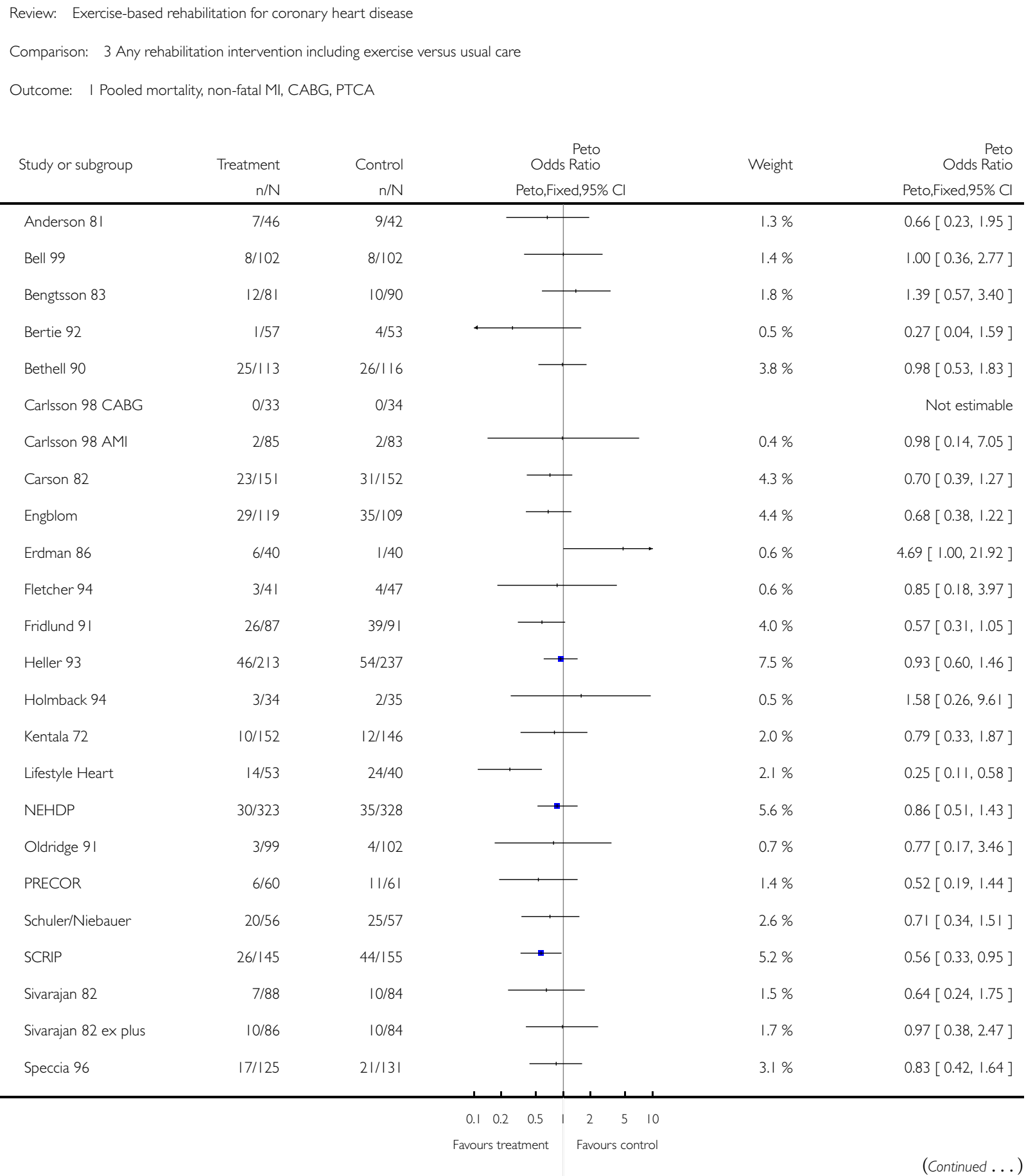




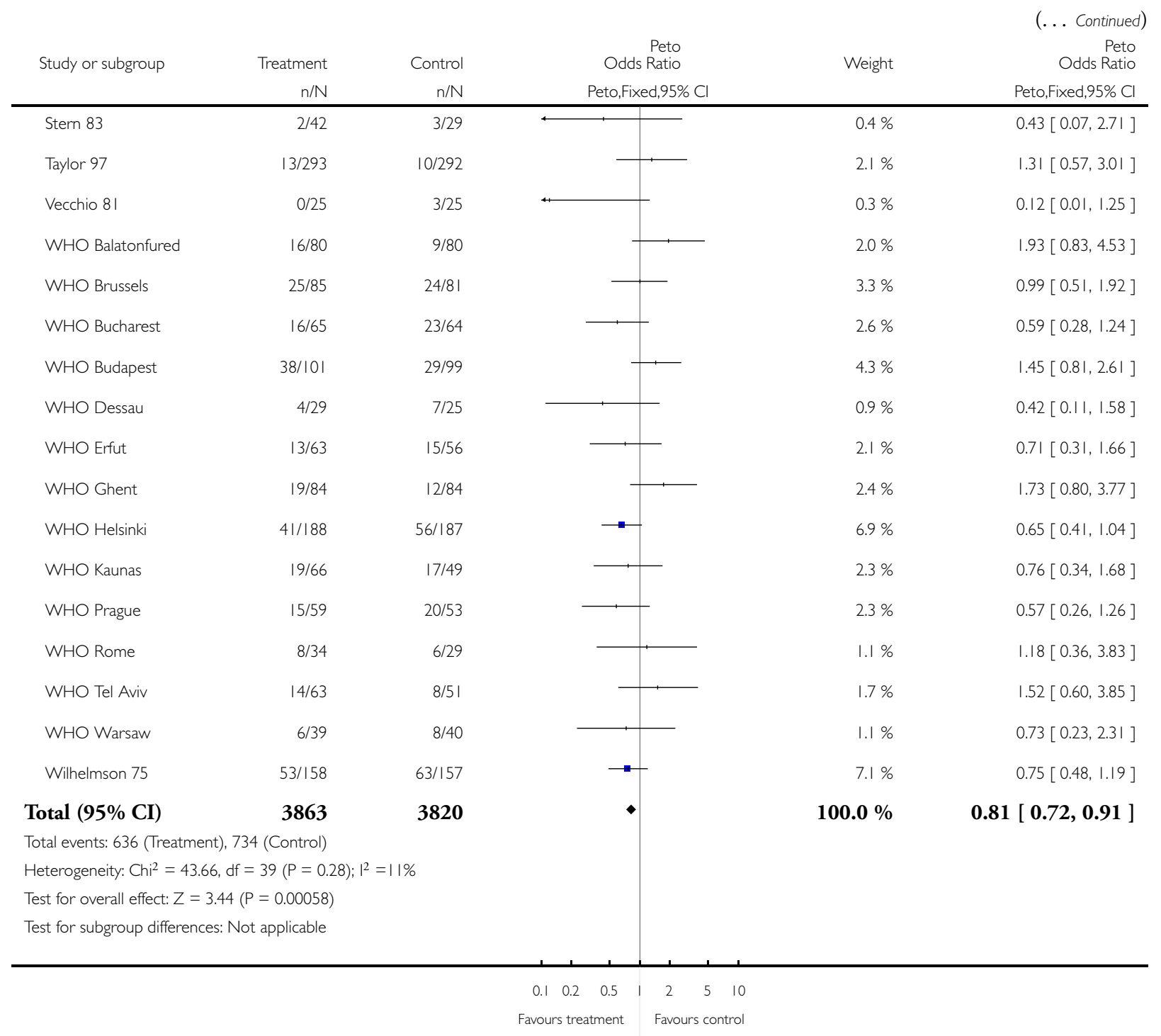


Analysis 3.2. Comparison 3 Any rehabilitation intervention including exercise versus usual care, Outcome 2 Quality criteria - Random allocation: Outcome total mortality.

Review: Exercise-based rehabilitation for coronary heart disease

Comparison: 3 Any rehabilitation intervention including exercise versus usual care

Outcome: 2 Quality criteria - Random allocation: Outcome total mortality

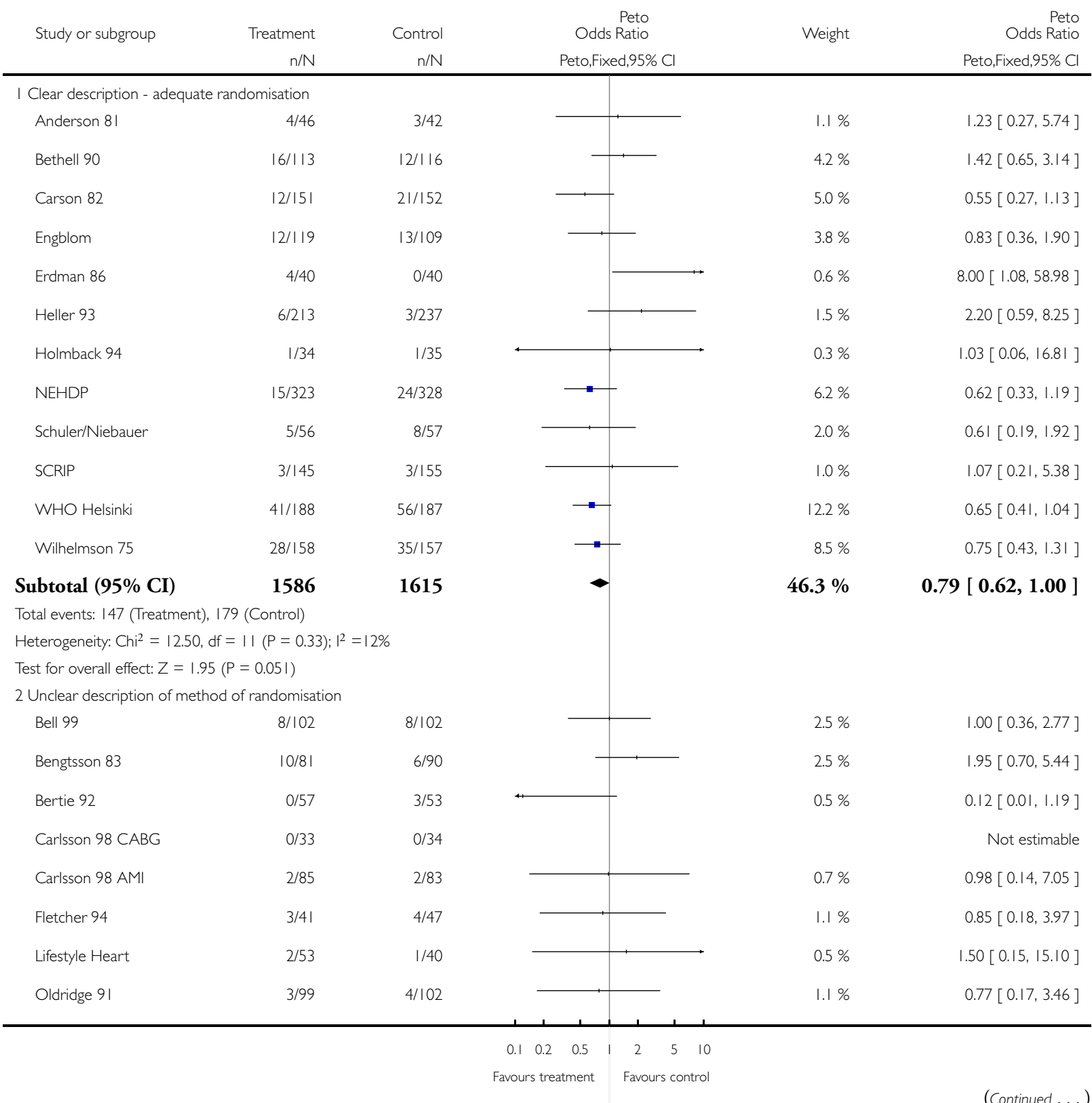

Exercise-based rehabilitation for coronary heart disease (Review) 


\begin{tabular}{|c|c|c|c|c|c|c|}
\hline \multirow[t]{2}{*}{ Study or subgroup } & Treatment & \multicolumn{3}{|c|}{$\begin{array}{r}\text { Peto } \\
\text { Odds Ratio }\end{array}$} & \multirow[t]{2}{*}{ Weight } & \multirow{2}{*}{$\begin{array}{r}\text { Peto } \\
\text { Odds Ratio } \\
\text { Peto,Fixed,95\% Cl }\end{array}$} \\
\hline & $n / N$ & $n / N$ & \multicolumn{2}{|c|}{ Peto,Fixed,95\% Cl } & & \\
\hline PRECOR & $0 / 60$ & $4 / 61$ & 4 & & $0.7 \%$ & $0.13[0.02,0.95]$ \\
\hline Sivarajan 82 & $3 / 88$ & 2/84 & & & $0.8 \%$ & $1.44[0.24,8.47]$ \\
\hline Sivarajan 82 ex plus & 3/86 & 2/84 & & & $0.8 \%$ & $1.47[0.25,8.67]$ \\
\hline Speccia 96 & $5 / 125$ & $13 / 13 \mid$ & & & $2.8 \%$ & $0.41[0.16,1.06]$ \\
\hline Stern 83 & $0 / 42$ & 1/29 & & & $0.2 \%$ & $0.09[0.00,4.66]$ \\
\hline Taylor 97 & $13 / 293$ & 10/292 & & & $3.7 \%$ & $1.31[0.57,3.01]$ \\
\hline Vecchio 8I & $0 / 25$ & $2 / 25$ & $\leftrightarrow$ & & $0.3 \%$ & $0.13[0.01,2.14]$ \\
\hline WHO Balatonfured & $9 / 80$ & $9 / 80$ & & - & $2.7 \%$ & $1.00[0.38,2.66]$ \\
\hline WHO Brussels & $14 / 85$ & $22 / 81$ & & & $4.8 \%$ & $0.53[0.26,1.12]$ \\
\hline WHO Bucharest & $8 / 65$ & $10 / 64$ & & - & $2.6 \%$ & $0.76[0.28,2.05]$ \\
\hline WHO Budapest & $21 / 101$ & $17 / 99$ & & $\mp$ & $5.2 \%$ & $1.26[0.62,2.56]$ \\
\hline WHO Dessau & $2 / 29$ & $4 / 25$ & 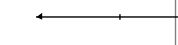 & & $0.9 \%$ & $0.40[0.07,2.18]$ \\
\hline WHO Erfut & $11 / 63$ & $12 / 56$ & & & $3.1 \%$ & $0.78[0.31,1.93]$ \\
\hline WHO Ghent & $15 / 84$ & $3 / 84$ & & $\rightarrow$ & $2.7 \%$ & $4.41[1.66,11.70]$ \\
\hline WHO Kaunas & $14 / 66$ & $12 / 49$ & & - & $3.4 \%$ & $0.83[0.34,2.00]$ \\
\hline WHO Prague & $9 / 59$ & |1/53 & & - & $2.8 \%$ & $0.69[0.26,1.81]$ \\
\hline WHO Rome & $7 / 34$ & $6 / 29$ & & & $1.8 \%$ & $0.99[0.30,3.35]$ \\
\hline WHO Tel Aviv & $5 / 63$ & $4 / 51$ & & & $1.4 \%$ & $1.01[0.26,3.96]$ \\
\hline WHO Warsaw & 1/39 & $7 / 40$ & & & $1.2 \%$ & $0.20[0.05,0.85]$ \\
\hline Subtotal $(95 \%$ CI $)$ & 2038 & 1968 & & & $50.9 \%$ & $0.88[0.70,1.10]$ \\
\hline \multicolumn{7}{|c|}{ Total events: I 68 (Treatment), 179 (Control) } \\
\hline \multicolumn{7}{|c|}{ Heterogeneity: Chi $^{2}=34.84, d f=25(P=0.09) ; 1^{2}=28 \%$} \\
\hline \multicolumn{7}{|c|}{ Test for overall effect: $Z=1.16(P=0.25)$} \\
\hline \multicolumn{7}{|c|}{3 Clear description - inadequate randomisation } \\
\hline Fridlund 91 & ।/87 & $3 / 91$ & & & $0.7 \%$ & $0.38[0.05,2.73]$ \\
\hline Kentala 72 & $5 / 152$ & $8 / 146$ & & & $2.1 \%$ & $0.59[0.20,1.80]$ \\
\hline Subtotal $(95 \% \mathrm{CI})$ & 239 & 237 & & & $2.8 \%$ & $0.53[0.20,1.40]$ \\
\hline \multicolumn{7}{|c|}{ Total events: 6 (Treatment), II (Control) } \\
\hline \multicolumn{7}{|c|}{ Heterogeneity: $\mathrm{Ch}^{2}=0.15, \mathrm{df}=1(P=0.70) ; 1^{2}=0.0 \%$} \\
\hline \multicolumn{7}{|c|}{ Test for overall effect: $Z=1.28(P=0.20)$} \\
\hline Total $(95 \% \mathrm{CI})$ & 3863 & 3820 & $\bullet$ & & $100.0 \%$ & $0.82[0.70,0.97]$ \\
\hline \multicolumn{7}{|c|}{ Total events: 32I (Treatment), 369 (Control) } \\
\hline \multicolumn{7}{|c|}{ Heterogeneity: $\mathrm{Ch}^{2}=48.67, \mathrm{df}=39(P=0.14) ; I^{2}=20 \%$} \\
\hline \multicolumn{7}{|c|}{ Test for overall effect: $Z=2.36(P=0.018)$} \\
\hline \multicolumn{7}{|c|}{ Test for subgroup differences: $\mathrm{Chi}^{2}=1.18, \mathrm{df}=2(\mathrm{P}=0.56), \mathrm{I}^{2}=0.0 \%$} \\
\hline & & & 0.10 .2 & $\begin{array}{lll}2 & 5 & 10\end{array}$ & & \\
\hline & & & Favours treatment & Favours control & & \\
\hline
\end{tabular}

Exercise-based rehabilitation for coronary heart disease (Review) 
Analysis 3.3. Comparison 3 Any rehabilitation intervention including exercise versus usual care, Outcome 3 Quality criteria - Loss to follow up: Outcome total mortality.

Review: Exercise-based rehabilitation for coronary heart disease

Comparison: 3 Any rehabilitation intervention including exercise versus usual care

Outcome: 3 Quality criteria - Loss to follow up: Outcome total mortality

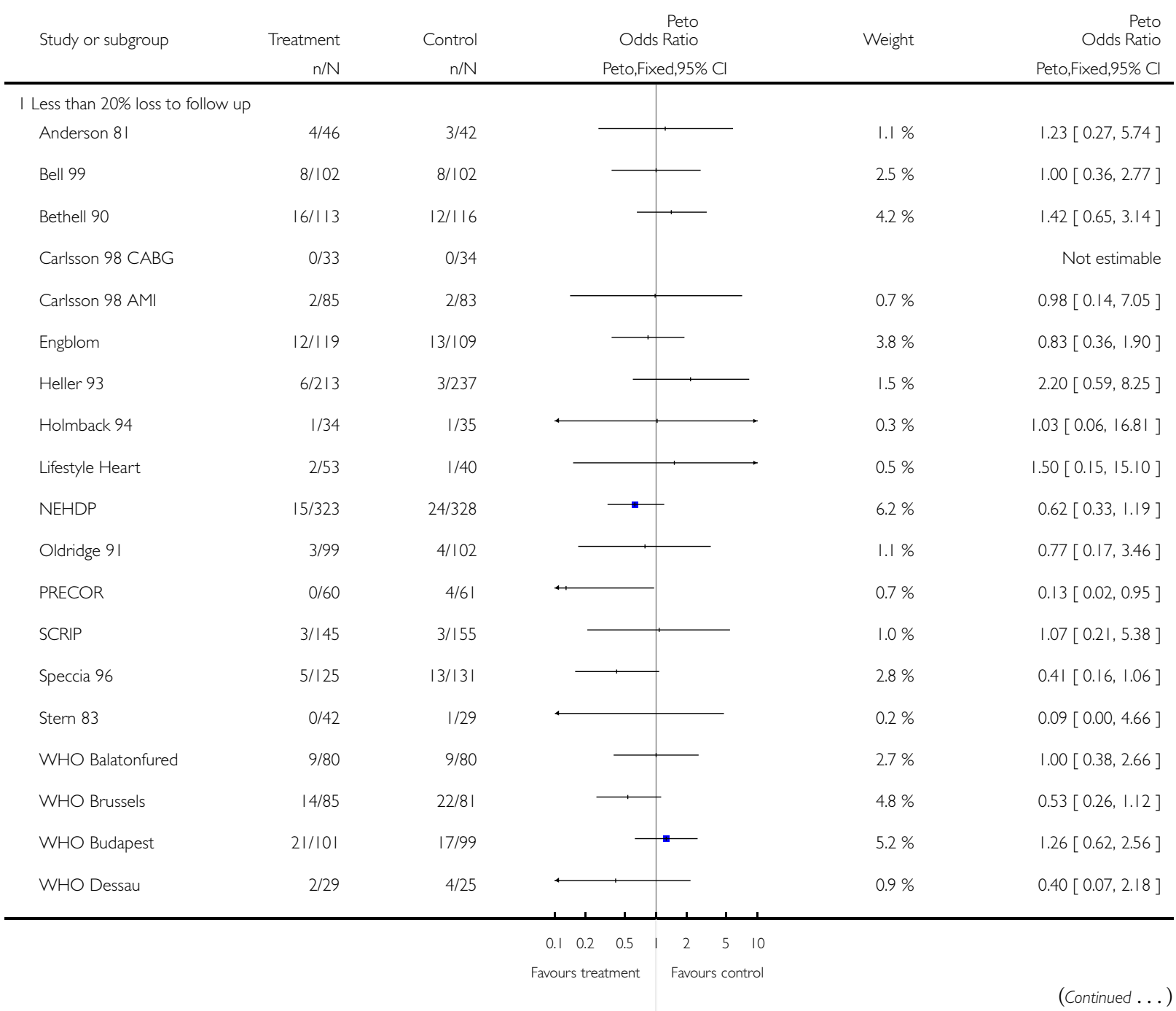




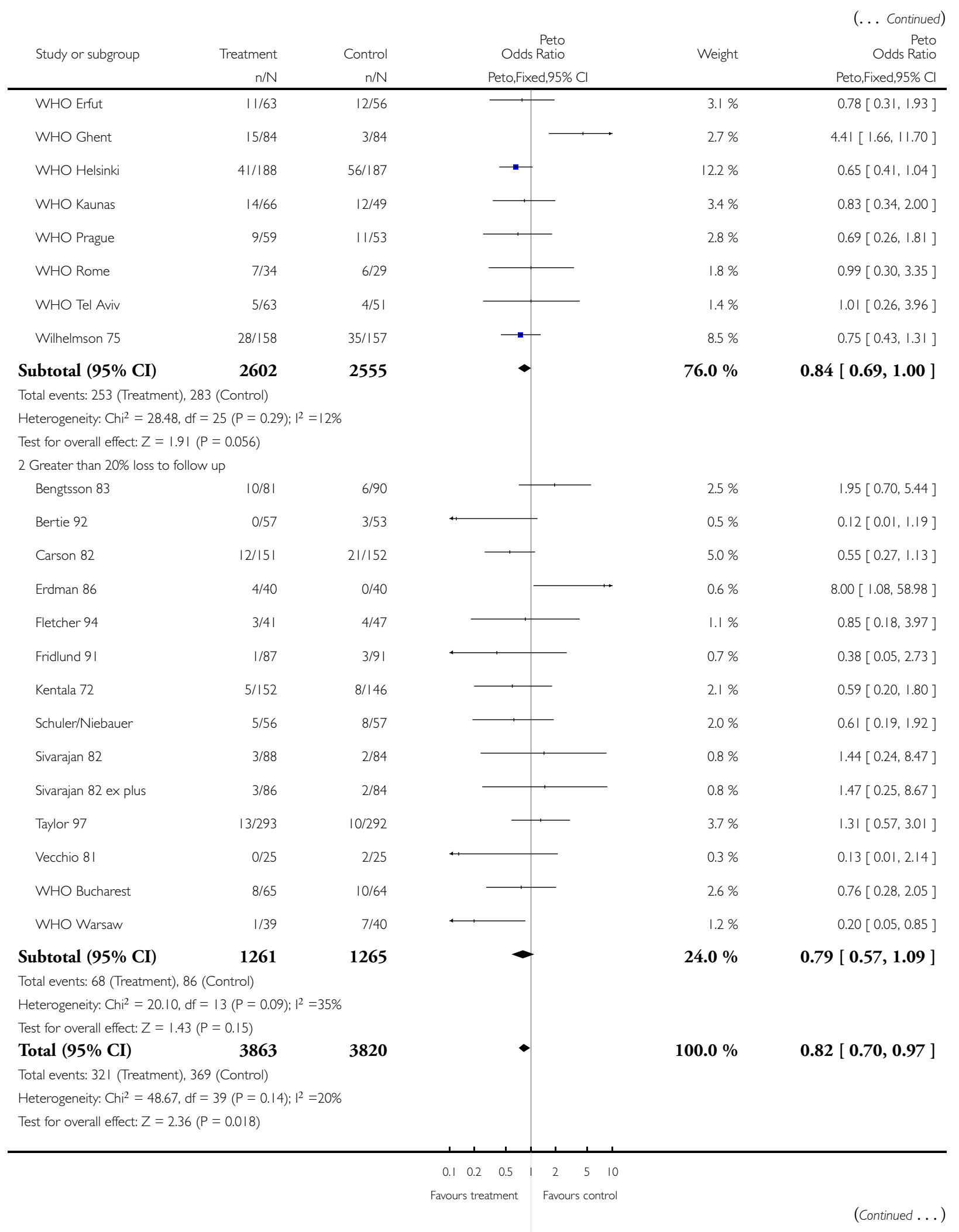

Exercise-based rehabilitation for coronary heart disease (Review) 


\begin{tabular}{|c|c|c|c|c|c|}
\hline \multirow{3}{*}{ Study or subgroup } & & & & \multirow{3}{*}{ Weight } & (... Continued) \\
\hline & Treatment & Control & $\begin{array}{r}\text { Peto } \\
\text { Odds Ratio }\end{array}$ & & $\begin{array}{r}\text { Peto } \\
\text { Odds Ratio }\end{array}$ \\
\hline & $\mathrm{n} / \mathrm{N}$ & $n / N$ & Peto,Fixed,95\% Cl & & Peto,Fixed,95\% Cl \\
\hline
\end{tabular}

Test for subgroup differences: $\mathrm{Ch}^{2}=0.09, \mathrm{df}=\mathrm{I}(\mathrm{P}=0.76), \mathrm{I}^{2}=0.0 \%$

$\begin{array}{lllllll}0.1 & 0.2 & 0.5 & 1 & 2 & 5 & 10\end{array}$

Favours treatment Favours control

Analysis 3.4. Comparison 3 Any rehabilitation intervention including exercise versus usual care, Outcome 4 Quality criteria - Blind assessment of outcomes.

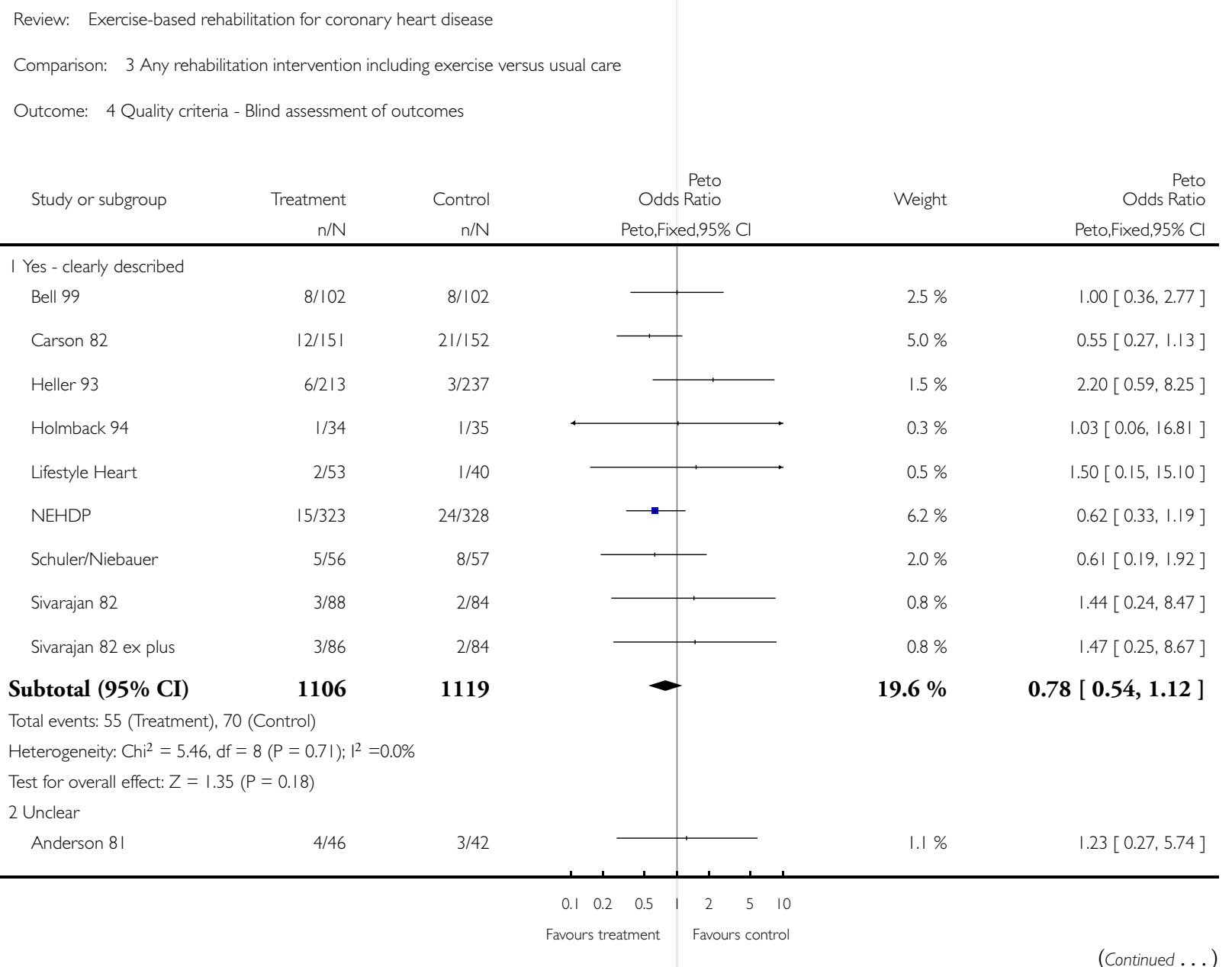

Exercise-based rehabilitation for coronary heart disease (Review) 


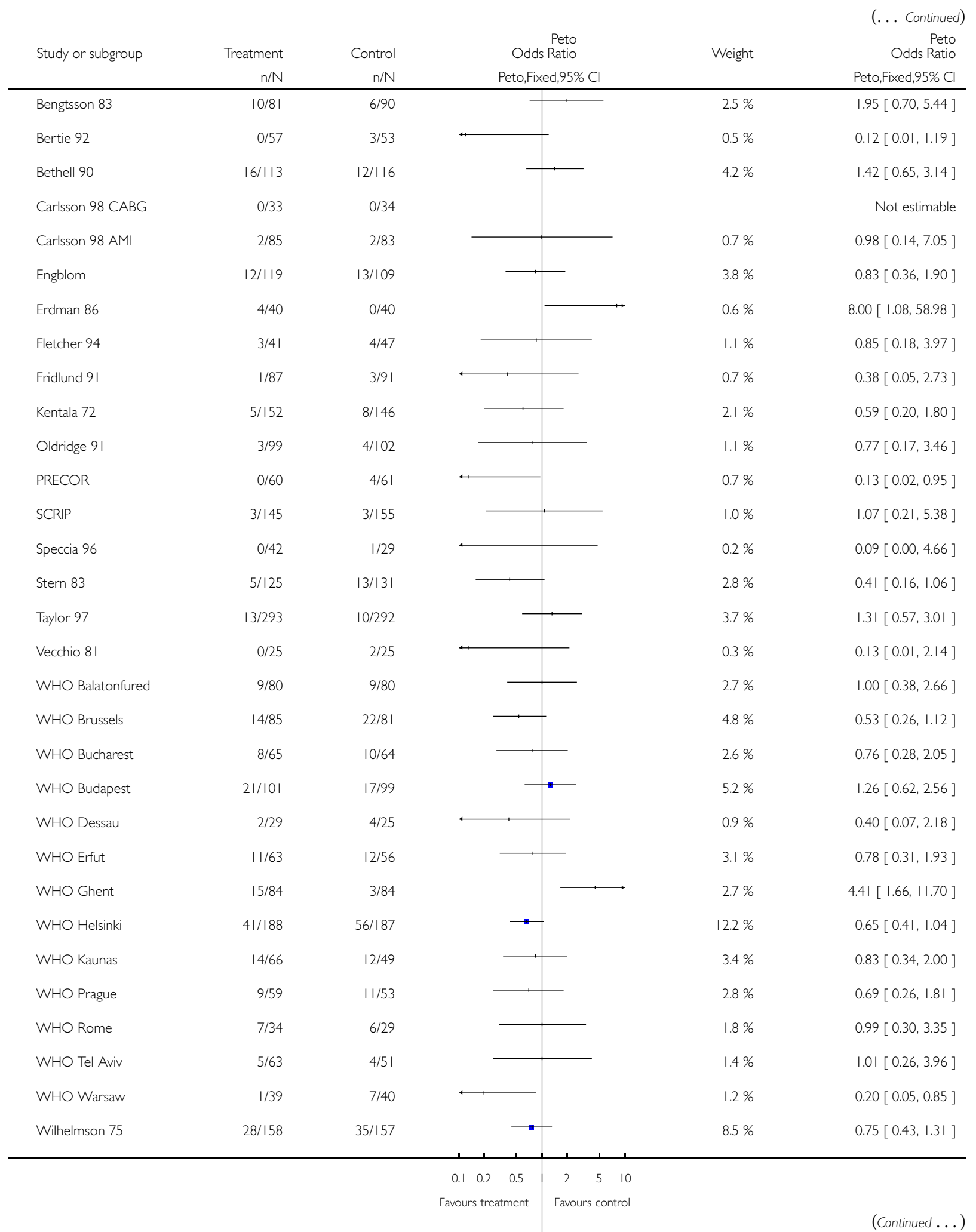

Exercise-based rehabilitation for coronary heart disease (Review) 


\begin{tabular}{|c|c|c|c|c|c|}
\hline \multirow[t]{2}{*}{ Study or subgroup } & Treatment & Control & $\begin{array}{r}\text { Peto } \\
\text { Odds Ratio }\end{array}$ & \multirow[t]{2}{*}{ Weight } & \multirow{2}{*}{$\begin{array}{r}\text { Peto } \\
\text { Odds Ratio } \\
\text { Peto,Fixed,95\% Cl }\end{array}$} \\
\hline & $\mathrm{n} / \mathrm{N}$ & $\mathrm{n} / \mathrm{N}$ & Peto,Fixed, $95 \% \mathrm{Cl}$ & & \\
\hline Subtotal $(95 \% \mathrm{CI})$ & 2757 & 2701 & $\bullet$ & $80.4 \%$ & $0.83[0.70,1.00]$ \\
\hline \multicolumn{6}{|c|}{ Total events: 266 (Treatment), 299 (Control) } \\
\hline \multicolumn{6}{|c|}{ Heterogeneity: $\mathrm{Ch}^{2}=43.09, \mathrm{df}=30(\mathrm{P}=0.06) ; 1^{2}=30 \%$} \\
\hline \multicolumn{6}{|c|}{ Test for overall effect: $Z=1.97(P=0.049)$} \\
\hline Total $(95 \% \mathrm{CI})$ & 3863 & 3820 & $\bullet$ & $100.0 \%$ & $0.82[0.70,0.97]$ \\
\hline \multicolumn{6}{|c|}{ Total events: 321 (Treatment), 369 (Control) } \\
\hline \multicolumn{6}{|c|}{ Heterogeneity: Chi $^{2}=48.67, \mathrm{df}=39(\mathrm{P}=0.14) ; 1^{2}=20 \%$} \\
\hline \multicolumn{6}{|c|}{ Test for overall effect: $Z=2.36(P=0.018)$} \\
\hline \multicolumn{6}{|c|}{ Test for subgroup differences: Chi $^{2}=0.12, \mathrm{df}=1(P=0.73), \mathrm{I}^{2}=0.0 \%$} \\
\hline
\end{tabular}

\section{WHAT'S NEW}

Last assessed as up-to-date: 31 October 2000.

\begin{tabular}{l|l|l}
\hline Date & Event & Description \\
\hline 8 September 2008 & Amended & Converted to new review format. \\
\hline
\end{tabular}

\section{HISTORY}

Protocol first published: Issue 3, 1999

Review first published: Issue 4, 2000

\begin{tabular}{lll}
\hline Date & Event & Description \\
\hline 1 November 2000 & New citation required and conclusions have changed & Substantive amendment \\
\hline
\end{tabular}




\section{CONTRIBUTIONSOFAUTHORS}

All co-reviewers were involved in the design of the review and in providing critical comments about the manuscript. Judy Jolliffe, Rod Taylor and Karen Rees independently assessed studies for inclusion or exclusion, and David Thompson arbitrated. Judy Jolliffe and Karen Rees independently extracted data from the source papers. Karen Rees and Rod Taylor performed statistical analyses. Shah Ebrahim and Neil Oldridge were the primary advisors. Judy Jolliffe was primarily responsible for carrying out the review and was principal author.

\section{DECLARATIONSOF INTEREST}

None known.

\section{SOURCES OF SUPPORT}

\section{Internal sources}

- NHS Research and Development Support Unit, Exeter University, UK.

- Department of Social Medicine, University of Bristol, UK.

\section{External sources}

- Physiotherapy Research Foundation, The Chartered Society of Physiotherapy, UK.

- British Heart Foundation, UK.

\section{NOTES}

The Peninsula Technology Assessment Group (PenTAG) at Peninsula Medical School, Exeter, UK and the Cochrane Heart Group have been awarded a 3-year grant from the National Institute for Health Research to update existing Cochrane systematic reviews relevant to public health, primary care and rehabilitation.

This review is scheduled to be updated in year 1 of the program. Publication of the updated review is anticipated by issue 2,2009 at the latest.

\section{INDEX TERMS}

\section{Medical Subject Headings (MeSH)}

*Exercise Therapy; Coronary Disease [mortality; * rehabilitation]; Myocardial Infarction [mortality; rehabilitation]; Outcome Assessment (Health Care); Quality of Life; Randomized Controlled Trials as Topic 


\section{MeSH check words}

Female; Humans; Male 